\title{
MANUAL FOR
}

FARRIERS. HORSESHOERS, SADDIERS AND WAGONERS OR TEAMSTERS

$$
1914
$$





\section{U. $S_{1}$ - WAR DEPARTMENT \\ OFFICE OF THE, CHIEF OF STAFF}

\section{MANUAL}

FOR

Farriers, Horseshoers, Saddlers and Wagoners or Teamsters

1914

WASHINGTON

GOVERNMENT PRINTING OFFICE

1915 


$$
\begin{aligned}
& V R \text { ) } \\
& \text { NEW BOLTON } \\
& \text { CENTER } \\
& \begin{array}{l}
636.15 \\
\text { Un3\% } \\
1915
\end{array}
\end{aligned}
$$

WAR DEPARTMENT,

Document No. 486.

OFFICE OF THE CHIEF OF STAFF.

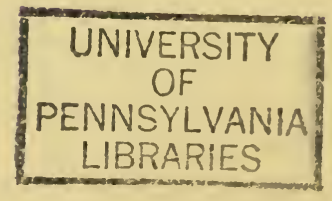




\section{War Department, Office of the Chief of Staff, December 16, 1914.}

The following instructions in elementary duties of the farrier, horseshoer, saddler, and wagoner or teamster, compiled in the Division of Militia Affairs, under the direction of Brig. Gen. Albert L. Mills, General Staff, Chief, Division of Militia Affairs, is approved and herewith published for the information of the Organized Militia.

It is believed that these instructions are all that need be mastered to do in a satisfactory manner the work ordinarily required. For situations not covered within, the services of a veterinarian or those especially skilled in the respective trades of the horseshoer, saddler, and wheelwright must be secured.

By order of the Secretary of War:

H. L. ScotT,

Brigadier General, Chief of Staff.

\section{8}


Digitized by the Internet Archive in 2009 with funding from

Lyrasis Members and Sloan Foundation 


\section{CONTENTS.}

Preface.

Page

General instructions for handling animals.

Vices.

Training horses.

Chapter I

Grooming

Feeding.

Watering

Shelter.

Farrier

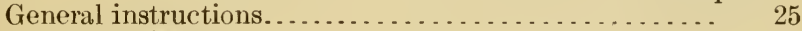

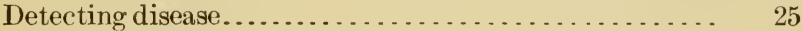

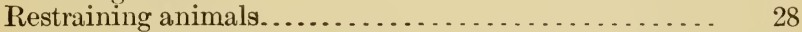

Table of weights and measures. . . . . . . . . . . . . . . 29

Disinfectants.................................. . . . 33

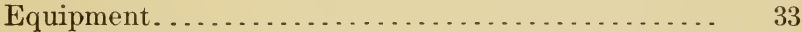

Veterinarians................................ 34

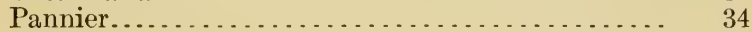

Farrier................................... 38

Horseshoers' emergency...................... . . . 38

Medicines............................... . . . 36, 43

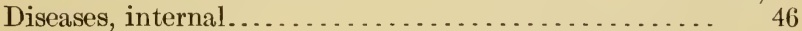

Diseases, external ........................... 49

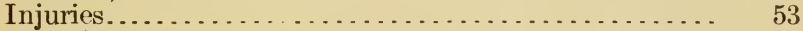

Wounds...................................... 54

Bruises....................................... 55

Saddle galls.............................. 55

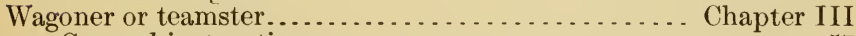

General instructions ............................... 57

Feeding and watering........................ 57

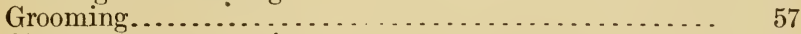

Classes of transportation........................ . . . . 58

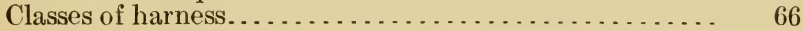

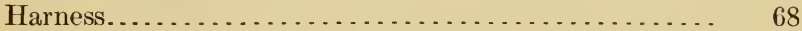

Wagon, care of . . . . . . . . . . . . . . . . . . . . 68

Routine of teamsters' duties..................... 74

Saddler

Harness and mounted equipment............... 75 
Saddler-Continued. Page.

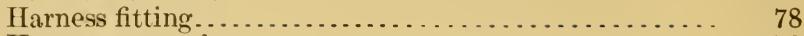

Harness, care of................................. 79

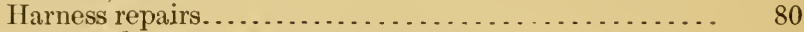

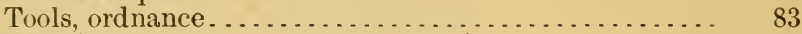

Materials..................................... 85

Tools, quartermaster...................... . 90,93

Packing. Chapter $\mathrm{V}$

Uses of pack mule............................. 96

Aparejo and accessories............................. 96

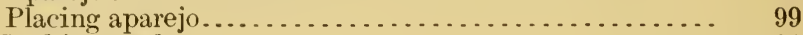

Lashing packs. ............................ 101

Blacksmiths' kit.............................. 103

Cargador's kit............................. 103

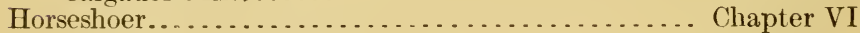

"The Army Horseshoer" ....................... . . 104

Purpose of shoeing.......................... 104

Frequency......................................... 105

Shoeing outfits............................... 105

Ordnance..................................... 105

Description of tools......................... 112

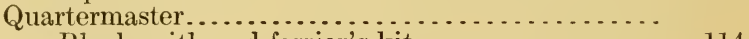

Blacksmith and farrier's kit.............. 114

Emergency horseshoer's equipment........... 114

Shoes, allowance............................ 116

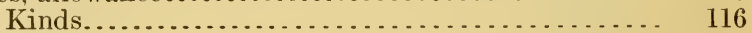

Nails.................................. 116

Shoeing.

Preparing hoof.............................. 116

Preparing shoe................................. 116

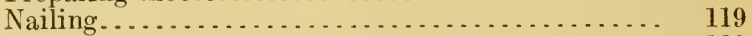

Clips.................................. 120

To tighten shoe............................ 120

To remove shoe............................ 120 


\section{MANUAL FOR FARRIERS, HORSESHOERS, SAD- DLERS, AND WAGONERS OR TEAMSTERS.}

\section{PREFACE.}

This manual is prepared as a guide for those who may be entrusted with Government animals but who may not have an opportunity to refer to professionals the many perplexing questions which arise in actual service.

Many authorities have been consulted and the ideas gleaned therefrom have been incorporated where applicable to a pamphlet of this character.

The subject of duties of the farrier has been prepared principally from notes by Dr. Ingild Hansen, Veterinarian, Quartermaster Corps.

Reference is made in several places within to "Field service" and equipments " $\mathrm{A}$ ", "B," and " $\mathrm{C}$," and to "Combat train," "Field train," "Baggage section," and "Ration section," which the following will explain:

Field service includes service in any of the following cases: In campaign, simulated campaign, or on the march. In mobilization, concentration, instruction, or maneuver camps.

Equipment $A$, as referred to herein, is the equipment for use in campaign, simulated campaign, or on the march, and includes the articles then worn on the person, carried on horse or pack mule, and transported in the wagons of combat trains and in the baggage section of field trains.

Equipment B, as referred to herein, is the equipment which, in addition to equipment $A$, is prescribed for the use of troops in mobilization, concentration, instruction, or maneuver camps, and during such pauses in operations against an enemy as permit of the better care of troops. Equipment B can accompany or follow troops only when other transportation-generally rail or boat-is available.

Equipment C, as referred to herein, includes every article necessary for field service, and is therefore the sum of equipment A plus equipment B.

Articles distinctively for winter use do not form a part of the field equipment unless specially ordered by proper authority. 
EXTRACTS FROM FIELD SERVICE REGULATIONS.

274. Trains.-Transportation attached to organizations is grouped under the following heads, i. e.:

(a) The trains assigned to organizations smaller than a brigade designated combat and field trains, respectively.

(b) The trains assigned to divisions, designated ammunition, supply, sanitary, and engineer trains, respectively.

In addition to the foregoing there are ammunition, supply, sanitary, and engineer columns which are attached to and belong to the advance section of the line of communications. (See par. 279).

275. Combat trains.-Combat trains include all personnel, vehicles, and animals attached to organizations for transporting ammunition reserve and special equipment required during combat, including the mule or cart carrying sanitary first aid equipment. To them also are attached those vehicles required for the technical service of engineers and signal troops. Combat trains remain at all times with the unit to which attached and follow it into action. In the cavalry and field artillery it may be advisable to temporarily separate combat trains from the troops.

276. Field trains.-Field trains include all personnel, vehicles, and animals attached to organizations or headquarters for the transportation of the authorized allowance of baggage, rations, and grain, and include rolling kitchens, if supplied. Wagons of sutlers, correspondents, etc., accompanying a field force by proper authority are assigned to the field train of the organization to which their owners are attached. On the march the headquarters wagons of brigades and divisions are generally attached to some regimental field train.

Field trains are assigned to regiments and independent battalions and are habitually divided into two sections: (1) $\Lambda$ baggage section carrying baggage; and (2) a ration section carrying rations and grain exclusively, and including rolling kitchen, if supplied.

For transportation of baggage each organization is assigned its proportionate space on the vehicles of the baggage section.

277 . When an organization is operating independently, the field trains are under the direct control of the organization commander. When organizations are not operating independently, field trains are ordinarily ordered to be grouped by the division commander and the senior line officer present with the train assumes command and moves it as directed by the superior authority. When the field trains are ordered grouped with the divisional train they are, for the time being, under the orders of the commander of trains.

The field trains are not again placed at the disposition of the organization until so ordered by the division commander. During 
combat the division commander holds the grouped trains well to the rear, thus relieving the roads of unnecessary vehicles.

In the late afternoon, or at the end of a march or close of a combat, the division commander directs the field trains to move up immediately in rear of the troops, and informs the commanding officers of organizations that their baggage sections and one day's rations from their ration sections have been ordered to be at a designated place. The organization commander at once sends an orderly to the designated place to conduct the vehicles to the organization. As soon as practicable after the arrival in camp of the ration vehicles they are unloaded, and, without delay, rejoin the grouped portions of the ration vehicles. The division commander usually returns the baggage sections to the same place early the following morning. 


\section{CHAPTER I.}

\section{GENERAL INSTRUCTIONS FOR HANDLING ANIMALS.}

Never threaten, strike, or otherwise abuse a horse. Never take a rapid gait until horse is warmed up by gentle exercise. Never put up an animal in heated condition; walk him until cool or throw a blanket over him and rub his legs. If wet, rub with straw until hair is dry.

In approaching an animal be sure he sees you. Therefore, go up to him from the front if practicable; if necessary to approach him from the rear, especially if in a stall, speak to him before nearing him. Command him firmly to "stand over," go up to his head on the left side, and pat on the neck.

An animal knows better how to meet an emergency than does a man; he does it instinctively; if he gets scared there is, almost without exception, a good reason for it. Therefore, do not punish a horse for getting scared, and never at all except for well determined viciousness, and then only at the very time of commission of the offense. Many times fright is due to defective vision, and if a horse is punished every time he thinks he sees something dangerous, he will grow to believe in his eyes, and will get scared at almost everything. If on the other hand he is petted when scared, he will see that there is nothing going to hurt him.

The old rule "an ounce of prevention is worth a pound of cure" is particularly applicable to the animals and the equipment in the field. An army can not afford to carry the pound of cure, but it can transport the ounce of prevention mostly in the wits and the fingers of the farrier, saddler, horseshoer, rider, and the driver.

Never feed or water an animal when he is warm unless he is to move off again and at once-hay will do no harm. If the journey or exercise is ended, sponging out the mouth and nostrils give considerable relief.

Never kick an animal and never strike one except with a whip and immediately after he misbehaves. Never strike an animal about the head.

The sheath should be washed at least once a month-better once a week-with warm water and castile soap.

The fetlock should never be trimmed; to do so may lead to the contraction of a disease known as "scratches," unless the tender skin at the back of the pastern can be kept clean and dry, which generally is not practicable in the field. 


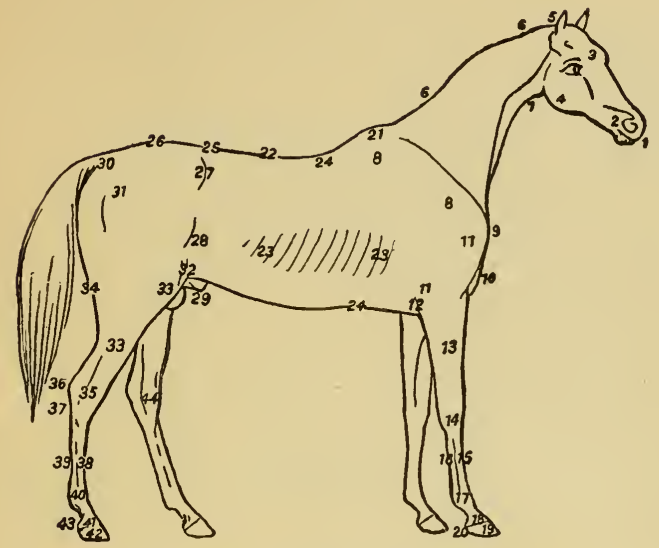

Plate I.-Points of the horse.

Head.

1, Muzzle.

2, Nostril.

3, Forehead.

4, Jaw.

5, Poll.

Neck.

6,6 , Crest.

7, Throttle or windpipe.

\section{Fore guarter.}

8,8 , Shoulder blade.

9, Point of shoulder.

10 , Bosom or breast.

11,11 , True arm.

12, Elbow.

13, Forearm (arm).

14, Knee.

15, Cannon bone.
16, Back sinew.

17, Fetlock or pastern joint.

18 , Coronet.

19, Hoof or foot.

20, Heel.

\section{Body or middle picce.}

21, withers.

22 , Back.

23, 23, Ribs (forming together the barrel or chest).

24, 24, The circumference of the chest at this point, called the girth.

25, The loins.

26 , The croup.

27, The hip.

28 , The flank.
29 , Sheath.

30 , The root of the dock or tail.

\section{Hind guarter.}

31, The hip joint, round, or whirlbone.

32 , The stifle joint.

33,33 , Lower thigh or gaskin.

34 , The quarters.

35 , The hock.

36 , The point of the hock.

37, The curb place.

38 , The cannon bone.

39 , The back sinew.

40, Pastern or letlock joint.

41, Coronet.

42 , Hoof or foot.

43, Heel.

44, Spavin place. 
Animals are tied either to picket line or wagon, or are tethered out with a lariat, or they may be herded.

There are two sorts of picket lines used-high and low. The low or ground picket line has been almost entirely discarded. The high picket line is stretched as tight as practicable at about $4 \frac{1}{2}$ feet from the ground, at the posts or forks placed about 30 yards apart. If wagons are parked on line the picket line may be run over every fifth wagon, which is run to the front for that purpose; loaded wagons should be used at the ends.

About $1 \frac{1}{2}$ yards of picket line are allowed per animal. The animals are tied on both sides of the line with shank just long enough for the animal to eat off the ground. If tied with too long a shank, animals are liable to get their forelegs over and thus cause rope burns, which are very difficult to cure and always leave a blemish.

Wagons are usually parked (that is, put in line) alongside each other and the picket line stretched parallel to the line of wagons and about 10 paces in front of the tongues or poles. The wagons are ordinarily spaced - if animals are tied to picket line - with an interval of about a yard between liubs. When animals are tied to the wagon tongue (two on each side), the distance between hubs should be about 7 yards.

The feed box should be washed out once a week, care being taken to get into the corners.

Nose bags should be cleaned frequently, care being taken to get into the cracks and to expose the inside to rays of the sun.

If weather is cold, before putting the bridle on, the bit should be warmed by holding in the hand or by blowing the breath on it.

To make a halter of rope: Tie a simple knot at one extreme end; draw tight. At about 12 inches from this knot tie another simple knot loosely, then bring the long end back through this last knot, leaving a loop of about 6 inches, and draw the knot tight. Now, with the long end tie a simple knot around the short end immediately against the last knot; this should make the loop nonslipping. Now, at about 3 feet (depending on the length of the horse's head) tie a simple knot loosely, and insert into it the knot at the extreme end. Then run the long end through the 6 -inch loop and make it fast to the loop by a simple knot about 6 inches (same distance as the loop is long) from the knot on the extreme end. To make the throat latch: Take a length of rope which will go around the head at the foretop and throat. Weave the two ends, one on each side, into the head rope of the halter at points 2 inches below the ears. Cut this rope at about 10 inches from the end on the left side.

To make a rope bridle: Double the rope (which should be about 14 to 16 feet long), make a loop by tying a tight, simple overhand 


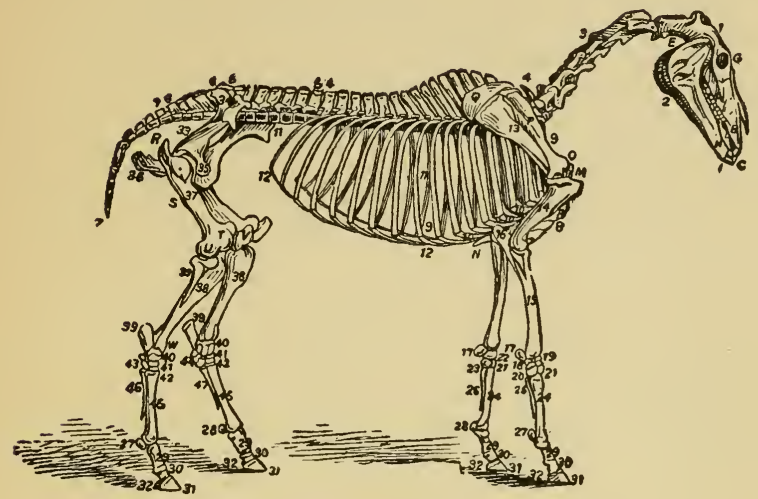

Plate II.-Skeleton of the horse.

A, Molar teeth.

B'II, Canine or tush.

C I, Incisors.

E, Atlas.

G, Orbit.

M, Cariniform cartilage.

N, Ensiform eartilage.

O, Coracoid process of

$P$, spine.

$\mathrm{Q}$, Cartilage.

R, Trochanter major.

$\mathrm{S}$, Subtrochanterian crest.

T, Trochlea.

U, External condyle.

V', Patella.

W, Hock joint.

1, Cranium.

2 , Lower jaw.

3 , Cervical vertebræ.
4, 4, Dorsal vertebræ.

5,5 , Lumbar vertebræ.

6,6 , Sacrum.

7,7 , Coceygeal vertebræ.

8, Sternum.

9,9 , True ribs.

10,10 , Cartilages of true ribs.

11,11 , False ribs.

12,12 , Cartilages of false ribs.

13, Scapula.

14, Humerus.

15, Radius.

16 , Elbow.

17 , Os pisiforme.

$18,19,20,21,22,23$, Carpal bones.

24, Large metacarpal bone. 25 , Outer small metacarpal bone.
26 , Inner small metacarpal bone.

27,28 , sesamoid bones.

29 , Os suffiraginis.

30 , Os coronæ.

31 , Os pedis.

32 , Wing of the pedal bone.

$33,34,35,36$, Os innominatum.

37, Femur.

38, Tibia.

39 , Os calcis.

40, Astragalus.

$41,42,43,44$, Tarsal bones.

45, Large metatarsal bone.

46, Outer small metatarsal bone.

47, Inner small metatarsal bone. 
knot, including both parts, about 9 inches from the middle point. Tie another simple knot about 9 inches above the first knot, but leave it loose - to be drawn over the foretop. Place the loop in the horse's mouth over the upper jaw, thus bringing the first knot on the nose. Carry the rope up to the foretop, placing the foretop through the second knot and drawing the knot tight upon it. Give the doubled rope a couple of twists, till the twists reach behind the ears; then carry one part down on each side the throat and twist together the two parts under the throat until the twist reaches a point about 2 inches above the upper edge of the mouth (i. e., where the loop of the rope emerges from the mouth); pass one part on each side, from rear to front, between the face and the loop in the mouth and carry the parts (the reins) back on the neck and tie together evenly.

\section{VICES.}

While inspection at the time of purchase is supposed to prevent the acquisition of unsuitable animals, there will always be found a few horses and mules which have bad habits or are defective. Every man charged with the duty of working cr caring for animals should learn to know the peculiarities, both of temperament and of physique, of those in his charge. Animals ordinarily meet with so little kindness that it is easy to gain their confidence and affection, and once these are gained they can be coaxed to do most anything-certainly everything required in ordinary work.

If an examination shows the horse to be nervous and excitable, the attendant's actions and words should be calm and soothing. If, on the other hand, the animal is slow and sluggish, his commands should be sharp and his actions more severe.

A man who has a horse with broken wind will not expect the same staying qualities as he would of a horse with strong lungs. (A broken-winded horse can be detected by the double effort made in expiration.) If his horse is a "roarer" (one with one side of the larynx throat paralyzed), he will not be surprised when the horse goes along wheezing. If a horse is a kicker or biter, the attendant will govern himself accordingly.

Much is gained by learning these individual peculiarities. For example, a mare used for racing would often be left at the starting point; by study it was found that she always propped her legs stiff and turned about half way to the left, so as to face the inside. It was soon discovered that in holding her (for she was nervous) at the start she harl invariably been held by an attendant on the left side. Thereafter the attendant was made to hold her on the right side and she never "got left at the (starting) post." 
Another instance: A mule having been assigned to a new driver, the latter found it impossible to get the bridle on-even with the assistance of several other men. Kindness and delicacy in handling the ears were shown, but to no avail. Finally, one man who had a great deal of confidence in himself (it happened that a "bighead" turned out all right in this case), said for them all to get away, he'd "bet he could bridle him." He took the bridle in his hand and with a firm step and knowing expression walked up to the mule's head and in a businesslike way proceeded to put the bit in the mule's mouth, and, without "whoaing" or coddling or gentle rubbing around the ears, simply but firmly took hold of the mule's ears and put them through the bridle. That mule saw that the others were shy and he thought something was wrong. The other man's manner was all business, and the mule knew he was going out to work and hence had to have a bridle on.

These instances show how very necessary it is to study each animal carefully. Many animals, however, have been treated badly so long that they are confirmed in their bad habits, but these are almost always due to bad handling on the part of some man who had less brains than muscle and much less sense than the animalbecause the latter learned how to checkmate by these vices the man who would be his master. Nevertheless, a few vices are due to temperament.

Among the vices most frequently encountered are pawing, kicking, biting, pulling back, balking, rearing, and cribbing, and windsucking.

Pawing is caused by nervousness due to pain, thirst, hunger, loneliness, or habit. There always is good reason, and if the cause is removed early the animal will not acquire the vice. Some stables are so arranged that by pawing, the animal can make grain fall into the feed box. It may becured by removing the cause. If this habit has been formed, the forelegs should be hobbled, thus enabling neighboring animals and men sleeping near to get some rest.

Windsucking and cribbing (which is windsucking combined with seizing the manger, fence, or other suitable object with the teeth) may be prevented by buckling a strap around the throat snug but not tight.

A kicker may be one of several kinds-those who kick because very ticklish or who are quick to defend themselves when frightened or when approached by a man or animal known to be an enemy, or when desirous of ridding themselves of strange or painful equipment. The way to prevent kicking of the first three sorts is to speak kindly to the animal upon approaching it and handle carefully until it appreciates that no harm will come to it. Can anyone 
blame a mule for looking out of the corner of his eye for a chance to give a good kick to a man engaged in scraping his hide off, especially about the joints, with a currycomb, or to pay back a man who has given him an unnecessary kick or blow? If you getsuch an animal, remember, if he has the liabit, that at first he doesn't know you from a man or men who mistreated him and it will take time to demonstrate your own kindly intentions-hence, be patient.

If he persists in kicking when approached from the rear, he may be hobbled, front fetlock to hind fetlock, until shown that trying
is useless. Tie a bag of straw up so it will hang against his hocks.
Put a pole up or hold pole against his Put a pole up or hold pole against his legs and rump to let him see that kicking does no good and that the pole, if let alone, does him no harm. If he kicks with both heels when placed in the wagon or when turned out with other animals, tie a cord about the size of a clothesline, fairly tight, around his girth just in rear of the backband; usually he will not offer to kick more than twice.

Biting is a vice caused, as usual with such failings, by faulty handling. Most times animals bite as a result of someone's having
teased them when young. In such cases they expect and usually
do see a jump on the part of the vistim, and the do see a jump on the part of the victim, and they like it. Horses
enjoy play-a joke-better than some men. If a person stands
still or pays no attention, taling just still or pays no attention, taking just enough action to prevent any injury, such as placing the hand on the nose, the disappointment will oftentimes be such as to cause them to give up the habit, for it will no longer be any fun. About the best thing that can be done to a confirmed biter is to muzzle the animal. If the habit is just forming, some cases may be cured by a short but sharp cut over the nose with a switch at the very moment the animal is giving the bj e. Kindness, however, is the best remedy-frequent rubbing of the

Some animals will break the halter shank by pulling back. This habit is due to careless handling of the head, especially abo it the ears, while grooming or when putting on the bridle. When once the animal knows it can break loose, there are many occasions when he finds this ability very convenient-for example, when tied to a hot picket line and he is surrounded by a green meadow with plenty of shade and running water. The habit must be cured, first, is perfectly willing and glad to be rubbed about the head. Then, to teach him to associate pain with pulling back, double a rope (the end on each side of the back, place the bight along the back, give it half a twist, and put the bight under the tail like a crupper. ('arry the ends forward, one along each shoulder, and tie the ends together evenly to a post or manger and short enough so that in 
pulling back the strain will come on this rope before it does on the halter shank.

A balky horse is a proof of some man's ignorance. Some balky horses are incurable, but if they are, it is man who is to blame. It is very desirable that the horse should see what is going on and an "open" bridle (one without blinds) should be used, at least until he sees what it is that is touching him, handling him, rattling about, and making such unusual noises. If patience is exercised in the beginning, much time, labor, and good horseflesh will be saved. First put on and take off the harness. The crupper and the breeching are the two parts which the green horse can not understand. They should be handled considerably, moved about, pulled so as to bring pressure on the usually untouched parts of the body. The lines should be held from behind and permitted to drop down on the legs. Move a large pole about his legs and sides and rump. Then walk him about (leading) in the harness. Then drive with the harness on, the lines being kept low (passed through the shaft tugs or the tug loops at the side of the backband or saddle), so as to give a sidewise pull and thus draw the head in the direction in which it is desired that he go. It is well to tie some small poles onto the shaft tugs (backband) and the breeching and let them dangle as he walks. Be sure and put them on securely, especially at the breeching, so the stick will not slip down or up when he kicks. While being driven with the harness on, there should be an assistant alongside near the head to guide him by pressure of the hand on the side of the head or neck and thus explain what is meant when the lines are pulled. Then the green horse should be hitched, in harness only, alongside a trained and quiet animal and driven about, considerable attention being paid to turning to the right and left. Particular care should be taken when working a green horse in a double team not to place him always on the same side. He should be changed frequently from the near (left) side to the off (right) side. The alternating of sides should continue until the animal is well "broken."

When he understands what to do when driven alongside the trained horse, the team should be hitched to a light wagon. An assistant should be alongside to quiet the green horse. If the driver sees that the horse intends to stop, it is very wise to say "Whoa!" before he has a chance to stop.

If a trained horse be not available for the use as above outlined, the green horse must be driven alone, and an assistant should be constantly alongside the animal. If available, a light breaking cart with long heavy shafts should be used for the first hitching. It is well to use a kicking strap, a strap about 2 inches wide, which is made fast to one of the shafts and carried over the horse's hips

$$
76881^{\circ}-15-2
$$


on top of or near the hip straps and made fast to the other shaft. The nearer the kicking strap is to the crupper, the more leverage the horse has to work against in kicking up. The whip should not be used in teaching a green horse except possibly to touch him very lightly, not so as to hurt but only to help the horse to know which direction it is supposed to move. Few, if any, horses or mules have ever been taught anything by severe use of a whip. Its use will certainly not cure the average balky horse.

The secret of curing a balky horse is to divert his attention. This may be accomplished in several ways. If hitched double and the horse props, the rope crupper referred to above as a cure for pulling back may be used, the ends being made fast to the wagon tongue. When the trained horse starts and moves the wagon forward, the rope crupper is thus brought into action. If, being driven single, he props, the rope crupper may be pulled by the assistant standing in front. A smooth rock placed in the ear, of size not too small, but just so it will go in easily, will sometimes make the victim think more of this than of his other troubles. A string tied around the ear will sometimes do the same thing.

Sometimes a balker can be cured by making him dizzy. Unhitch him (but do not take harness off) and tie his head (bending the neck around) to the tail-as close as possible. Then make him move around and around-he must follow his tail-until he gets dizzy. Hitch him up quickly and the chances are he will go.

Sometimes an animal will plant his feet deliberately and will withstand any amount of swaying in any and all directions, but he makes up his mind to "stay put." If he props backward, he can sometimes be caught leaning hard backwards and forced back suddenly, thus getting the best of him, which he will appreciate. Sometimes he can be moved by picking up his feet one at a time; or light taps of the whip (not a kick) will make him pick up his feet. Occasionally an offer of some food (sugar is very good) or water will get him out of a stubborn state. The smell of the "warts," sometimes called, on the inside of the legs (just above the knees on the front legs and below the hocks behind) seems to be peculiarly agreeable to the horse; some of the softer portion rubbed on the glove and held to the horse's nose will make him friendly disposed. Oil of cumin has the same effect.

Rearing is another manifestation of gross mishandling on the part of some man. It is due almost invariably to the use of too severe a bit, or too severe use of a proper bit, or the use of a proper bit improperly adjusted in the mouth. $\Lambda$ snaffle bit is the only one which should ever be used on a green horse, and on every horse which can be controlled with it. In our mounted service this rule is not adhered to because a bit for general use is required, 
and a mild curb is adopted. Jerking, especially on a curb bit, will cause the horse to yield suddenly to that pressure, consequently he will go up in the air. Not only jerking but continued pulling on a severe bit will cause him to seek the same sort of relief and he soon appreciates that he always can get it by that method, and he naturally forms the bad habit of rearing. A change of bit will sometimes effect a cure. A leather or rubber bit or leathercovered bit will often relieve the case. Occasionally the teeth are in bad condition, and the mouth generally sore and feverish; if so, this condition should be relieved. A martingale which is drawn quite short will often cure mild cases; it is better to use the type which runs directly from the girth to the bit or the nose band instead of the kind which has rings through which the reins are run.

To make a check rein: Pass a rope (about the size of the little finger) through the swivel on the right (throat) of bridle (if the bridle is not provided with swivels for check reins, fasten a ring at each end of a strap or rope about 8 inches long, then fasten the middle point of this rope or strap to the crownpiece at top of the head), then down through the right ring of the bit (it should be straight and additional to the one to which the lines or reins are fastened), then over the nose and through the other ring of the bit and up through the swivel (or ring) on the left throat of the bridle and make this (running) end fast to the other part of the rope about the withers. In case the horse is being driven in harness, the two parts of the rope should pass through the terrets (loops in the saddle or backband), and the short or running end made fast to the bight of the part of the longer end at a point just in rear of the saddle or backband; the longer end is then carried to the rear and held in the hand of the driver, ready for instant use. To keep the part over the nose from falling down, a strong cord should be tied from it to the brow band on the forehead.

If, when a runaway starts to run, the lines and this check rein are pulled at the same time, he will be quickly stopped. A kicker can often be cured if, just as he is kicking, he is given a good strong haul on this check; the point is-do it quickly.

Sometimes a horse will kick so quickly and so often that the driver will have his hand full managing the lines. In this case the check can be rigged so as to always be ready for work. To do this, fasten a ring on the back strap (running from the crupper to the saddle or backband) at the top of the rump, and instead of fastening the running end to the bight of the longer or "standing" end, both ends are passed through this ring, and both ends tied to the shaftsone on each side or to the crossbar; or, if hitched double, to the axle or other rigid part in rear. 


\section{GROOMING.}

It seems hardly credible, but it is stated by authorities that the skin excretes as much waste matter as do the bowels; hence, the necessity for regular and thorough grooming to keep the skin open and healthy.

The currycomb's principal service is to clean the brush by drawing the brush across it every few strokes.

The brush must be used with force (except about the head), putting the weight of the body into the stroke; this makes the work much easier and gives grooming very much the effect of a delightful massage, which the animal soon learns to appreciate, and for which he learns to like the giver.

In grooming, remember that the currycomb is a severe instrument when applied to bony or sharp points. Animals with tender skin (they are usually the most intelligent) can be easily ruined by carelessness or roughness in grooming, while if the spirit of the old adage "Scratch me and I'll scratch you" is duly appreciated by the man as well as it is by the animals, friendship is sure to result from the frequent and careful wielding of the soothing currycomb and brush.

Begin to groom where you naturally pat or caress the animalon his neck on the near (left) side, then gradually work to the tail and legs. Don't forget to groom the folds and cracks-between and just in rear of the forelegs, and in the flanks-but remember that these points are as ticklish as they are important. Go to the head last; use the brush or a cloth only, and these very carefullyespecially about the ears. Many a horse and mule is ruined by rough handling of his head. Clean out the feet with a bluntpointed instrument and examine them carefully; this is the most important part of the grooming; brush thoroughly the skin just above the rear part of the hoof. Brush the mane (especially near the roots), the foretop, and the tail thoroughly, but never touch them with a currycomb. Don't groom when the animal is wet or damp-it only mats the hair-but dry by rubbing lightly with a cloth or a wisp of hay or straw and, when dry, groom as usual.

Remember that the feet, stomach, and the shoulders of a draft animal or the back of a riding animal are the three most essential points.

A wisp of straw is not ordinarily used in our service, though no implement will contribute more, if as much, toward keeping the coat in a smooth and healthy condition. It is made by twisting hay or straw into a rope, about 6 feet long, and making of this an oblong, compact mat by forming two loops at the middle and weaving the ends through the four parts of the loops. 


\section{FEEDING.}

Transportation facilities for an army will vary greatly due to the difference in nature of the theater of operations, character of the enemy, resources of the country, and rates of the march required. Against a first-class power, large bodies of troops would be assembled and maneuvered; in campaigns, such as those in the Philippines, the soldier carried on his back everything required except occasionally when "cargadors" (natives who packed loads on their backs) were procured to carry rations. In mountainous countries, or in very wet weather and on earth roads, pack mules or pack horses (the larger foot makes considerable difference sometimes) might be the only practicable means of transport. On winding roads two-wheeled carts are suitable. On earth roads in fairly good or good condition escort wagons, and on metaled roads the automobile truck could be used.

When the weight of forage (23 pounds for the mule and 26 pounds for the horse) and the round trip are considered, we see that a pack mule (net carrying capacity 250 pounds) could only go five days to the front of his base of supply; if he goes two days to the front he can carry 150 pounds in addition to his own forage.

The capacity of the escort wagon is 2,765 pounds with field trains and 2,465 pounds with the combat trains. This is the equivalent (for a wagon in the field train) of either 230 horse or 300 mule rations of grain, or 175 horse or mule rations of hay, or 565 garrison rations, or 675 travel rations, or 920 field rations, or 1,380 reserve rations. In other words, a wagon could go about 12 days to the front living on the forage in the wagon load; if a trip requiring 3 days' travel to the front of the base of supply were contemplated, it could carry to that point about 1 ton.

When it is seen how great a part of the load is taken up with forage for the animals, the importance of "living off the country," grazing where possible, and of securing grain at the various stops may be appreciated. Moreover, it will be impossible to always get oats and hay, and the necessity of teaching the animals to eat different kinds of food is apparent. The bulk as well as most weight of the forage ration is the hay; therefore grain only is carried in campaign. For each animal there is carried along with the animal normally two days' grain ration and a "reserve grain ration," which makes a total of three days. The reserve ration is not to be touched except "in case of extreme necessity, when no other supplies are available," and not without an express order from the commander.

Great care should be exercised to see that the grain, hay, and straw are of good quality and are sound. If it is impossible to 
secure good quality, every step should be taken to make it as palatable and as wholesome as practicable. There will probably be many times when, due to the exigencies of the service in campaign, many varieties and grades of food must be used. Horses can eat most any kind of food and will do so if they are properly coaxed; they will readily learn to eat carrots, bread, etc., and have been known to eat meat even. Musty hay or other grain can be made much more edible by shaking, sieving, sprinkling just before feeding, mixing with other foodstuff such as molasses or cane, green corn or other vegetables, or adding a little salt.

When carrots or similarly shaped vegetables are fed they should be cut lengthwise; if cut round, the pieces may become lodged in the throat.

Good bran contains large flakes and considerable proportion of flour; the hand thrust into bran should when withdrawn appear well powdered.

Dry bran will constipate while a bran mash (made by stirring into boiling water and then covering with a layer of dry for 15 minutes) is laxative.

It is generally impracticable - if on the march-to feed hay in the morning; most of it is given at night-about two-thirds-and one-third at noon or after the march for the day is over.

Grass should be given at every opportunity; it keeps the bowels in good condition.

The ration of forage is for the horse 12 pounds of oats (or bran), and 14 pounds of hay, and for the mule 9 pounds and 14 pounds, respectively. Bran when necessary (usually once a week) is made into a "mash"; it must be fed when freshly mixed; if more of a purgative effect is desired a tablespoonful of common salt should be added. Grain only (3 days) is carried in the field; hay or grass is secured locally. Barley should always be ferl crushed and preferably wet.

An animal is just as much entitled to good forage as a man is to good food. Good oats are plump, have the beard on the grain. The kernel can be seen through the split in the hull. The grains will not break under pressure of the nail. They smell and taste sweet. Weight should not be under 36 pounds per bushel, although we accept 32-pound nats. If a handful of good oats be taken in the hand, it will be impossible to compress them much by hand pressure. Good hay has the leaves and top on the stem, has a fresh appearance, and smells and tastes sweet. Corn is sometimes fed but it produces more fat than working tissues; it is best to feed it ground or cracked. One hundred pounds of straw per month is allowed each animal for bedding; it is not allowed in the field. 


\section{WATERING.}

There is some difference of opinion as to whether it is best to water before or after feeding; it is generally thought best to water before, if practicable. Of course, if it is cold weather and the water is cold the animal will not drink anyway early in the morning, or if at all he will do so very slowly. Man can best appreciate how a horse feels under such circumstances by trying to drink down ice water in a hurry. If not watered before feeding it is best not to water until a couple of hours afterwards; however, unless sure that water will be procurable after this length of time, water them sooner.

An animal can not be given too much water-except, of course, when he is hot-for he will not drink any more than is good for him. Water should be given at least three times per day; in hot weather, as often as practicable. A horse will drink almost a barrel of water in tropical countries, for he loses so much by sweating.

Water from a bucket or from a running stream-never frcm a trough, unless specific authority has been given. Take care that the oil from the lantern which is carried in the bucket does not spill into it. Horses will not drink tainted water. Some horses are very particular about food and water. They should be humored, for generally such traits indicate a superior type of animal.

When going to the watering place, go very slowly. If you are ever going to humor a horse, do it when going to water. No jerking, crowding, or fighting is permissible.

For a half hour after watering or after feeding, an animal should not be required to take up a gait faster than a walk.

Remember that a horse is entitled to as good water as is the man. $\mathrm{He}$ is not affected by certain of the germs which attack man but, on the other hand, there are many germs which are the horse's enemies and which do not attack man. The only difference is that the horse can not talk while the man can and does not usually lose any opportunity to growl at any slight discomfort.

The usual allowance of water for the horse is 5 gallons if not working and 10 gallons if at labor. In hot weather 20 or even 30 gallons will be needed.

The rule as to not watering when animals are warm should not be understood to apply if they are to be kept moving for a half hour or more after they drink. But never water a warm animal and then let him stand, for it will cause founder. 


\section{SHELTER.}

Shelter should be given the horse if possible, but only to protect him from the hot sun, rain, snow, and strong wind. When very cold use the blanket.

If a horse is very hot and sweating and the weather is cool, put a good thick layer of straw or hay under the blanket. In campaign about all the shelter that can be given is that to be obtained from the blanket, and by placing the animals in a dry place and as protected from the wind as possible. Windbreaks made of brush or other materials found lying around the vicinity will often be of great help toward enabling animals to pass a comfortable night. Always stop or tie your horse in the shade if hot, or under the protection of a building if cold.

In camps when it is very hot it is very desirable-and if troops remain for any length of time it is almost imperative-that some sort of shelter be improvised against the hot rays of the sun. It does not require a great amount of labor to construct an open shed in which the posts are trees having forks about 14 to 16 feet from the ground (sunk into the ground about 3 feet) and the rafters and covering consist of the branches of the trees and grass, hay, or brush. If hay or grass be available, the covering can be made waterproof also.

Horses will sleep and receive considerable rest while standing up, but they will generally lie down if given suitable surroundings.

Manure should be burned or otherwise treated so as to prevent breeding of flies. The Department of Agriculture recommends sprinkling borax on the manure and then sprinkling with water; this sterilizes the eggs. Lime, iron sulphate, and potassium cyanide will also sterilize fly eggs, but the two last-mentioned chemicals are very costly and the last-named very poisonous. It is estimated that, using borax, the cost of treating the manure-where borax is bought in 100-pound lots or more-is about 1 cent per horse per day.

If fly nets be not available, some protection against flies may be given the animals by tying branches of trees or weeds on the harness so as to cover the shoulders and the sides and on the throatlatch to protect the throat. Stock will stamp and switch a great many pounds off fighting flies, so save feed and prevent suffering by the slight attention mentioned.

Flies will not attack a horse which has been rubbed with a cloth moistened with fish oil, or a decoction of tobacco, walnut or elder leaves, or carbolized water. 


\section{CHA PTER II.}

\section{DUTIES OF THE FARRIER.}

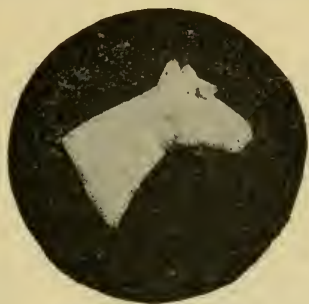

Farrier's chevron.

\section{GENERAL REMARKS.}

Look after your horses, first, last, and all times. Treat them with kindness; it will not only be humane, but will make your work easy. Do not allow any man in your detachment to mistreat an animal; see that his punishment is more severe than that he gave the animal.

Look after your horses' shoes.

After horses reach quarters or camp look carefully over each one and do the same before they leave.

When a horse is reported sick, attend to him at once, no matter if it rains or shines, if it is day or night. If two or more horses are sick with the same symptoms, call the veterinarian. If a horse dies suddenly with no apparent cause, call the veterinarian.

Whenever a new horse comes to the detachment, examine his nose for sores and ulcerations, for discharge from one of both nostrils, for swellings of the glands on under part of the lower jaw. If any of these symptoms are found, keep animal isolated until it can be examined by a veterinarian. These symptoms indicate glanders, a fatal disease, communicable to man as well as to animals. If any animal in the detachment shows such symptoms, isolate it at once. Do not permit saddles, harness, or tools used for the sick horses to be used for sound animals.

Temperature.-The normal temperature of horse, taken by thermometer in the rectum for three or four minutes, is $99^{\circ}$ to $100^{\circ} \mathrm{F}$.

A permanent rise of $2^{\circ}$ or $3^{\circ}$ indicates fever.

A persistence of high evening temperature lasting into morning shows an aggravation of the condition. 


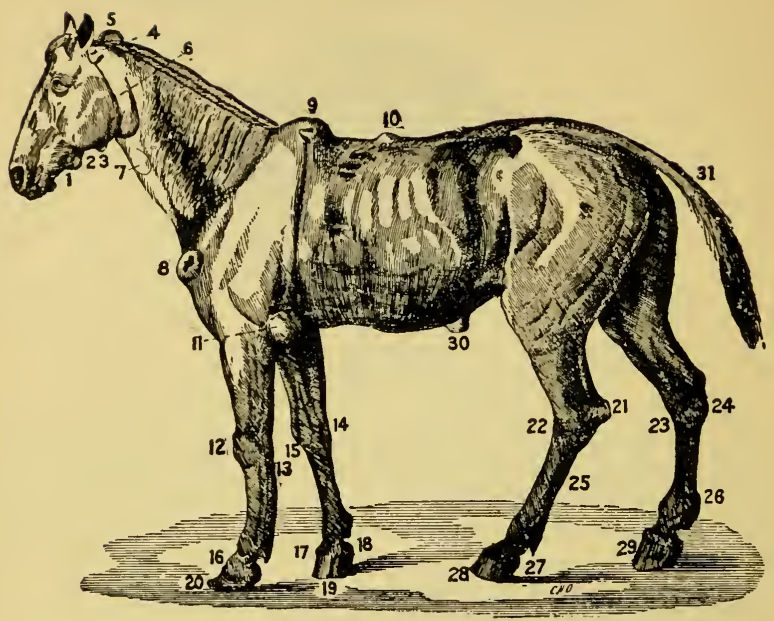

Plate III.-Diseases of the horse.

1, Caries of the lower jaw,

2 , Fistula of the parotid duct.

3 , Bony excrescence or exostosis of the lower jaw.

4, Swelling by pressure of the bridle.

5, Poll evil.

6, Inflamed parotid gland.

7, Inflamed jugular vein.

8 , Fungus tumor, produced by pressure of the collar.

9 , Fistula in the withers.
10, Saddle gall.

11, Tumor of the elbow.

12 , Induration of the knee.

13 , Clap of the back sinews.

14, Malanders.

15, Splint.

16, Ringbone.

17 , A tread upon the coronet.

18, Quittor.

19, Sand crack.

20 , Contracted or ring foot of a foundered horse.
21, Capped hock.

22, Malanders.

23, Spavin.

24, Curb.

25, Swelled sinews.

26 , Thick leg.

27, Crease.

28 , A crack in front of the foot, called cow crack.

29, Quarter crack.

30 , Ventral hernia.

31, Rat-tail. 
A persistence of low morning temperature lasting into the evening indicates improvement.

Pulse.-This is felt on lower jaw or inside forelimb inside the elbow joint. In the horse it should be 36 to 49 per minute. In old age it is less frequent. Young and nervous animals and females have a greater rapidity of the pulse.

Breathing.- The young horse breathes 10 to 12 times per minute, the adult animal 9 to 10. Any excitement accelerates. Exercise, even walking few hundred yards, increases the respirations to 25 or 28 per minute; after trotting five minutes, to 52 ; after galloping five minutes, to 62 .

Hurried breathing not caused by exercise, nor heat of atmosphere or not accompanied by distension of the abdomen, is indication of fever, especially if associated with rapid pulse and increased heat of the body.

The well horse has a smooth coat (inculding the hair at the root of the tail), skin pliable and easily rolled on the flesh, clear, bright, open eyes, salmon-pink colored membranes in the nostril, lightyellow colored urine, erect ears; he holds his neck at an angle considerably above the horizontal, stands on four feet squarely, plants his feet in regular cadence in walking or trotting, and has no unusual discharges from any part of the body. He has a good appetite-this being probably the best means of telling his state of health.

The remarks as to carriage do not apply to a horse at rest when sleeping or when drowsing, for then the neck is naturally drooped and oftentimes the animal rests his hind quarters by standing on one leg or stands on one foreleg and one diagonal hind leg, allowing the others to bend and thus relax the muscles. However, if an animal stands always on one of the legs (front or hind) and rests the other, a weakness may be the cause. It is almost invariably so if he does not stand evenly on both front legs.

An unusual discharge from any part of the body, distended and red nostrils, drooping eyes or ears or neck, shifting about on the feet, refusal to stand on one foot, especially if he "points" the toe (that is, holds it out to the front, resting lightly on the ground), an unsteady or irregular gait, cracked hoofs, sores or irritation of the quarters (just above the rear part of the hoof), or lack of appetite indicate a diseased condition.

In treating animals it should be borne in mind that few medicines of themselves do the curing. Nature does it. Man helps by giving food which is easily digested, by giving extra care to the sick, and by guarding, as it were, against the attack of any enemies in the shape of germs which are ready to seize the weak or wounded. 
A general rule as to the symptom of a discharge from the nose: Little fear need be entertained if the discharge runs freely from the nose (that is if it is not sticky), or if it is stringy and will not mix (break up) with water; these symptoms indicate a cold. If, on the other hand, the discharge is creamy, sticky, and it will break up into fine particles, and hence will mix with water, the symptoms indicate a serious condition, and prompt steps should be taken to isolate the animal and to get expert veterinary attention.

\section{RESTRAINT OF ANIMALS.}

It will be necessary in some cases to restrain the animal while it is being treated, but it will be remembered that by a kind handling the animal will not be so refractory as when treated in a rough manner.

Beating, kicking, jerking should be absolutely avoided. It does not quiet the animal, but does frighten him and serves to demonstrate the lack of sense in the man doing it.

There are three principal methods of restraint, viz, hobbling, putting on a twitch, and throwing.

Hobbling is the least severe, consisting of simply raising one of the forefeet almost to the elbow and tying or strapping the leg in the bent position. A loop is passed around the leg at the pastern (just above the hoof), and with the leg in the bent position the ends of the strap or rope passed around the forearm and made fast. If rope is used, the skin should be protected by several layers of cloth, such as pieces of oat sack. If a strap be used, it should have a keeper at the back near the buckle, or a keeper be improvised by a small rope or several strands of a strong cord.

To prevent kicking or to make the animal stand for very short periods only, an assistant may be directed to hold up the foreleg opposite the side on which the animal is being treated. If he attemps to go down on that leg, follow him down still holding the foot and leg in the same relative position; don't try to resist, for if you do you give him that which you took away from hima point of support for his leg-and he can lunge.

The twitch is made of a strong stick $1 \frac{1}{2}$ feet long, $1 \frac{1}{2}$ inches diameter. Near one end two holes about 3 inches apart are made to pass a $\frac{1}{2}$-inch (diameter) rope. $\Lambda$ loop about large enough to hold the closed fist is made in the rope by passing the ends through these holes and tying knots in the ends; or any method may be used by which a loop about the size of the fist can be fastened near the end of the stick.

The hand is passed through the loop and the upper lip is gathered in the hand and the loop is passed over the hand and onto the lip. The stick is given several turns so that the rope twists, thereby 
exerting a pressure on the sensitive upper lip, and this will ordinarily make the animal quiet. The twitch should not be twisted too severely.

To throw an animal (which should be rarely necessary), hobble, as before explained, the foreleg on the side on which you wish him to lie when down.

The casting harness, Plate IV, figure 1, should be used if available. Wrap the pasterns of the rear legs (between the fetlock ankle and the hoof) very carefully with cloth to prevent rope burn. If casting hame be not available, double the lariat and tie a knot near the middle so as to form a loop large enough to fit like a collar over the horse's shoulders. The loop is passed over the head and onto the shoulders like a collar, the knot being so adjusted that it will come on the horse's breast. Pass the two ends between the forelegs under the belly and then between the hind legs.

Then pass the ends one under the right and one under the left hind ankle, previously wrapped, and then along the side and up through the loop around the horse's neck. There is an assistant on each end, one on each side; another assistant holds the head and stands on the side on which the animal is intended to lie.

The reins are off the neck and passed to the shoulder opposite the side on which the animal is to lie, and are grasped by the thrower (the man handling the reins) with the hand farthest from the head; the other hand grasps the ear on the opposite side.

The head is drawn to the side by the reins and the command "pull" is given. At this signal the two assistants at the sides pull forward on the ends of the lariat, thus drawing the hind feet forward; the head is drawn further back toward the girth and the animal settles down on its side. The thrower quickly places his knee on the neck near the head, and raises the muzzle of the horse from the ground. The assistants at the sides carry the ends of the rope to the hind legs and make fast near the hoofs-where the cloth has been previously placed. The horse thus fettered can not get up nor struggle effectively as long as a man has his knee on the animal's neck and holds its nose off the ground.

\section{WEIGHTS AND MEASURES.}

In order to intelligently handle medicines and other supplies used in caring for animals a familiarity with tables of weights and measures is necessary.

It will sometimes be necessary to improvise measures. A balance is easily constructed by placing containers of some sort, one on each end of a stick, balance on a sharp edge, and mark the point of balance. 


\section{METRIC SYSTEM.}

The metric system of weights and measures is used in many foreign countries. It is based on the decimal system. There are three units; of length, the meter (m); of weight, the gram (g); of capacity, the liter (1). There is also a unit of surface based on the meter, one "are" being a square 10 meters on a side. The subdivisions or the multiples of these units are indicated by prefixes, as follows:

PARTS.

Deci equals $\frac{1}{10}$. as decimeter ( $\frac{1}{10}$ of a meter).

Centi equals $\frac{1}{100}$, as centiliter ( $\frac{1}{100}$ of a liter).

Milli equals $\frac{1}{1000}$, as milligram ( $\frac{1}{1000}$ of a gram).

\section{MULTIPLES.}

Deka equals 10 times, as dekaliter (10 liters).

Hecto equals 100 times, as hectometer (100 meters).

Kilo equals 1,000 times, as kilogram (1,000 grams).

The meter (39.37 inches) is $\frac{1}{40.000 .000}$ of the circumference of the earth; the grain (15.43 grains) is the weight of 1 cubic centimeter (that is, of a cube whose edge is $\frac{1}{100}$ of a meter in length), of water at its maximum density; the liter (1.06 quarts) is 1 cubic decimeter (that is, a cube whose edge is $\frac{1}{10}$ of a meter in length).

The quantities usually used in business where the metric system is established are as follows:

Meter, 39.37 inches; a centimeter is $\frac{2}{5}$ of an inch; kilometer, $\frac{5}{8}$ mile $(0.62137)$.

Hectare, 2.471 acres; or 1 acre $\frac{4}{10}$ of a hectare.

Liter, 0.9081 quart (dry) or 1.1 quarts (liquid).

Kilogram ${ }^{1} 2.2046$ pounds (avoirdupois).

Metric ton, 2,204.6 pounds.

One liter of. water weighs 1 kilo.

The following are weights per bushel of various foods for animals:

Wheat, 60 pounds.

Corn, in ear, 70 pounds.

Corn, shelled, 56 pounds.

Rye, 56 pounds.

Barley, 48 pounds.

Bran, 20 pounds.

Corn meal, 48 pounds.

Salt (fine), about 60 pounds.

Oats, 36 pounds (32 pounds is accepted). 
Contents of various containers:

Bucket, G. I. (level), 12 pounds oats.

Bucket, G. I. (level), 16 pounds cracked corn.

Bucket, G. I. (level), 7 pounds bran.

A flake of baled hay weighs about 13 pounds.

APOTHECARIES FLUID MEASURE.

60 minims or drops (m) equal 1 dram (f5) (1 teaspoonful).

8 drams equal 1 ounce (f $\tilde{\jmath})$ (2 tablespoonfuls).

16 ounces equal 1 pint $(0)$.

2 pints equal 1 quart.

4 quarts equal 1 gallon.

A drop (Gtt.) is a minim.

1 teaspoonful is a fluid dram (1 drop of water weighs almost 1 grain).

1 tablespoon is 4 teaspoonfuls, or one-half a fluid ounce.

1 pint is about a pound (avoirclupois).

16 drops are approximately 1 cubic centimeter (c. c.).

The issue (Ordnance Department) spoonful (scant) is a tablespoonful containing therefore about 250 grains, or 15 cubic centimeters (c. c.).

The issue cup models of 1904 (old tin cup) contains 60 tablespoons or nine-tenths of 1 quart; 1908 and model of 1910 (aluminum with handle) holds 50 tablespoonfuls or 24 ounces.

APOTHECARIES WEIGHT.

20 grains (gr) equal 1 scruple (Э).

3 scruples equal ]. dram (3).

8 drams equal 1 ounce $(亏)$.

12 ounces equal 1 pound (lb.).

\section{IMPROVISED WEIGHTS.}

One drop of water weighs about 1 grain.

A silver (United States) dollar (new) weighs about $1 \frac{1}{6}$ ounces apothecaries and $1 \frac{1}{19}$ ounces avoirdupois.

A nickel (United States 5-cent piece) weighs about $1 \frac{1}{4}$ drams apothecaries.

Ten pennies (United States 1-cent pieces) weigh (new) exactly 1 ounce apothecaries.

One gram is equivalent to $\mathbf{1 5 . 2 2}$ grains (the weight of a cubic centimeter of water). 
One pound apothecaries is 5,760 grains. One pound avoirdupois (scales used in stores for weighing provisions, grain, etc.) weighs 7,000 grains. The "grain" is the same in all weights-apothecaries, troy, and avoirdupois.

\section{ABBREVIATIONS USED IN MEDICINE.}

Py means "take.",

ss means "half," as ₹ ss means "half ounce."

i means "one," as 5 i means "1 dram" or 5iss " $1 \frac{1}{2}$ ounces." ij means "two," as Эij means " 2 scruples."

"Ad" means "add to"; "Ad lib." means "at pleasure."

"Aq." means "water;" "D.," means "dose;" "Dil." means "dilute."

"Ess" means "essence;" "Filt" means "filter;" "Lot." "means "wash."

"M" means "mix"; "Mac" means "macerate" (to steep); "Pulv." means "powder;" "Pil." means "Pill;" "Solv.", means "dissolve."

"St." means "let stand;" "Sum" means "to be taken."

\section{DRY MEASURE.}

8 quarts $=1$ peck.

4 pecks $=1$ bushel.

1 bushel contains $2,150.4$ cubic inches.

\section{LIQUID MEASURE.}

4 gills $=1$ pint.

2 pints $=1$ quart.

4 quarts $=1$ gallon .

1 gallon contains 231 cubic inches.

LENGTH.

12 inches $=1$ foot.

3 feet $=1$ yard.

$5 \frac{1}{2}$ yards $=1$ rod.

1,760 yards $=1$ mile.

1 meter $=39.37$ inches.

1 kilometer $=0.62$ (about $\frac{5}{8}$ ) mile.

A penny (United States 1-cent piece) is $\frac{3}{4}$ inch in diameter. 


\section{DISINFECTANTS.}

Heat is the best disinfectant. Boiling for not under 15 minutes serves very well. Soap and water and then sunlight are, next to heat, probably the best germ killers in most practical instances. In especially malignant diseases, such as glanders and rinderpest, where thorough disinfection is imperative, total destruction by fire is the best method. Oil sprinkled on ground and burned is very good.

Chemical disinfectants are effective if they reach the microbes. Disinfecting vapors are, next to heat, most effective. Sulphur placed in a shovel or other metal container and burned in an infected building or room which has been thoroughly sealed will generate fumes which will thoroughly disinfect in 24 hours. One pound of sulphur is required per 1,000 cubic feet. Liquids come next in efficacy. Creolin (Pearson) 1 part, water 25 parts; carbolic acid 1 part, water 20 parts; corrosive sublimate (mercury chloride) 1 part, water 1,000 parts, are good. Never use a sponge in cleaning wounds-always cotton; then burn or boil or otherwise disinfect it. Whitewash or paint simply cover up objectionable matter.

When it is advisable, either from necessity or from dictates of humanity, to dispose of an animal, the easiest method is by shooting with either a rifle or a pistol. Care must be taken to see that no person or animal is in rear of or within close distance of the animal, for even after having passed through a portion of the animal's body bullets occasionally still have considerable velocity. The barrel of the weapon should be held at right angles to and the muzzle not over 2 inches from the center of the forehead, aimed at a point above the eyes about half an inch below the lowest hairs of the foretop.

\section{EQUIPMENT FOR THE FARRIER.}

General Orders, No. 115, War Department, 1911, gives a list of veterinary medicines and equipment and allowances for organizations of the Regular Army which have public animals. The total weight of such supplies to be transported in field or store wagons, or on store pack mules, will not exceed a quantity based on a rate of 18 pounds, including containers and cases, per 100 animals. These supplies will be transported in combat trains in all cases where organizations have store wagons or store pack mules, and in field wagons for other organizations. In mounted organizations the work of the farrier is performed under the supervision of the veterinarians; therefore the following information regarding the veterinarian's equipment is given.

$$
76881^{\circ}-15 \longrightarrow 3
$$


Each veterinarian is supplied with a veterinarian's field equipment weighing about 150 pounds, which consists of a set of "Veterinarian's field chests," veterinarian's saddlebags and their contents. (See Pl. IV, p. 35.)

Veterinarian's field chests.-Each set consists of 5 chests. Of the two large chests, one is supplied with 10 empty bottles, 14 or 16 ounces, height not to exceed $7 \frac{1}{2}$ inches; the other containing 18 empty round jars with screw tops, $3 \frac{3}{4}$ inches high by $2 \frac{3}{4}$ inches in diameter. These two chests with the other three chests (to be supplied empty) contain the veterinarian's field supplies.

Instruments and appliances for field chests-

Figure 1. 1 casting harness.

Figure 2. 1 catheter.

Figure 3. 1 clipper, hand.

Figure 4. 1 drenching bottle, rubber.

Figure 5. 1 flat, tooth, straight and angular.

Figure 6. 1 graduate glass.

Figure 7. 1 hoof-knife set, in roll.

Figure 8. 1 stomach tube, with stylet.

Figure 9. 1 syringe, metal, 2-ounce.

Figure 10. 1 tray, enameled, 10-inch.

A veterinarian's saddlebag should contain the following articles:

Figure 11. 1 hypodermic syringe and case; 1 tray, tin (to be filled with sponge or gauze when packed).

Figure 12. 1 case, surgical, small, vest-pocket size, to contain the following:
1 scalpel.
1 bistoury, probe pointed.
1 bistoury, sharp pointed.
1 tenaculum.
1 probe, silver, jointed, two sections.
1 director, grooved.
2 forceps, artery, with catch.
6 needles, suture, curved and half curved, assorted sizes.
1 scissors, curved or flat.

For organizations which have animals but which have no veterinarian, such as Infantry, Engineers, and Signal troops, a "Veterinary pannier" is supplied. (See Pl. V.) It weighs approximately 70 pounds.

The contents of a veterinary pannier are not prescribed in detail. A pannier should be equipped with such supplies as are appropriate and necessary for any particular march or expedition. Panniers supplied to organizations having no veterinarians are for use as containers of veterinary medicines and dressings. Panniers may be supplied to Cavalry and Field Artillery regimental head- 


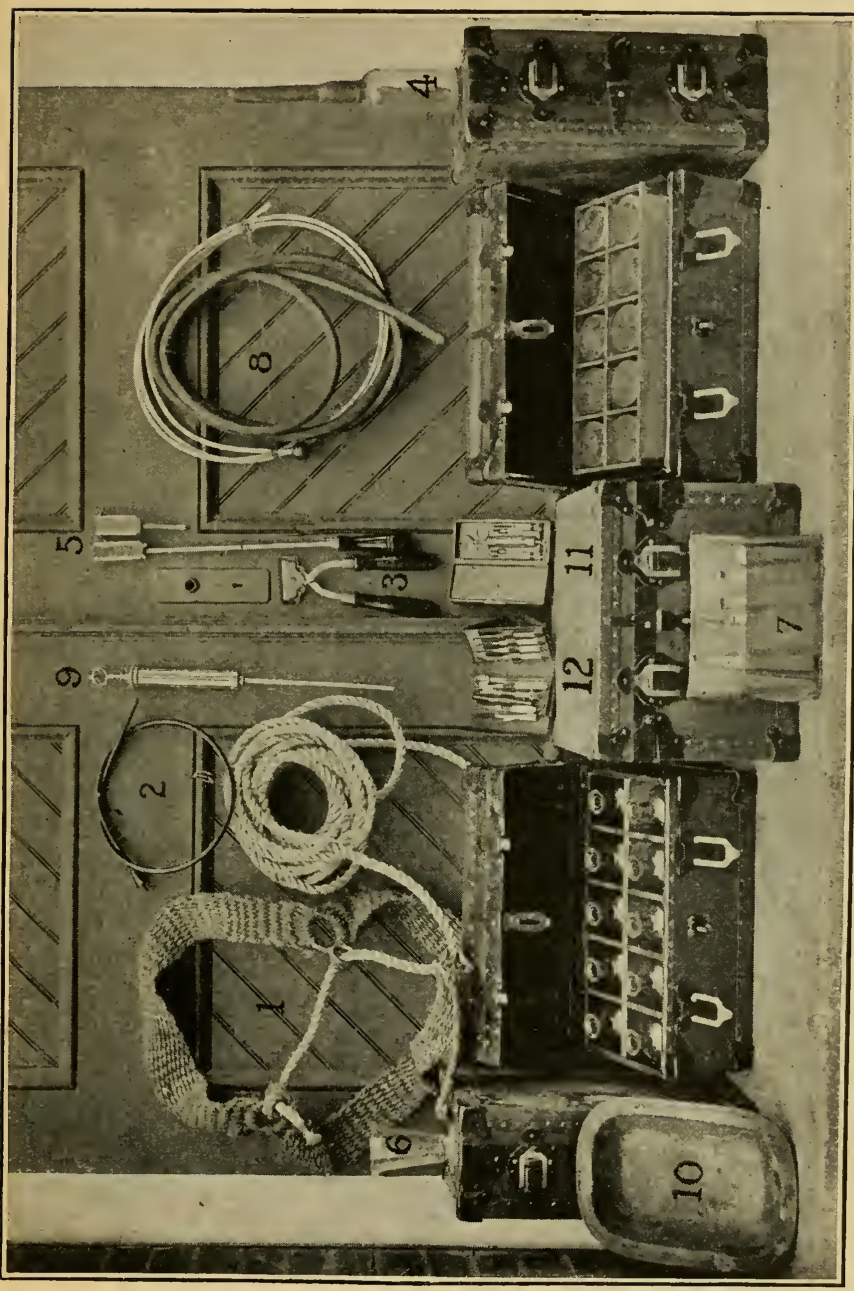

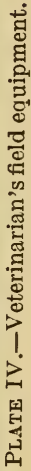


quarters and may also be equipped with instruments and appliances selected from the veterinarian's field equipment; or one of the veterinarian's field chests may be used for this purpose in lieu of the pannier supplied regimental headquarters.

One authority has suggested the following list of veterinary supplies. Under ordinary conditions it should suffice for 100 animals for 10 days:

Medicines-

3 aloes balls.

$\frac{1}{4}$ pound ammonia, aromatic spirits.

$\frac{1}{4}$ pound ammonia liniment.

$\frac{1}{4}$ pound charcoal.

$\frac{1}{2}$ pound chloronaphtholeum or kreso.

$\frac{1}{2}$ pound colic mixture.

$\frac{1}{2}$ pound cosmoline.

$\frac{1}{4}$ pound iodine tincture.

$\frac{1}{2}$ pound lime, chloride of.

3 ounces mercury, bichloride of.

$\frac{1}{4}$ pound oil, linseed.

$\frac{1}{4}$ pound oil, olive.

$\frac{1}{4}$ pound ointment, antiseptic.

$\frac{1}{4}$ pound tar, pine.

$\frac{1}{4}$ pound three sulphates (copper, iron, and zinc).

Dressings-

$\frac{1}{4}$ pound absorbent cotton.

1 package antiseptic gauze.

Bandages-

1 flannel.

4 cotton, white.

1 pound oakum.

1 pound soap, Castile.

The above list might be amended by omitting the third, fourth, ninth, tenth, eleventh, and fifteenth items, increasing quantity of olive oil to 1 quart, changing fifth item to " 1 pound of Creoline, Pearson," adding 1 pound of turpentine, and increasing amount of absorbent cotton to 1 pound.

In the Organized Militia when continuous service in the field is expected the same equipment should be carried as by Regular troops. In time of peace such an elaborate outfit is unnecessary; the possession by each troop of the prescribed "Farrier's field equipment" (specified in General Orders, No. 115, War Department, 1911), and certain additional supplies, will meet the requirements. 


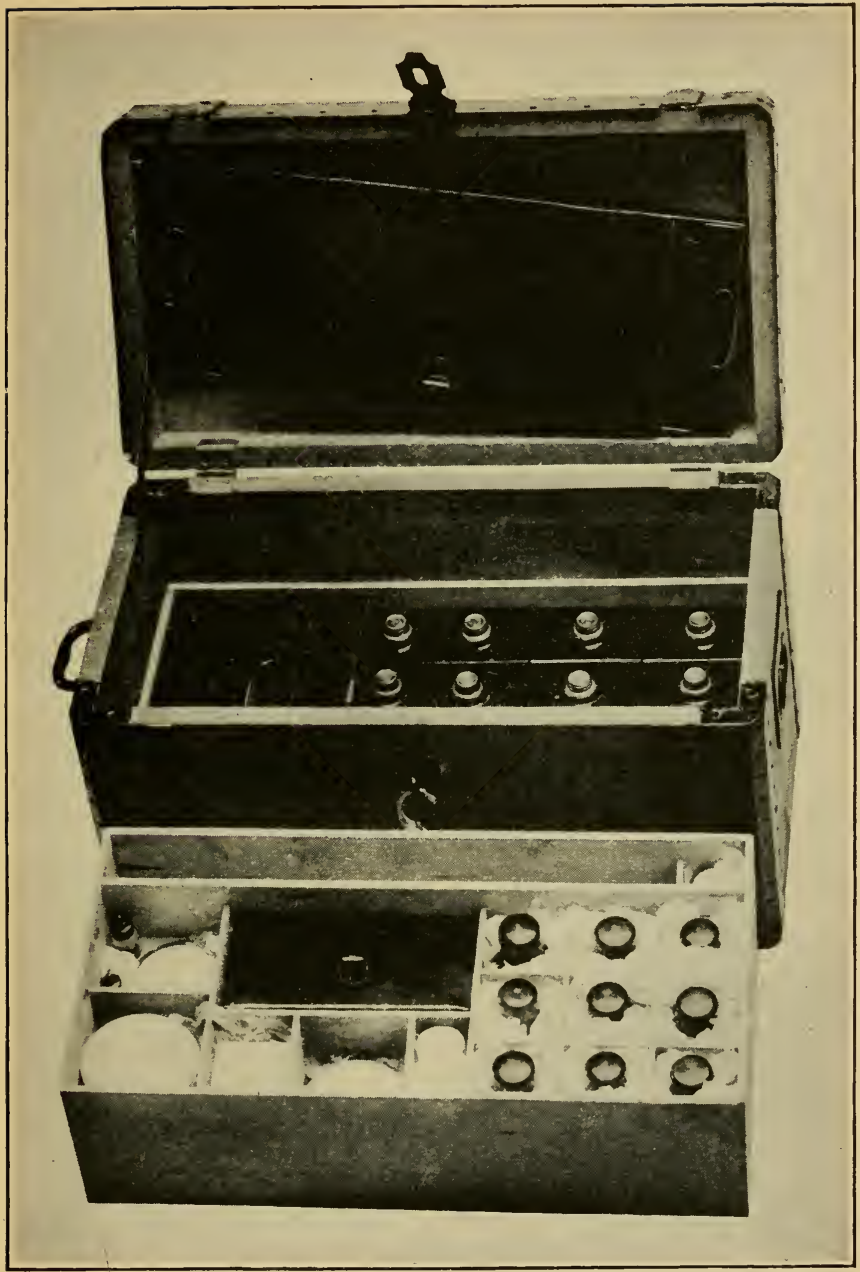

Plate V.-Interior of veterinary pannier; tray removed. 
FARRIER'S FIELD EQUIPMENT.

(See Pls. VI and VII, pp. 39 and 40.)

For the farrier an outfit much simpler than that for the veterinarian is prescribed. Eighteen pounds are allowed for the entire equipment required by the farrier in the performance of his special duties.

1 basin, granite, 1-quart.*

4 bottles, 1-pint†-

1 for colic, drench.

1 for restorative in heat exhaustion and rise in temperature.

1 for antiseptic wash (creolin, Pearson).

1 with detachable rubber neck, for drenching bottle. 1 farrier's instrument pocket case.

1 graduate glass, 2 -ounce.*

1 dose syringe, metal, 4-ounce.*

\section{Additional equipment and supplies needed.}

1 funnel, enamel, 1-quart.*

10 bandages, gauze, about 4 inches wide, and 5 yards long. $\dagger$

10 bandages, cotton, same dimensions. $\uparrow$

5 pounds cotton, absorbent. $\dagger$

10 days' supply of medicines.† (See table below.)

There is also issued to the farrier when he acts as horseshoer a

\section{HORSESHOER'S EMERGENCY EQUIPMENT.}

(See Pl. VIII, p. 41.)

1 shoeing hammer.*

1 pincers.*

1 hoof knife.*

1 jointed horseshoe, No. $2 . \dagger$

1 rasp.*

Horseshoe nails, $\uparrow$ as reçuired.

${ }_{4}^{1}$-pound oakum. $\dagger$

1 4-ounce bottle chlorolin or kreso. $\dagger$

Articles marked † are expendable upon certificate of the accountable officer that they were used in the public service.

Articles marked * are expendable on the certificates of the accountable officer, approved by the commanding officer, that they were worn out in the public service and have no salable value, and the certificate of a disinterested officer that he witnessed the destruction. If they have any salable value, they must be submitted to the action of an inspector (Bulletin No. 3, War Department, 1914). 


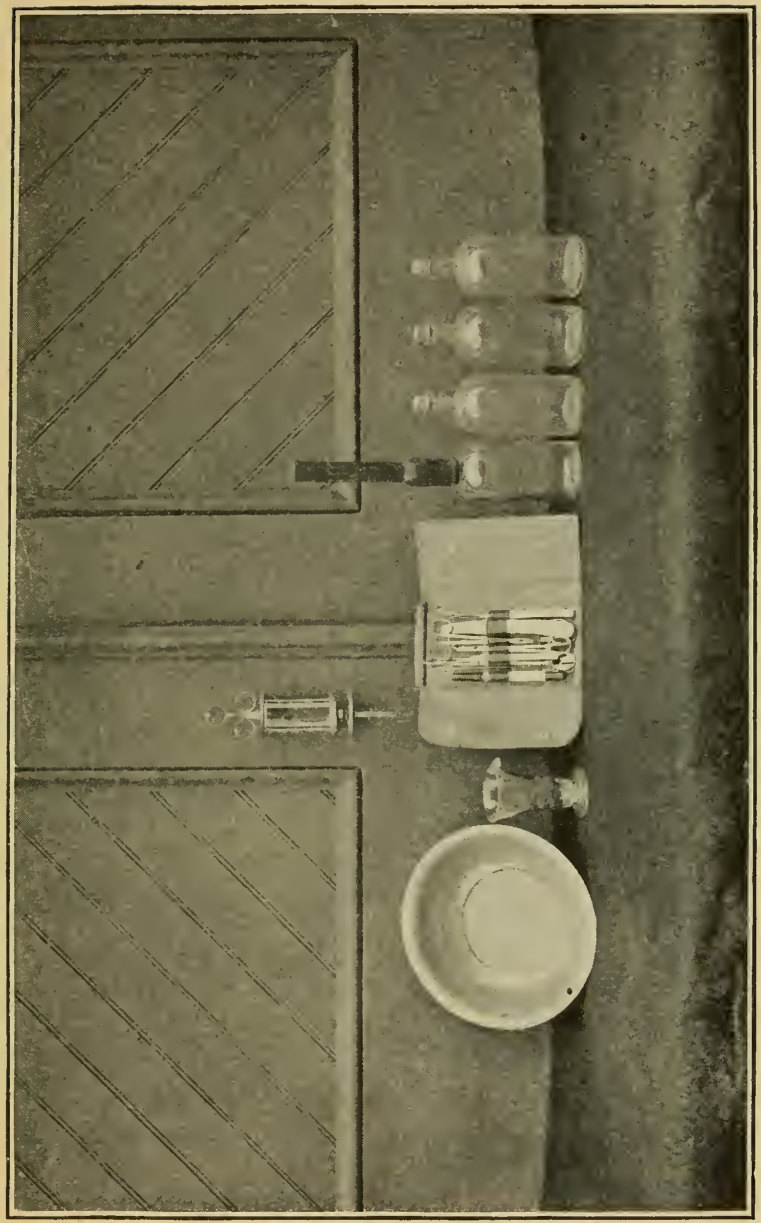

迥 


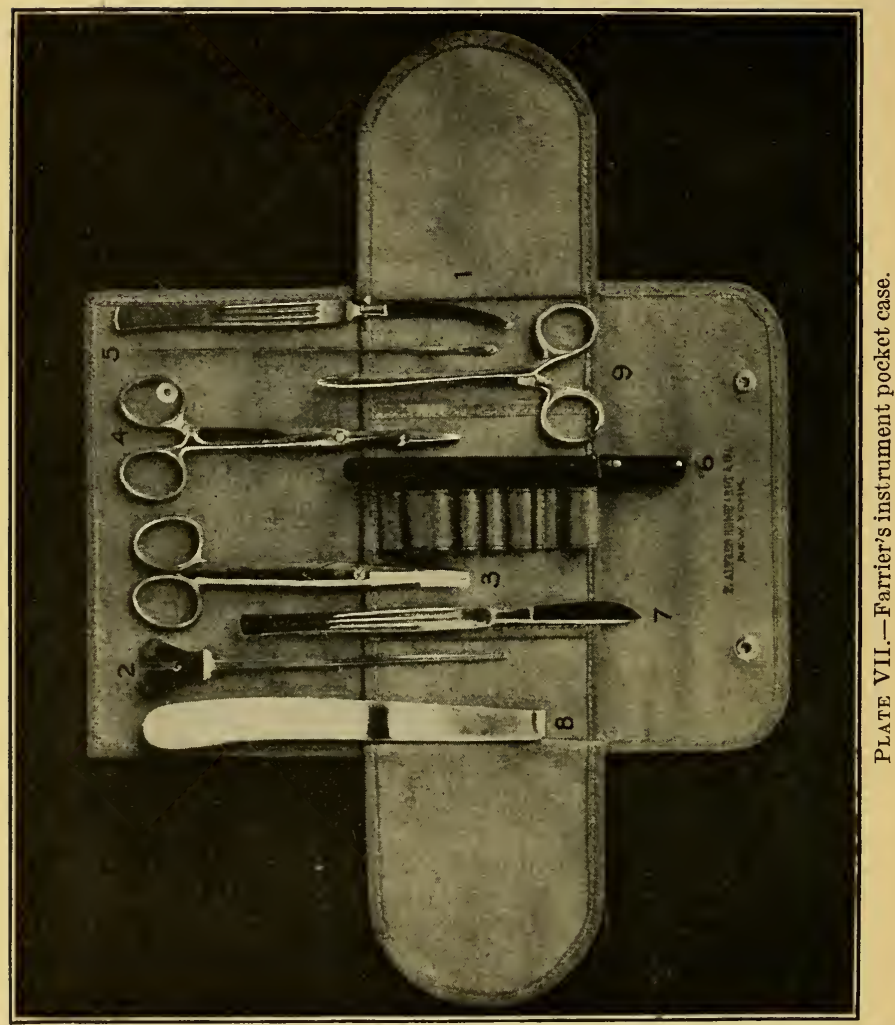




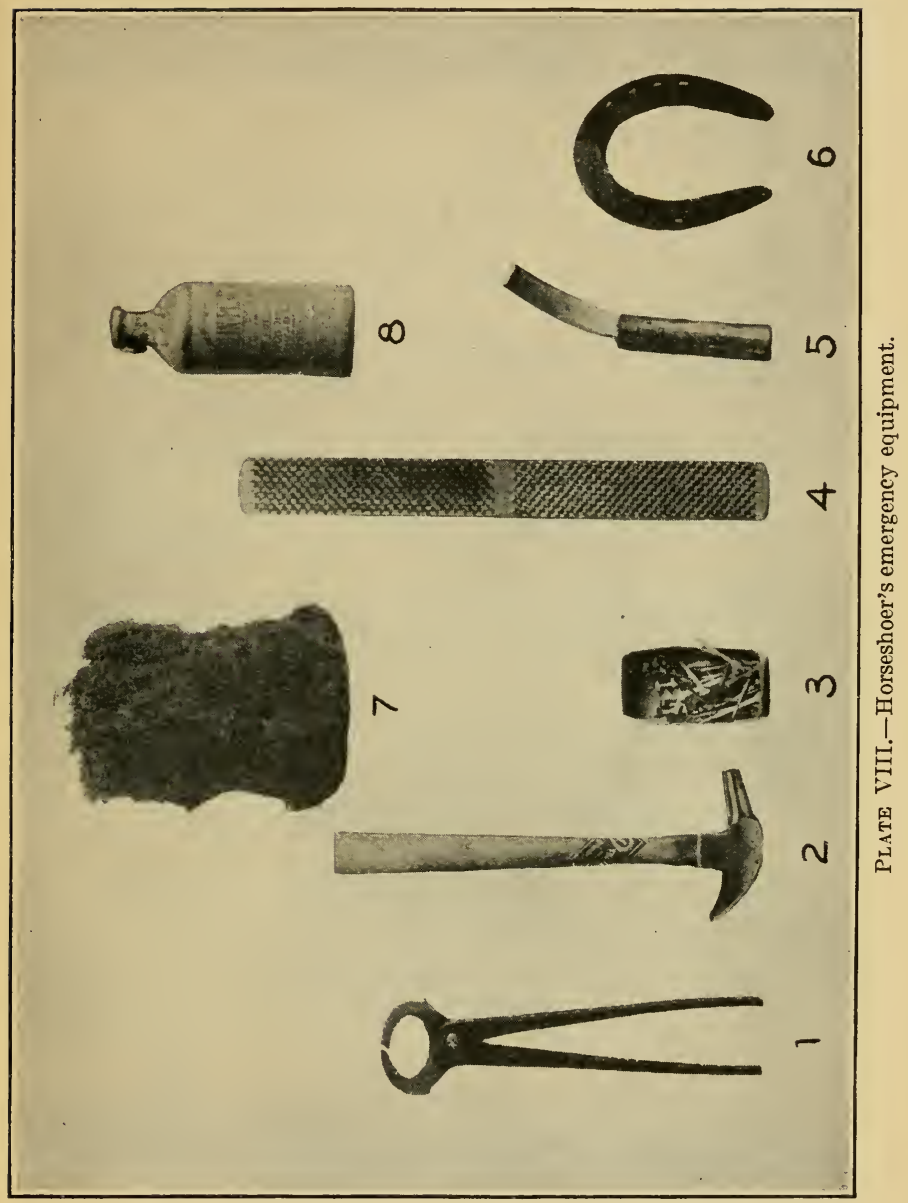


FARRIER'S INSTRUMENT POCKET CASE (IN CANVAS ROLL).

(See Pl. VII, p. 40.)

Contents:

Fig.

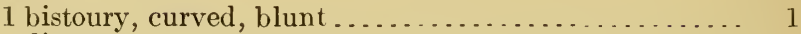

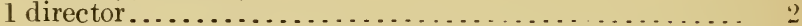

1 scissors, curved ................................. 3

1 forceps, artery . . . . . . . . . . . . . . . . . . . . 4

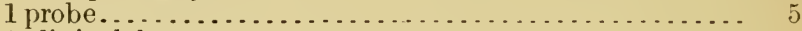

1 clinical thermometer. . . . . . . . . . . . . . . . . . 6

1 scalpel .................................... 7

1 hoof knife................................... 8

1 forceps, dressing. . . . . . . . . . . . . . . . . . . 9

6 needles, curved.

1 silk, skein.

Uses-

(a) Bistoury, curved, blunt, for opening of absces es; use scalpel, making small opening at lowest point of abscess, and when pus (matter) shows enlarge opening with probe-pointed bistoury. Do not make opening larger than necessary to give pus easy flow. Wash and disinfect before and after opening and keep area clean.

(b) Curved scissors for clipping the hair off parts when knife is to be used, and for trimming ragged edges off. Keep instrument clean, use an antiseptic solution (noncorrosive), such as creolin and water.

(c) Artery forceps, for picking up a cut artery for ligation. Arterial bleeding is recognized by the blood coming in spurts corresponding to the pulse. When the artery is picked up, tie silk around it and remove forceps. Also used for removing foreign substance from wound.

(d) Needles, for sewing up fresh-cut wounds. Start sewing from top of wound; tie each stitch and do not close wound entirely at its lowest point but leave outlet for pus that may form. Take stitches out if suppuration is detected down in the wound (the wound has in that case become infected before being dressed or not been properly cleansed). If no suppuration occurs, remove stitches when wound appears to have healed -3 to 5 days. Few wounds will heal without suppuration in a horse or mule unless dressed when wound is quite fresh and absolutely clean.

(e) Suture silk, for sewing up wounds. It must be clean and be well soaked in pure Creolin before used. After the wound is sewed up, dust iodoform on it or apply a little vaseline.

(f) Probe, used to find out if any foreign substance is in the wound-for example the bullet in a shot wound.

(g) Tenaculum is used to pick up ends of arteries and tissues. 
(h) Director: Little used, except as a probe. For deep cutting (very rarely done) it is sometimes used as a guide for the bistoury or scalpel.

Clinical thermometer: Insert in rectum for three or four minutes.

After using the thermometer the mercury should be shaken down. Before using, it should be examined to see that it registers under $95^{\circ}$.

The farrier should always have with him-

1. Instrument pocket case.

2. Colic mixture-5 doses (see "Medicine" below).

3. Antipyretic (antifever) mixture-5 doses (see "Medicine" below).

4. Antiseptic (Creolin), $\frac{1}{4}$ pint (see "Medicine" below).

5. 1 dose syringe, 2 ounces.

6. Clinical thermometer.

7. Bandages, cotton (4).

8. Bandages, gauze (4).

9. Cotton, absorbent, 2 pounds.

10. 3 feet rubber tubing with funnel to fit, or drenching bottle.

Conditions of service should determine what other articles of the field equipment, if any, ought to be so carried. For example, in very hot weather a bottle of heat-exhaustion restorative should be taken; if horses are soft or have just had a change of diet, a pint of colic drench might be useful; if the wagons do not closely follow the column, some antiseptic wash might be carried. All articles of the field equipment not carried by the farrier personally should be packed in a box of convenient size, which should be left in the field wagon.

Every mounted command liable to go into the field unaccompanied by a veterinarian should keep on hand 10 days' field-service supply of such necessary and simple medicines as can be properly prescribed and administered by the farrier. Such medicines, for a command numbering about 70 horses and mules, would be about as shown in the table below under "Medicines." The financial allowance is 25 cents at home or 30 cents in tropical stations per quarter per animal. In case the strength is materially above or below 70 , quantities should be varied accordingly.

\section{MEDICINES.}

Medicines are of assistance in healing, but their principal purpose is to keep away outside interference, mostly microbes, from the animal while nature does the healing. When necessary to give medicine, this may be accomplished by (1) introducing it through the mouth into the intestinal tract, (2) by inhalation (through the nostrils or mouth and the lungs), (3) by absorption through the 
skin, (4) by injection under the skin, (5) by injection into and absorption through the rectum.

Through the mouth medicine may be given in various ways, viz, in the shape of powder either dry or dissolved in water and then sprinkled on the food; an electuary made by mixing the medicine with honey or sirup together with enough dope (some sort of food) to make it into a puttylike mass, and this placed on the back of the tongue with a paddle, or formed into a cylindrical form usually called a "ball," about 2 inches long and three-fourths of an inch in diameter, wrapped with tissue paper and placed on the back of the tongue; a drench, made by adding the medicines to water or some other liquid and pouring slowly from the mouth of a bottle placed between the cheek and the elevated lower jaw; syringe, the contents of which are squirted onto the back of the tongue (this is the best method; see below).

Giving liquid medicines: Fill a syringe with the medicine. Face the horse, take hold of its tongue with left hand (do not pull the tongue out, but simply hold it); insert nozzle of syringe over tongue and squirt the medicine in; turn loose tongue and with left hand hold horse's head high until the sound of swallowing is heard.

If a dose syringe be not available, "drenching" may be resorted to, although as usually performed this method is most.y a waste of medicine, the horse usually swallowing little. The liquid medicine should be placed in a bottle, preferably one having no shoulders. The muzzle of the horse is elevated until the lower jaw is slightly above horizontal; this may be done by hand with some animals, but others require the head to be drawn up by a strap or rope thrown over a limb of a tree or other elevated point of support; ordinarily the shank attached to the halter may be used, but it is better to use, in addition to the halter, a nonslipping loop placed over the nose and in the mouth, so as to come against the roof of the mouth in rear of front teeth. With head in the elevated position, the month of the bottle is placed between the molars and the incisors (back and front teeth) and the contents very slowly poured onto the tongue. If the animal chokes, let his head down. Do not strike or rub the throat or windpipe "to make him swallow.".

Inhalation is used usually to relieve a stoppage of the breathing apparatus, such as occurs in case of a cold; it is given by causing a vapor or steam to be breathed into the lungs. Several arrangements can be made for accomplishing this; ingenuity will enable any farrier to devise some means; the simplest is to pour the steaming liquid onto clean hay in a sack which has been fastened over the animal's head.

Absorption through the skin is accomplished by applying the medicine to the skin, sometimes by standing the animal in a tub, and sometimes by soaking cloths in the medicine and applying with bandages. 
Injections under the skin are administered by the hypodermic syringe, but are rarely resorted to, and are given by a veterinarian only and usually for the purpose of relieving an animal's suffering.

Injections into the rectum are resorted to for the purpose of cleaning it out, or as a means of administering moderate heat in order to increase the circulation in adjacent parts, or to provide nourishment when the animal is prevented by weakness, injury, or other incapacity (such as in lockjaw) from taking food into the mouth, or to reduce the temperature (cold water) in case of fever.

\begin{tabular}{|c|c|c|c|}
\hline Medicine. & Use. & $\begin{array}{l}\text { Ton days' field- } \\
\text { service supply } \\
\text { for } 70 \text { animals. }\end{array}$ & Dose. \\
\hline 1. Creolin, Pearson.. & Antiseptic..... & 1 1-pound bottle. & $\begin{array}{c}\text { For external use, } 1 \\
\text { tablespoonful to } 1 \\
\text { pint of water; for } \\
\text { internal use, }, 1 \text { to } 1 \text { ta- } \\
\text { blespoonful mixed } \\
\text { with } 6 \text { to } 8 \text { table- } \\
\text { spoonfuls ofoliveoil. }\end{array}$ \\
\hline 2. Glauber salts. . & Laxative..... . & 2 1-pound cans.. & $\begin{array}{l}2 \text { to } 4 \text { handfuls; in } \\
\text { feed or dissolved in } \\
\text { water as a drench. }\end{array}$ \\
\hline $\begin{array}{l}\text { 3. Acetanilide in al- } \\
\text { cohol. }\end{array}$ & Fever reducer.... & $\begin{array}{l}4 \text { ounces dis- } \\
\text { solved in } 1 \\
\text { pint of alco- } \\
\text { hol. }\end{array}$ & $\begin{array}{l}\text { Mix on receipt of in- } \\
\text { gredients; ke e ps } \\
\text { indefinitely. (See } \\
\text { under "Colds," p. } \\
\text { 46.) D o s e, } 2 \\
\text { ounces; do not' re- } \\
\text { peat within } 12 \\
\text { hours. }\end{array}$ \\
\hline $\begin{array}{l}\text { 4. Fluid extract of } \\
\text { cannabis. }\end{array}$ & Pain deadener..... & 2 ounces........ & 1 teaspoonful (in \\
\hline 5. Olive oil... & Emollient.. & 1 quart... & $\begin{array}{l}2 \text { ounces (in various } \\
\text { mixtures). }\end{array}$ \\
\hline 6. Cosmoline........ & Scab softener.. & $\frac{1}{2}$ pound... & Coating. \\
\hline 7. Castile soap....... & Cỉeanser........... & 5 pounds........ & As required. \\
\hline $\begin{array}{l}\text { 8. Lugol's solution: } \\
\text { Iodine, } 5 \text { parts; } \\
\text { potassium io- } \\
\text { dide, } 10 \text {; water, } \\
100 .\end{array}$ & $\begin{array}{l}\text { Saddle sores, } \\
\text { scratches, and } \\
\text { eczema. }\end{array}$ & $\begin{array}{l}1 \text { fluid ounce io- } \\
\text { dine, } 4 \text { ounces } \\
\text { p ot a s s i u m } \\
\text { iodide. }\end{array}$ & $\begin{array}{l}\text { Mix on receipt of in- } \\
\text { gredients; a p ply } \\
\text { externally; time, } \\
\text { daily. }\end{array}$ \\
\hline 9. Iodoform .......... & $\begin{array}{l}\text { Disinfectant for } \\
\text { drying up open } \\
\text { wounds. }\end{array}$ & 1 ounce.. & Sprinkling. \\
\hline 10. Iodine solution... & $\begin{array}{l}\text { Disinfect fresh } \\
\text { open wounds. }\end{array}$ & 1 pint..... & $\begin{array}{l}\text { Pouring onto or coat- } \\
\text { ing of the exposed } \\
\text { flesh. }\end{array}$ \\
\hline 11. Colic mixture.... & Abdominal pain. . & $\begin{array}{l}\text { Fluid extract } \\
\text { c a n n a b i s } \\
\text { Americana, } 1 \\
\text { part; creolin, } \\
\text { (Pears on) 1 } \\
\text { part; olive oil, } \\
2 \text { parts. }\end{array}$ & $\begin{array}{l}\text { See "Diseases, in- } \\
\text { ternal colic,"(p. 46). }\end{array}$ \\
\hline
\end{tabular}




\section{INTERNAL DISEASES.}

The appetite is generally a very good index of he state of health of the animal. If a horse refuses to eat his food or eats part only or eats laboriously, it is important to ascertain the cause as soon as possible. The mouth should be carefully examined to see whether the sharp edges of the back teeth have cut the tongue or the cheeks. Examine the front teeth to determine whether food has become lodged between the gums and the teeth. It should be remembered that except in old horses the upper gum is almost level with the lower edge of the upper teeth.

\section{COLIC.}

Abdominal pain without inflammation.

Cause.-Faulty feeding.

Symptoms.-Sudden attack; paws, looks anxiously at flank, goes down, sits, rises, shakes himself. These symptoms more or less violent.

Treatment.-Take feed away from reach of animal. Give a dose of "colic mixture"-fluid extract cannabis Americana, 1 teaspoonful; creolin (Pearson), 1 tablespoonful; olive oil to fill 2-ounce syringe.

Rub animal's abdomen with straw and cover with blanket. Walk animal slowly until it is relieved. Inject lukewarm soap water in rectum, 1 gallon or more. Don't repeat dose of medicine before three hours, even if animal still suffers. Don' $t$ feed animal until six hours after pain disappears. Don't offer water before attack is over and then only in small quantity-half a bucket full. If animal's temperature rises it is indicative of intestinal inflammation and chances for recovery are not good. Do not in such cases give "fever mixture," but give only creolin (Pearson), 1 tablespoonful with 8 tablespoonfuls of olive oil, and repeat every fourth hour.

COLD, CATARRH, STRANGIES, PNEUMONIA, INFLUENZA.

Inflammation of mucous membranes, with or without rise of tem. perature.

Symptoms.-Dullness, discharge from nostrils, cough, heary breathing.

Causes.-Exposure and infection.

Treatment.-If cold, put blanket on. Take temperature in the animal's rectum; if over $102^{\circ} \mathrm{F}$., put animal under shelter, but be careful to keep it in well-aired place. Give fever mixture: Acetanilide, 1 tablespoonful dissolved in 8 tablespoonfuls alcohol, and 
half an hour later give creolin (Pearson), half tablespoonful with 8 tablespoonfuls olive oil.

Dont't again give acetanilide until 12 hours, even if temperature is still above $102^{\circ} \mathrm{F}$. Give 2 ounces of olive oil four times daily. If swelling shows around throat, heat a small quantity of olive oil and rub in on swellling twice a day; don't heat the oil more than can be borne by finger kept continuously in it. If lumps appear under lower jaw and break open, they do not indicate glanders.

If temperature rises to $104^{\circ} \mathrm{F}$. or above, indications are that animal has pneumonia. The animal will then not lie down and breathes quicker than normal.

Let animal have the feed it wants and give a bran mash once a day-not over 1 quart of wheat bran and only sufficient hot water to make it damp.

\section{DIARRHEA.}

Cause.-Change of water or food, bad water or food, diseased teeth, exposure, exhaustion, or too much physic.

Symptoms.-Passing frequently liquid feces.

Treatment.-Correct the fault if practicable. Rest the animal. Give creolin, 1 teaspoonful in 4 tablespoonfuls of water or olive oil. If the looseness of the bowels continues, give wheat flour stirred in water. The animal should be kept quiet and made comfortable; especially if the weather is cold keep it warm. Give less water to drink.

\section{WORMS.}

Disposing cause.-Failure to give salt as often as should be, poor condition.

Symptoms.-Itching of upper lip, licking the hide or stalls, rubbing the tail, rough coat, bowels irregular. Occasionally worms may be seen in the feces. There are many kinds-tapeworms and roundworms. Those ordinarily encountered are round, reddish or white and are about 6 to 12 inches long and $\frac{1}{8}$ to $\frac{3}{8}$ of an inch in diameter. Tapeworms are flat, thin, jointed, white in color, and vary in length, sometimes being 30 feet long.

Treatment.-If possible, keep food from animal one day before beginning treatment and while giving it; or give gruel and water only. Give twice daily for three days creolin 1 ounce, olive oil 3 ounces, and the next day a physic. The bot which lodges in the rectum may be removed by enema of tobacco water or weak creolin (disinfectant) twice per day for two days and followed by a physic the next day. The animal should receive careful attention afterwards to insure his building up in strength. See that the horses get the proper amount of salt at regular intervals. 


\section{RETENTION OF THE URINE.}

Cause.-This is caused by a contraction of the mouth of the bladder which occurs when the bladder is irritated or when a foreign body gets into the canal or-most frequently-when the fecal matter in the rectum accumulates and gets hard and presses on the canal from above. The bladder lies just under the rectum; it is gourd-shaped with the handle or neck immediately under the anus; the outlet is immediately under the anus in the mare and in the horse through the urethra which runs down between the hind legs just beneath the skin to the male organ.

Symptoms.-The animal may be in great pain, in which case he acts quite the same as when affected with the colic. He spraddles his hind legs, strains, and tries to pass water.

Treatment.- The hand and fore arm, well oiled or soap-lathered, should be inserted in the rectum when it will be easy to feel if the bladder is distended. The rectum should first be thoroughly cleaned by an enema (about a gallon of warm and soapy water injection), after which it should be thoroughly examined to see that all matter is removed. Then a very gentle massaging of the mouth of the bladder by the hand in the rectum - using plenty of oil-may relieve the irritation. Do not give sweet spirits of niter (which is usually prescribed), for it only further irritates the urinary system. Wash the sheath and the outlet thoroughly. If the patient be a mare, the fingers may be oiled and inserted in the urethra, and possibly the opening thus enlarged sufficiently to permit the water to flow. In the male the only way, if those suggested fail after several hours' trial, to relieve the pressure of the water in the bladder is by passing a catheter-but this requires the skilled veterinarian. Often the throwing and shaking of a little straw under the horse will induce the discharge of urine. A little soap on the point of the penis will frequently produce the same effect.

\section{EXCESSIVE URINATING.}

Cause.-Feeding of moldy grain and hay.

Treatment.-Remove cause. Give animal a pint of olive oil twice a day for two days. If no sound feed can be obtained, have the moldy grain or hay spread in open air, but protected against rain.

HEAT EXHAUSTION, SUNSTROKE, THERMIC FEVER.

Symptoms.-Muscular weakness. Heart's action feeble, pulse rapid, general depression, collapse.

Cause.-Prolonged exertion in hot atmosphere.

Treatment.-Rest animal. If no rise of temperature, give stimulants such as alcohol in small often-repeated doses $-\frac{1}{2}$ ounce every 
half hour. Rub the body and limbs; give warm bath. If temperature is high (over $104^{\circ} \mathrm{F}$.), give cold water bath, place ice on head, rub body and legs. Give internally double dose of "fever mixture" (see p. 45). Cold-water enema (injection of water into the rectum).

\section{EXTERNAL DISEASES.}

(See Pls. I, II, and III.)

Most of the external diseases coming to the attention consist either of lameness, local irritation, skin diseases or abscesses. In some cases (such as founder) the disease is really internal, but the treatment is taken up under this heading for convenience.

\section{LAMENESS.}

Find leg that animal favors. Trot him off; he will step lightly on the lame leg, raising the head and lame leg together if lame in front, and plant the other foot harder.

The degree of lameness varies from being hardly perceptible, to one where the animal does not put the foot to the ground. Some forms of lameness will show less after the animal has been exercised awhile; in other cases the animal will show more lameness. The former generally indicates something wrong with tendons, the latter of the joints. Never forget to examine the hoof for punctures by picked-up nails, pieces of glass, or small, sharp rocks wedged between shoe and frog. Examine shoe and shoe nails. Tap with hammer on heads of nails and if the animal shows pain, have shoe removed. If pulsation can be noticed by putting hand on space between canon bone and tendons about half distance from the knee to fetlock (ankle) joint, it is likely that the cause for lameness is to be found in the hoof. After the thorough examination of the hoof has shown no cause for the lameness, proceed with the examination to the joints, tendons, bones, and muscles. Notice any swelling, soreness, enlargement, or wounds. If the cause is then not apparent, pull the shoe and examine the nails. If damp the indications are that the nail has penetrated the sensitive hoof. If so, the nail hole should be thoroughly disinfected, openings packed, and re-dressed from day to day until animal recovers.

Don't forget to find out how long animal has been lame.

PUNCTURE OF THE HOOF.

Treatment.-Thin the horn around the injured place so that pus can have outlet; then cleanse hoof with creolin solution, pack hoof with cotton or oakum well saturated with pure, undiluted

$76881^{\circ}-15-4$ 
creolin and held in place by doubled sack wrapped around hoof and tied between ankle and hoof. Be careful not to tie so tight as to cut off circulation in the leg. Dress once a day until animal shows no lameness; then put on shoe, but have leather sole put between hoof and shoe.

\section{FOUNDER OR LAMINITIS.}

Congestion and inflammation in the hoofs. Usual in front hoofs, but sometimes in all hoofs.

Symptoms.-Stiff walk, hind feet put forward under body. Pulsation marked above affected feet.

Causes.-Overfeeding, change of feed from one kind of grain to another; exhaustion on long marches, especially when horses are unaccustomed to it.

Treatment.-Give a laxative, as Glauber salts, 4 to 8 handfuls dissolved in water, or 1 to 2 quarts of olive oil. Don't give any grain feed; if animal is hungry, give bran mash. Place animal with feet in cold water and give slow exercise every hour for from 5 to 10 minutes. Don't remove shoes on horse.

\section{SPRAINS.}

Sprains of joints and tendons are treated with cold water at first; this must be continued as long as part feels hot by touch. Then bathe with warm water or, better, use a hot-water poultice.

Hot-water poultice is made by taking a piece of a clean oat sack large enough, when folded, to go twice around the joint. Soak sack cloth in as hot water as the hands can bear, wring and place it around the affected part, hold $\mathrm{jt}$ in position by a 4 -inch wide cotton bandage. Bandages must be clianged at least once a day; hot-water bandage should be taken off bofore it gets cool. It is useless to try to bandage at places on the legs above knce or hock. Warm oil can be used with advantage in case a sprain has existed for several days. The use of either liniment, blister, or firing is inadvisable.

Massage is useful and advisable when the skin is unbroken. Massage consists of rubbing with th , hands, and it should be done in a direction toward the heart, but it must not be continued after the skin gets irritated.

\section{DRY IIOOFS.}

Under ordinary stable conditions the hoofs will become dry and will crack. The animal should be stood in water for several. hours each day or hoofs packed with well-moistened clay. 
CONTRACTED HEELS.

Caused by bad shoeing. (See under "Shoeing.")

\author{
THRUSH.
}

Cause.-This disease is generally due to dampness accompanied by filth.

Symptoms.-The seat of the discase is in the center crack or cleft of the frog, which at first shows dampness and has an offensive smell. This dampness develops into a discharge which is watery at first, but soon changes to a thicker and heavier colored consistency. Lameness does not result at first, but if not attended to the crack gets very deep, the frog becomes.more and more affected and withers away, the heel becomes contracted, and lameness finally results.

Treatment.-Bathe thoroughly with creolin wash; remove the affected portions carefully; pack with creolin-soaked oakum or cotton and bandage this on well. Renew the treatment daily until cured.

\title{
CANKER.
}

Cause.-This is a malignant growth which begins between the bar and the frog and spreads to the sole between the horny and the fleshy part. Dampness does not cause it, but it does provide the conditions which are almost essential to the commencement and which favor the continuation of the disease. Filthy standing places-especially stables which are not cleaned-and bruises of the frog or the sole are favorable conditions for the disease to get a foothold.

Symptcms.-It differs from thrush in that thrush attacks the frog and is accompanied by a discharge from the cleft or the center crack of the frog, while the former begins where the frog joins onto the sole and spreads rapidly to the entire foot. It is practically a rotting away of the sole accompanied by a watery discharge. Small cheeselike growths of new-apparently healihyhorn grow out but they soon break out and decay. The discharge is very offensive to the smell.

Treatment.-This is a very serious disease which is puzzling to even those most skilled in veterinary science. Some think it is a parasite, others believe it to be very similar to cancer. $A$ veterinarian should be called at the first opportunity. Until one can be secured the foot should be cleaned, diseased parts removed, and the foot packed with full-strength creolin and the 
foot encased in sack. The animal should be placed on a footing of lry sand.

This disease is contagious, and great care should be taken to see that other animals are protected against standing in the place formerly occupied by a diseased horse, and the diseased animal should have the unaffected feet kept from contamination. (See "Disinfectants," p. - .)

\section{ABSCESS.}

Is a swelling, at first hard and firm, painful on pressure; gradually the center bulges and a softening is felt. This may occur in many places-such as on the poll, called "poll evil"-but the treatment is essentially the same.

Treatment.-Apply warm olive oil twice a day until fluctuation is detected; after the area has been washed with warm water and castile soap and rinsed with pure water or an antiseptic solution, open with curved bistoury. Don't make too large an opening but one sufficiently large that the pus may flow. Then syringe out cavity with antiseptic solution and apply oil around opening. Keep area clean.

\section{SORE EYES.}

Swelling of eyelids caused by injury is best treated with a weak solution of creolin (Pearson), 10 drops in $\frac{1}{2}$ pint of lukewarm water. Repeat wash every hour. If eyeball is clouded, see to it that the solution gets on the eyeball.

\section{DISEASES OF THE SKIN.}

\section{SCRATCIIES.}

A cracking of the skin between the fetlock and the heels. Some horses are predisposed to this disease, especially horses with longhaired fetlocks. Moisture and mud are causative agents. Cleanliness is the most important part of the treatment and it should be remembered that cold water should not be used for washing of the affected parts. Use lukewarm soap water, rinse off with pure boiled and cooled water, and wipe very dry with cotton or clean linen rag. $\Lambda$ pply a thin cover of vaseline, lanolin, or grease, to which has been added a little creolin or iodine. During winter campaigns in country where the soil becomes deep mud, do not clip the hairs on fetlocks as they are a protection for the delicate skin, and it is far better to let the mud dry and brush it off than to wash. 
MANGE, ECZEMA, AND LICE.

These are affections of the skin, and they attack all parts of the body. They are manifested by itching and the hair falling out. Mange is caused by a small mite that lives in the skin, and the irritation set up causes a secretion that dries and forms scabs. Eczema, caused by fungi, is detected in shape of small or large pimples causing itch and falling out of hair. Lice are parasites that live on the skin and can be seen best when the horse is taken in sunshine.

Treatment.-Attention must first be directed to destroying the parasites without injuring the skin. A soap wash to which is added coal oil (1 to 10) is very good. It must be left on the animal for one day, and during this time the animal should not be exposed to the sun. Then wash with plain soap water, rinse with pure water, and dry the horse with straw or clean rags.

Ticks are often encountered, being usually picked up from bushes, and if a horse is in poor flesh they will be found very troublesome to get rid of. They should not be pulled off, for the head will generally remain fast and will, if left, cause irritation and sores; turpentine or carbolic water or a heated knife or nail will cause them to let go.

BITES.

For bites of poisonous reptiles or insects apply ammonia water. It may also be given internally, but very diluted when the bite is that of a snake. Strong solution of creolin may be used.

\section{INJURIES.}

Injuries may be grouped into two classes-wounds and contusions.

A wound is a separating of organic tissue caused by mechanic action that pierces the external covering (skin, mucous membrane). Wounds may be considered according to the cause, form, and the danger of the injury.

A cut wound is caused by a sharp instrument or the like, and is marked by its smooth edges and extension lengthwise.

A stab wound has the greatest extension in depth and is caused by a pointed instrument.

A contused wound is a wound where the separating of the tissue is caused by an instrument that acted by pressure and crushing or tearing, and where there is more or less blood infiltration (swelling) in adjacent tissue. The contused wound has not the smooth bleeding surface of the cut wound, often no bleeding at all, and has irregular form with ragged edges. 


\section{WOUND INFECTION AND HEALING.}

In a wound, the tissue that was protected by the skin comes in contact with the air or with external bodies, and is liable to be contaminated or infected by pathogenic (disease producing) germs which influence the process of repair which the animal system starts almost immediately the injury is inflicted.

Treatment.-The first step in the treatment of a wound is the cleansing by which foreign bodies in the wound are removed. Stopping the hemorrhage (bleeding) must be considered also.

The cleansing is done by applying an antiseptic solution, as creoline ( 1 part to 25 parts water), or carbolic (phenol) acid, 1 part to 20 parts water, or corrosive sublimate (mercuric chloride), 1 to 1,000 , or tincture of iodine, or simply sterilized (boiled) and cooled water. A syringe can be used for this purpose with advantage. Do not use a sponge, but instead use a plug of absorbent cotton, and this should be thrown away after use. Foreign bodies, as splinters, straw, hair, etc., must be carefully removed; an artery forceps is very handy. In a shot wound a bullet extractor is useful.

Hemorrhage (bleeding) is either from very small blood vessels (capillary) or from larger blood vessels. The capillary bleeding will soon cease and will rather assist in the cleansing of the wound. When larger vessels have been cut, a stopping will be necessary and can be effected by torsion (twisting) of the blood vessel with the artery forceps or by ligation (tying a string around the bleeding artery).

After the wound has been cleansed it must be decided whether healing by first intention (that is, an immediate union of the parts without suppuration) is possible or healing by granulation, is to take place. The question must be considered as to whether an open treatment of the wound or a covering by bandages is preferable.

The healing by first intention can rarely be expected in horse or mule, and therefore suturing (sewing up) should only be resorted to in cut wounds where no loss of tissue has occurred. The intention with the suture is to bring the edges of the wound in contact and hold them so, firmly. Sutures must therefore be put rather deep and each stitch tied in a knot. At certain parts of the body this healing seems to take place easier than on others, for example, the eyelids and lips. The most common way of wound healing is by granulation; that is, by formation of new organized growth of tissue. The healing should take place with least possible supperation (pus discharge), and to obtain this the disease-producing germs already in the wound should be destroyed by the use of antiseptic wash. Do not use too strong antiseptics, as they will destroy sound tissue and create a favorable soil for the disease-producing germs. 
Keep the wound well protected from further contamination and have the wound well drained, so that no pus or secretion from the wound is retained. This is done by placing a thoroughly sterilized (boiled) strip of cloth in the wound letting the end stick out of the wound. The protection of the wound can be accomplished either by a bandage or by an antiseptic dusting powder that will form a scab. Sometimes the granulations will grow too freely and will have to be cherked so they do not protrude in the wound (form proud flesh). This can be done by caustics as bluestone or by a hot iron.

\section{CONTUSION (BRUISES).}

By this is understood a disease process caused by undue compress of organic tissue, and generally without the skin's being broken. As a rule the force is from outside (kick and pressure).

The extent of the contusion depends on the force, the direction from which it is inflicted, and the duration of the time in which the cause arts.

By a slight contusion we only notice the swelling caused by blood that comes in the tissue from the broken smaller or larger blood vessels, and this will, if not exposed to new cause, soon be absorbed. Bathing with cold water or a cold-water compress will assist the resorption.

The two forms of contusion that are of most importance in the Army Service are those caused by pressure of saddle and harness (saddle and harness galls), or the aparejo, and by kicks from other animals.

Prevention is better than cure. No mounted man must ever be negligent in saddling nor driver in harnessing his horses or mules. Therefore grat care should be taken to examine animals when the saddle or harness is taken off. Give attention to any swelling or skin abrasion. When found, wash the part at once with soap and water, and rinse with cold water and then bathe with cool creolin water. Repeat this treatment every hour and the swelling will ordinarily soon disappear. See that next time the saddle or harness is put on the horse that no pressure comes to the injured part.

If the swelling does not disappear by this treatment, use bathing with warm water or hot water poultice. If part of the skin is so badly injured as to show signs of mortification (partial death), and a poultice will not remove it, this mortified part must be cut away by a knife. Turpentine mixed with flour, equal parts, made to a paste and applied to the mortified part will usually remove it. After the dead tissue is removed, treat as a wound.

Contusions caused by kick should be treated by bathing with cold or warm creolin solution and, if complicated with wound, as already advised. 
Contusions are sometimes caused by man's abuse of forks, sticks, whips, and spurs. To prevent this we can only remind those that can not control their bad temper that they are unfit for handling animals and are deserving of severe punishment.

Rope burns and injuries from interfering are contused wounds and should be treated as such. The first mentioned is due to careless hitching-too long.

Interfering-the striking of one foot against the other in traveling-is due mostly to careless shoeing but sometimes to faulty conformation and action or to weakness. Young horses in poor condition will often interfere as soon as they get tired. The shoeing should be observed, to see that no part of the shoe protrudes on the inside of the hoof and that the clinches of the nails are made level with the wall of the hoof. In an emergency-on the march-a twisted hay or straw band wrapped around the fetlock below the joint on the injured leg will prevent further injury.

Shot wounds are essentially contused wounds, and they are treated accordingly. Tincture of iodine is especially effective in such cases. 


\section{CHAPTER III.}

\section{WAGONER OR TEAMSTER.}

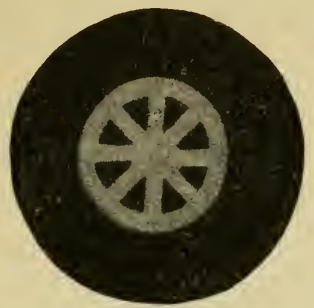

Wagoner's Chevron.

The wagoner or teamster is responsible for his team, harness, and wagon, with tools and repair parts. The condition in which he keeps them is a measure of his efficiency. Keep your animals in good flash, clean, and free from lameness and bunches or boils, and get your load to the destination and you will be a successful driver. Excuses do not go. If anything happens which you think might excuse you for not getting your load to the desired point, remember that it only makes hungry men madder if you tall them you "broke the harness" or "lost the axle nut" or your "mule lost a shoe" or "shoulders got sore." Unlass y ou "get there" some way, they will brand you "no good," and you can not always get there unless you keep your outfit always in first-class shape.

Feed and water your mules before you do yourself. Look over their feet every morning the first thing and every evening after you unhitch; clean them out and see if the shoes are loose. It is a good idea to tap the shoes lightly with a knife handle or hammer; if the animal flinches there is something wrong.

Great care should be taken in making crossings such as bridges (especially ponton), fords, and ditches. A swift-moving load causes about twice the strain on a bridge as does a stationary or slow-moving one.

Before passing a swollen stream with a team it should be examined by wading or by riding an animal across. If the team should happen to get beyond its depth, release the animals by cutting the top hame straps and the check lines; if practicable the bellybands also should be cut.

In pulling heavy loads or in heavy ground if there is any liability of the team's stopping, stop the animals yourself before they get stalled. Many animals will not pull again on a load in the same place where they have met with a resistance which has impressed 
them as insurmountable. If the team should get stuck, it may be induced to try again by turning the tongue slightly to the right or left and then getting all off together.

In starting a team with a heavy load or in any situation where it is necessary to get the united power of the animals, the reins should be held fairly tight so that the animals may be made to feel the aid and guidance of the driver.

Draft animaIs should never be driven out of a walk. Those user on buckboards, spring wagons, and other light vehicles, and which are usually specially chosen for the purpose, may be driven at a trot when necessary.

Army transportation by animals consists of pack mule (see p. 96), spring wagon, ambulance, escort wagon (see Pl. IX to XV) and "Army six" (see Pl. XII).

The complete equipment of spare parts and accesscries for the escort wagons and teams is as follows:

\section{ESCORT WAGON AND HARNESS, COMPLETE SET.}

1 wagon, escort, includes running gear, wagon body, 1 tongue, 1 doubletree, 1 lead bar, 4 singletrees, 6 bows, 2 chains lock, 1 wagon cover, 1 jockey box, and 1 tool box, each with padlock and key; 1 driver's seat and 1 axle wrench (total weight 2,000 pounds).

Wagon equipment:

Wagon pa.ts, extra (total weight 106 pounds)-

2 blocks, brake. ${ }^{1}$

$1 \mathrm{bolt}$, king. ${ }^{1}$

Bolts, tire-

$1 \frac{1}{4}$ by $2 \frac{3}{4}$ inches. $^{1}$

$5 \frac{1}{4}$ by 3 inches. $^{1}$

Bolts, wagon-

$2 \frac{1}{4}$ by $1 \frac{1}{2}$ inches. $^{1}$

$2 \frac{5}{16}$ by $1 \frac{3}{4}$ inches. $^{1}$

$1 \frac{5}{16}$ by 2 inches. ${ }^{1}$

$2 \frac{5}{16}$ by $2 \frac{1}{2}$ inches. $^{1}$

$2 \frac{3}{8}$ by 3 inches. $^{1}$

$1 \frac{1}{2}$ by 11 inches. $^{1}$

$4 \frac{5}{8}$ by 4 inches. ${ }^{1}$

3 links, open. ${ }^{1}$

2 nuts, axle. ${ }^{1}$

1 reach. ${ }^{2}$

6 rivets, iron, $\frac{3}{16}$ by $1 \frac{1}{2}$ inches. ${ }^{1}$

4 rivets, iron, $\frac{1}{4}$ by $1 \frac{1}{2}$ inches. ${ }^{1}$

1 tongue. ${ }^{2}$

1 tree, double (carried bolted to compling pole).

1 tree, single. 1 


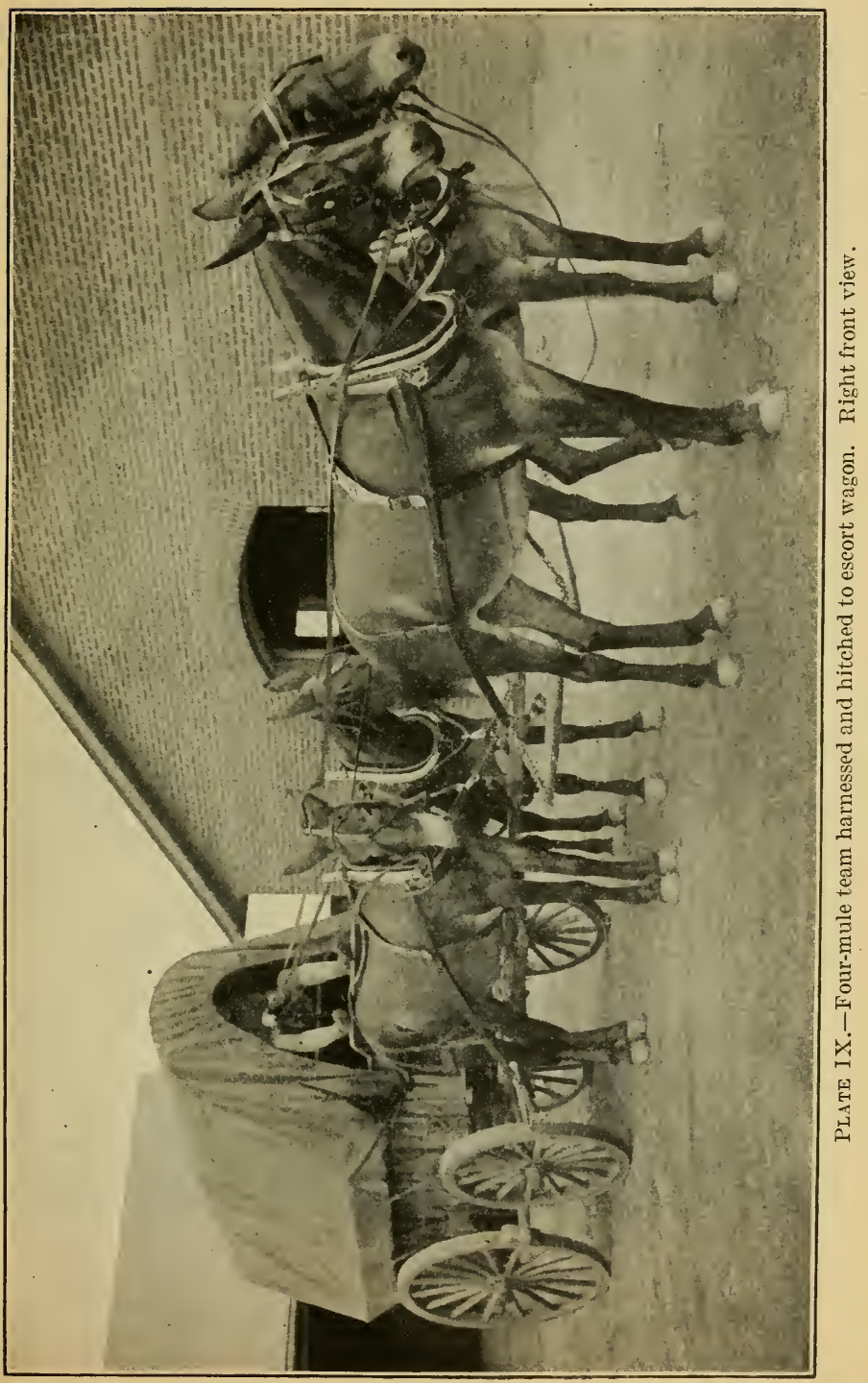




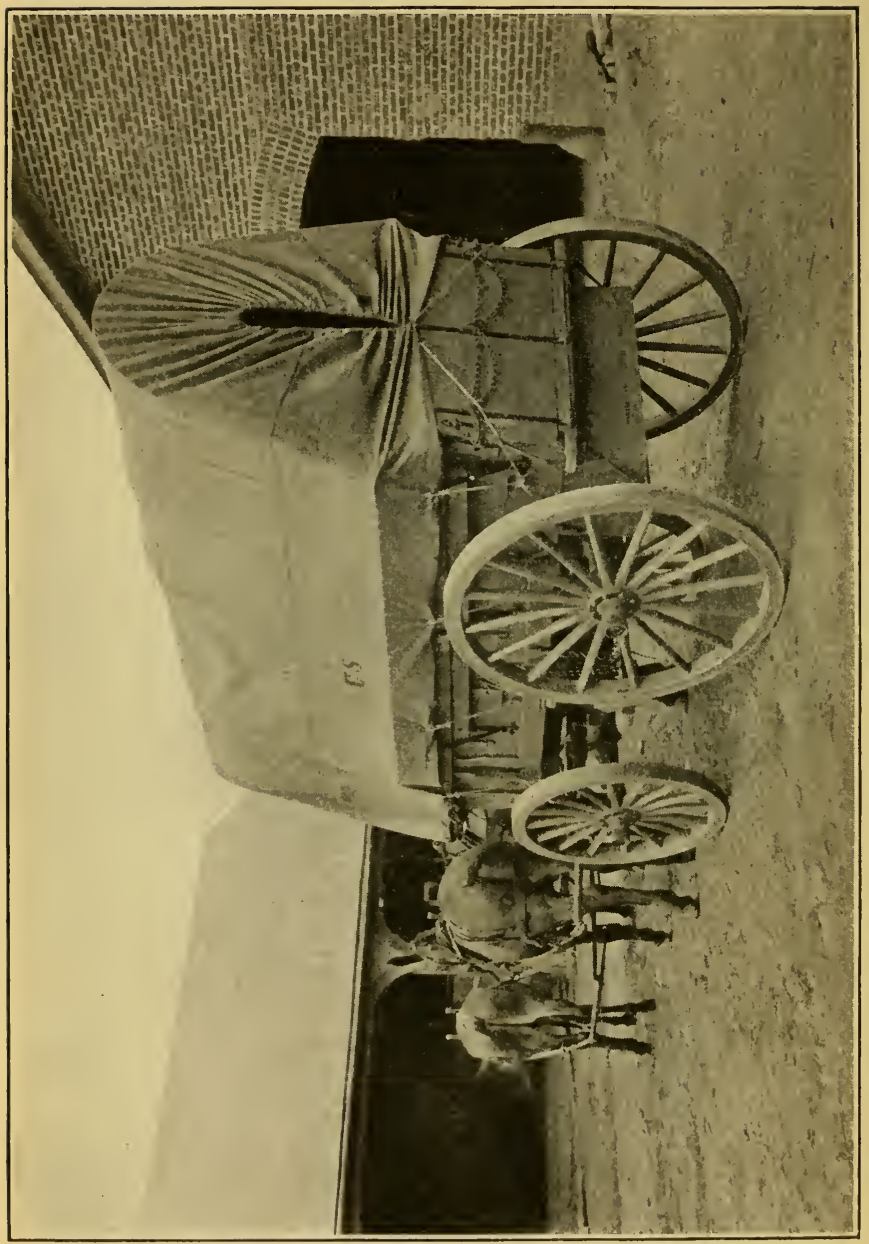




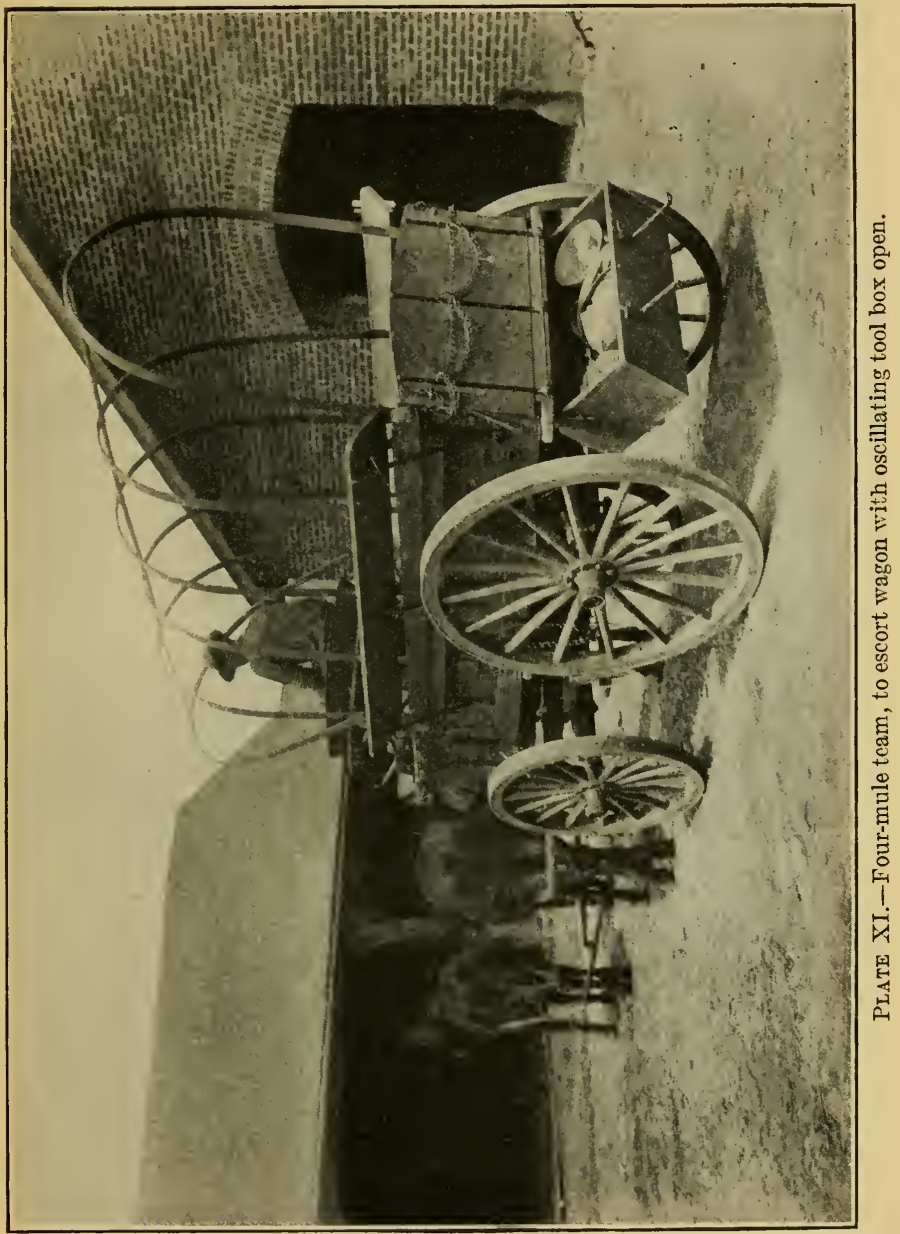


WAGONER OR TEAMSTER.

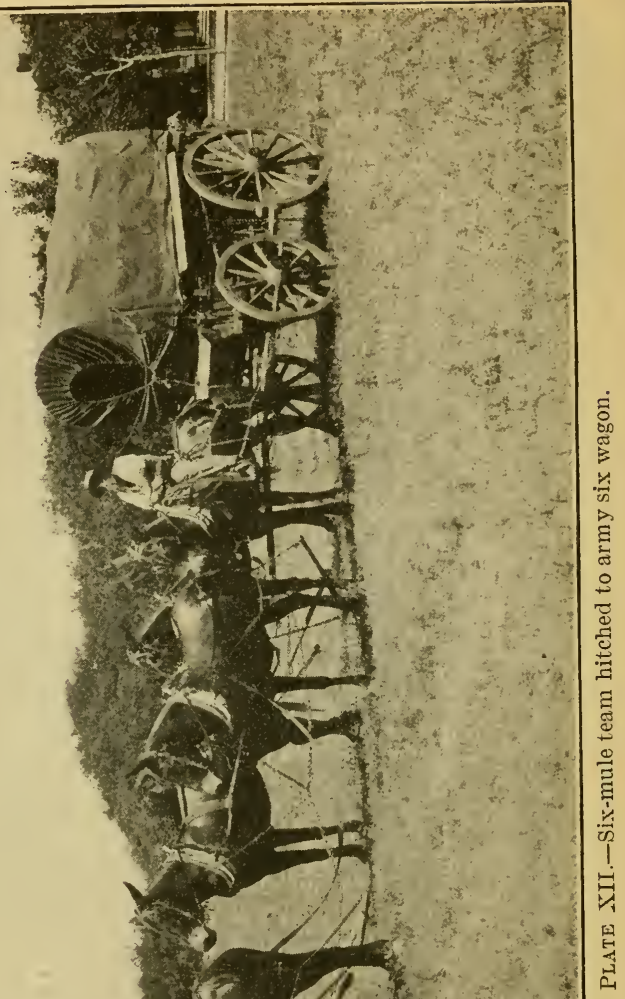




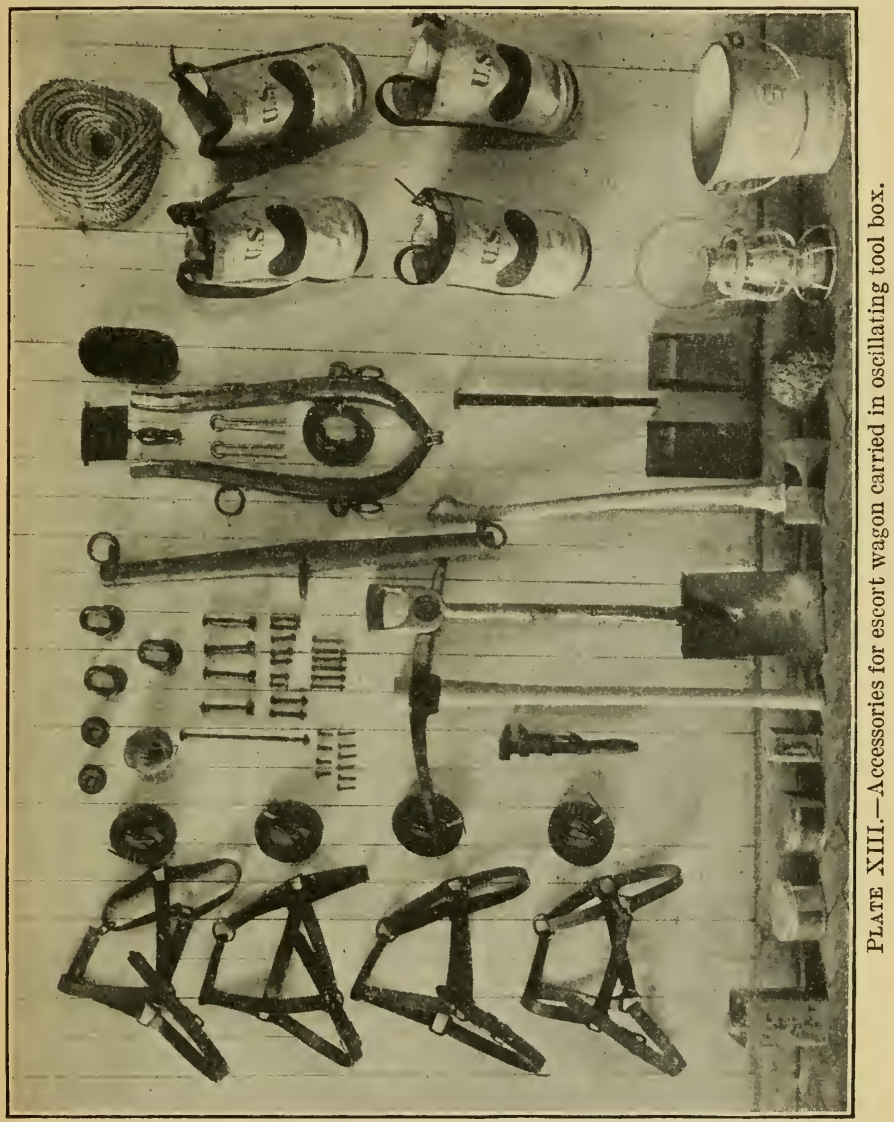


WAGONER OR TEAMSTER.

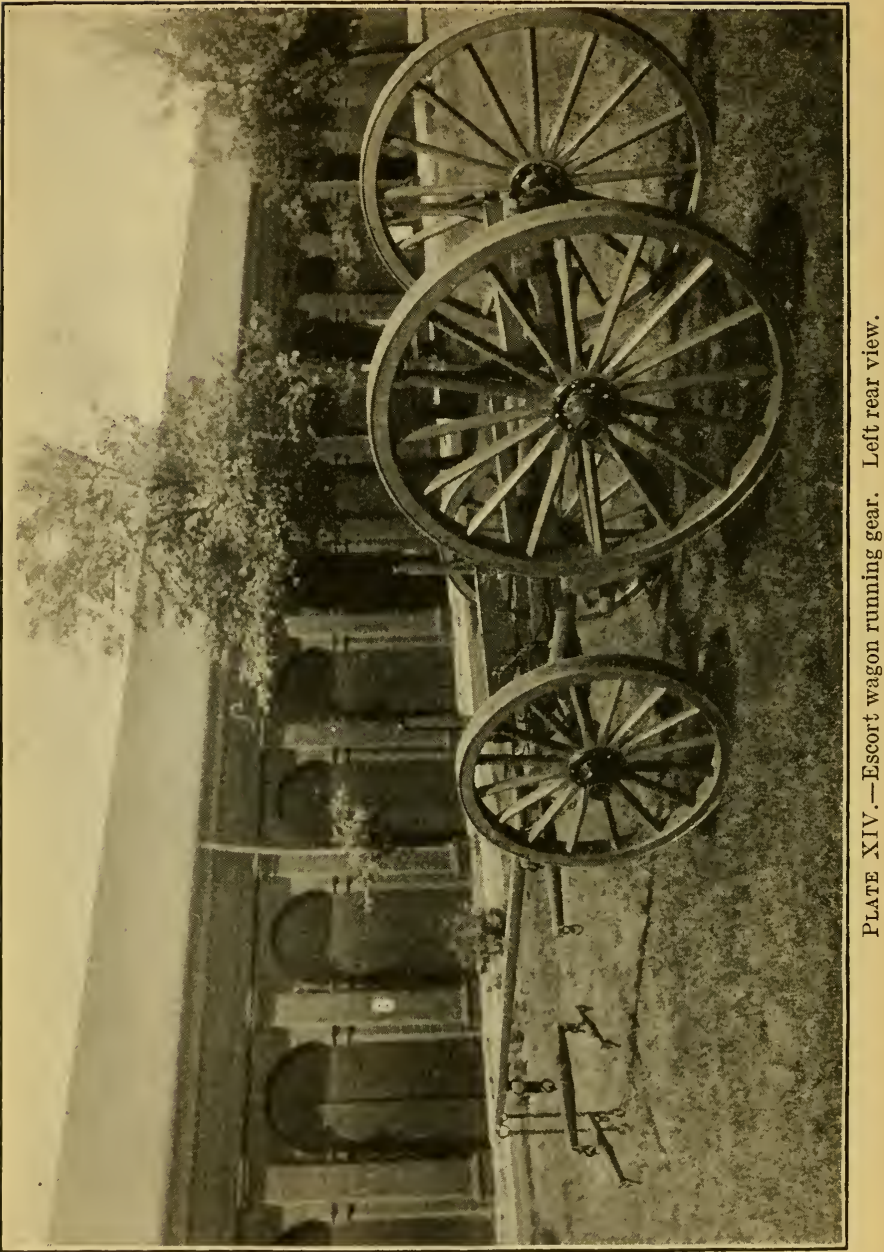




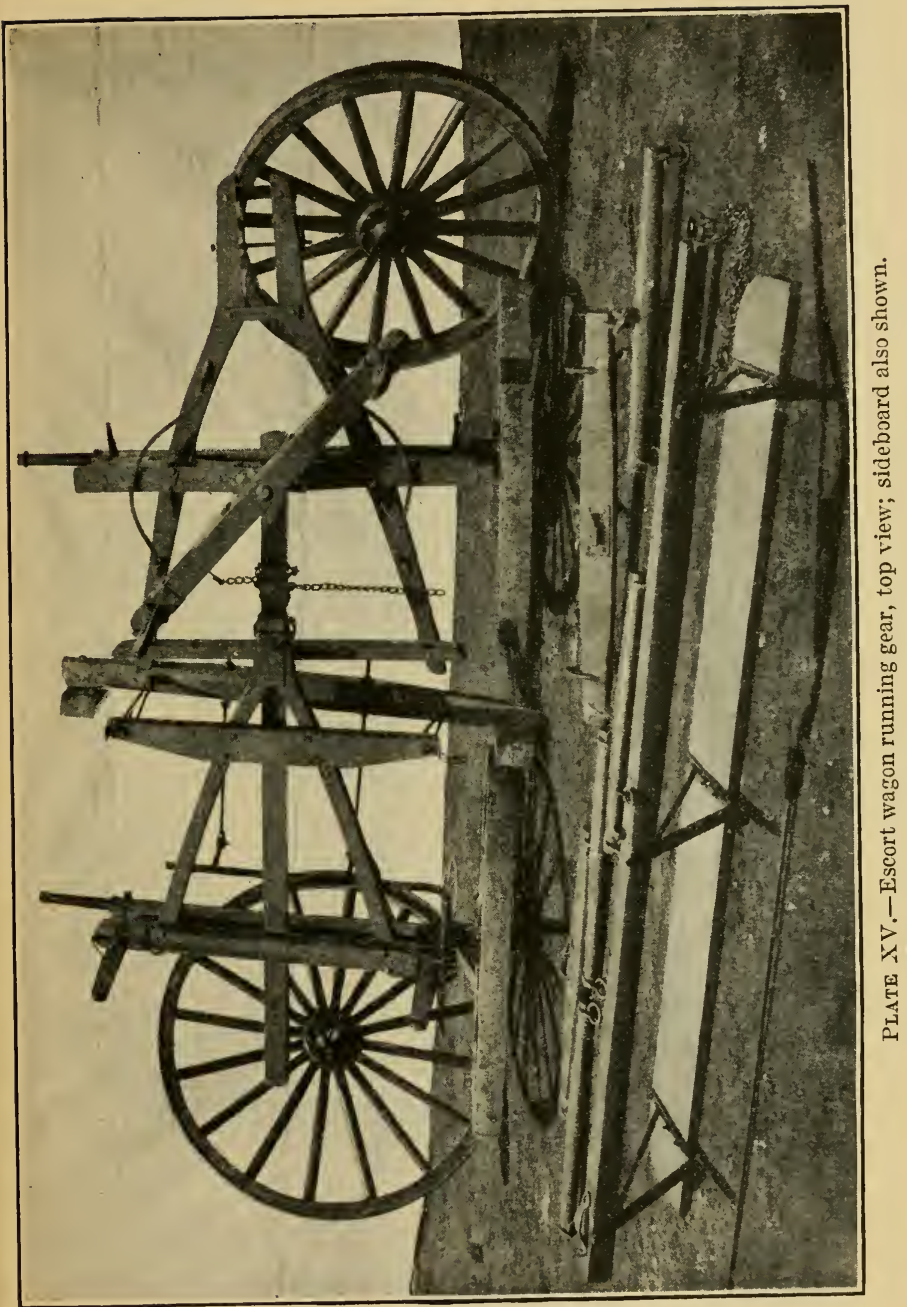


Wagon equipment-Continued.

Wagon accessories (total weight 83 pounds):

1 ax and helve. ${ }^{1}$

4 bags, nose. ${ }^{1}$

1 brush, horse. ${ }^{1}$

1 bucket, galvanized iron. ${ }^{1}$

1 comb, curry. 1

1 globe, lantern (caried in lantern). ${ }^{1}$

4 grease, axle, pounds. ${ }^{1}$

4 halters, and straps. ${ }^{1}$

1 lantern, combination. ${ }^{1}$

1 pickax and helve. ${ }^{1}$

150 rope, $\frac{3}{8}$-inch, feet. ${ }^{1}$

1 spade. ${ }^{1}$

1 whip, carried in socket.

1 wick, lantern (carried in lantern). ${ }^{1}$

1 wrench, monkey. 1

1 twine, ball. ${ }^{1}$

(For winter use, when authorized, 1 blanket-lined cover for each mule.)

Harness:

2 lead, s. s. (72 pounds), carried on mules.

2 wheel, s. s. (90 pounds), carried on mules.

Harness equipment-

Harness parts, extra (total weight $8 \frac{1}{2}$ pounds)

1 buckle $\frac{3}{4}$-inch. ${ }^{2}$

1 buckle, $\frac{7}{8}$-inch. ${ }^{2}$

1 buckle, 1-inch. ${ }^{2}$

1 buckle, 2 -inch. ${ }^{2}$

2 clips, trace. ${ }^{1}$

2 hames. ${ }^{1}$

1 ring, $\frac{3}{4}$-inch. ${ }^{2}$

1 ring, 1-inch. ${ }^{2}$

1 ring, $1 \frac{1}{2}$-inch. ${ }^{2}$

1 ring, 2 -inch. ${ }^{2}$

1 snap, 1-inch. ${ }^{2}$

1 snap, $1 \frac{1}{4}$-inch.2

1 snap, 2-inch. ${ }^{2}$

3 straps, hame. ${ }^{1}$

Harness accessories (total weight 6 pounds) -

$\frac{1}{2}$ gallon oil, neat's foot. ${ }^{1}$

1 pound soap, harness. ${ }^{1}$

l sponge. 1

1 wire, stove, spool. ${ }^{2}$ 


\section{Harness-Continued.}

Additional supplies to be carried in wagon, which are not included in the "complete set." These supplies are provided and maintained by organizations:

128 nails, horseshoe, number (1-pound). ${ }^{1}$

16 shoes, mule, fitted, number (16 pounds). ${ }^{1}$

In campaign (F. S. R. 302):

36 grain, reserve, pounds. ${ }^{2}$

2 rations, reserve, number. ${ }^{2}$

The foregoing list of articles is prescribed for each escort wagon and team wherever used. The oscillating tool box may be fitted on the escort wagon of any model.

Wheels, extra: One wagon of each regimental field train-preferably the most lightly laden grain wagon-will be equipped with one extra hind wheel in addition to the usual wagon equipment.

For each mule-drawn vehicle of the combat trains of engineers and signal troops, two single sets of wheel harness and as many single sets of lead harness as there are lead mules (see Tables of Organization, 1914), are provided; the extra parts of the harness and the harness accessories are, for 4-mule teams, as prescribed under escort wagons; for 6-mule teams, multiply by $1 \frac{1}{2}$. The extra parts of the wagons are not supplied by the Quartermaster Corps. The remaining wagon accessories supplied are limited to the following:

\begin{tabular}{|c|c|c|}
\hline Articles. & $\begin{array}{c}\text { For 4-mule } \\
\text { wagon. }\end{array}$ & $\begin{array}{c}\text { For 6-mule } \\
\text { wagon. }\end{array}$ \\
\hline 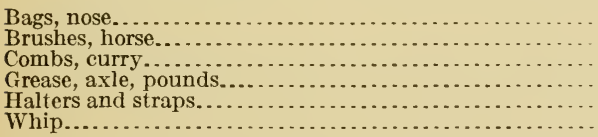 & $\begin{array}{l}4 \\
1 \\
1 \\
4 \\
4 \\
1\end{array}$ & $\begin{array}{l}6 \\
2 \\
2 \\
6 \\
6 \\
1\end{array}$ \\
\hline
\end{tabular}

(For winter use, when especially authorized, 1 blanket-lined cover for each mule.) 


\section{HARNESS.}

The subjects of description, methods of cleaning, caring for, and repairing of harness are covered under the heading of the duties of the saddler.

\section{CARE OF WAGON.}

The principal effort required to keep a wagon in order is the daily examination of all nuts to see that they are tight, and greasing the wheels about every 30 miles. Even if the wagon is used but little, the axles should be examined twice a week at least. The 4 pounds of axle grease furnished with the escort wagon should last about a month. In greasing, remove the old grease, because, if not, the dirt and sand will accumulate and cause a "hot box," and completely disable the wagon, make you late getting in, and cause a lot of trouble.

To grease a wagon without using a wagon jack: Remove the axle nut (remember that the nuts on the right side are right handed and those on the left are left handed). Get a board or a stick slightly longer than the distance from the axle to the ground. Place one end on the ground and inside the wheel, the other end leaning toward the wheel; place this upper end under a spoke which is about horizontal (level). Then raise the wheel slightly by lifting carefully on the spoke on the opposite side of the wheel, when, if it has been greased often enough, the weight of the wagon will cause the wheel to slide down the spindle. Be careful the wheel doesn't get more than three-fourths of the way off; however, the wheel should be taken off far enough to get the old grease off. This method will not work if the axles have not been kept properly greased.

To put on the wheel, reverse the process, placing the stick on the outside. Needless to say, though, the wheel will not run on (like it does off), but, with the inclination of the stick and slight pressure on the wheel (toward the wagon), it will go on.

It is also unnecessary to remark that the nearer the upper end of the stick is placed to the hub, the less power it will take to lift the wheel off the ground. 


\section{REPAIRS TO WAGONS.}

For each regiment, wagon company, ambulance company, engineer train, engineer battalion, and signal corps battalion (those organizations having a large number of wagons) is issued, by the Quartermaster Corps, a set of carpenters' and wheelwrights' tools, as follows (PI. XVI):

\begin{tabular}{|c|c|c|}
\hline Figure. & Article. & Number. \\
\hline 1 & Axe, hand *. & 1 \\
\hline 2 & 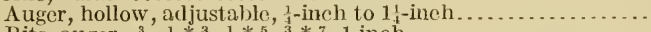 & 1 \\
\hline 3 & 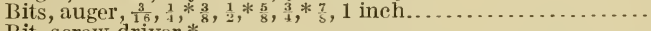 & 8 \\
\hline 4 & 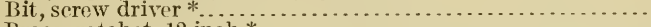 & 1 \\
\hline 5 & 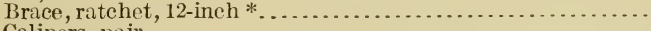 & \\
\hline 6 & Calipers, pair & \\
\hline 7 & 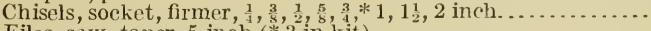 & 8 \\
\hline 8 & 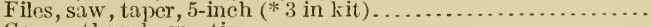 & 6 \\
\hline 9 & 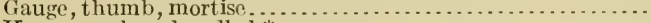 & \\
\hline 10 & Hammer, claw, handled * . . . . . . . . . . . . . . . . . . . . . . . & \\
\hline 11 & (n, & 1 \\
\hline 12 & 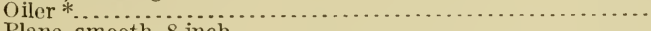 & \\
\hline 13 & 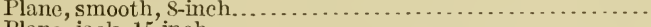 & 1 \\
\hline 14 & $\ldots \ldots \ldots \ldots \ldots \ldots \ldots \ldots \ldots \ldots \ldots \ldots$, & \\
\hline 15 & (n. & \\
\hline 16 & 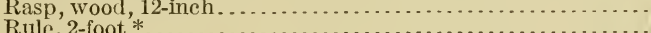 & \\
\hline $\begin{array}{l}17 \\
19\end{array}$ & $\begin{array}{l}\text { Rule, } 2 \text {-foot } * . . . . . . . \\
\text { Saw, hand, crosscut *. }\end{array}$ & \\
\hline $\begin{array}{l}15 \\
19\end{array}$ & Saw, hand, rip.......... & \\
\hline 20 & Nest of saws, compass, with 1 handle, 3 blades............ & \\
\hline 21 & 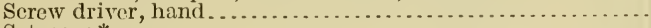 & \\
\hline 22 & 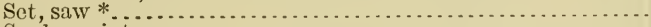 & \\
\hline 23 & ......................... & \\
\hline 24 & 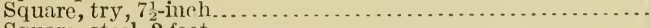 & \\
\hline 25 & (n..., & \\
\hline 26 & 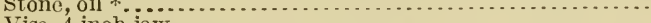 & \\
\hline 27 & 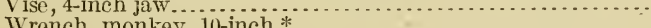 & \\
\hline 25 & rencn, monkey, 10-1п & \\
\hline
\end{tabular}

The articles marked * when extracted from the set form the carpenters' and wheelwrights' tool kit and form part of equipment " $\mathrm{A}$ " (see preface). Remaining articles are in equipment "B."

There is issued by the Ordnance Department to the Field Artillery, to be carried in the battery and forge wagon, a set of carpenter tools, shown on Plates XVII and XVIII as follows. 


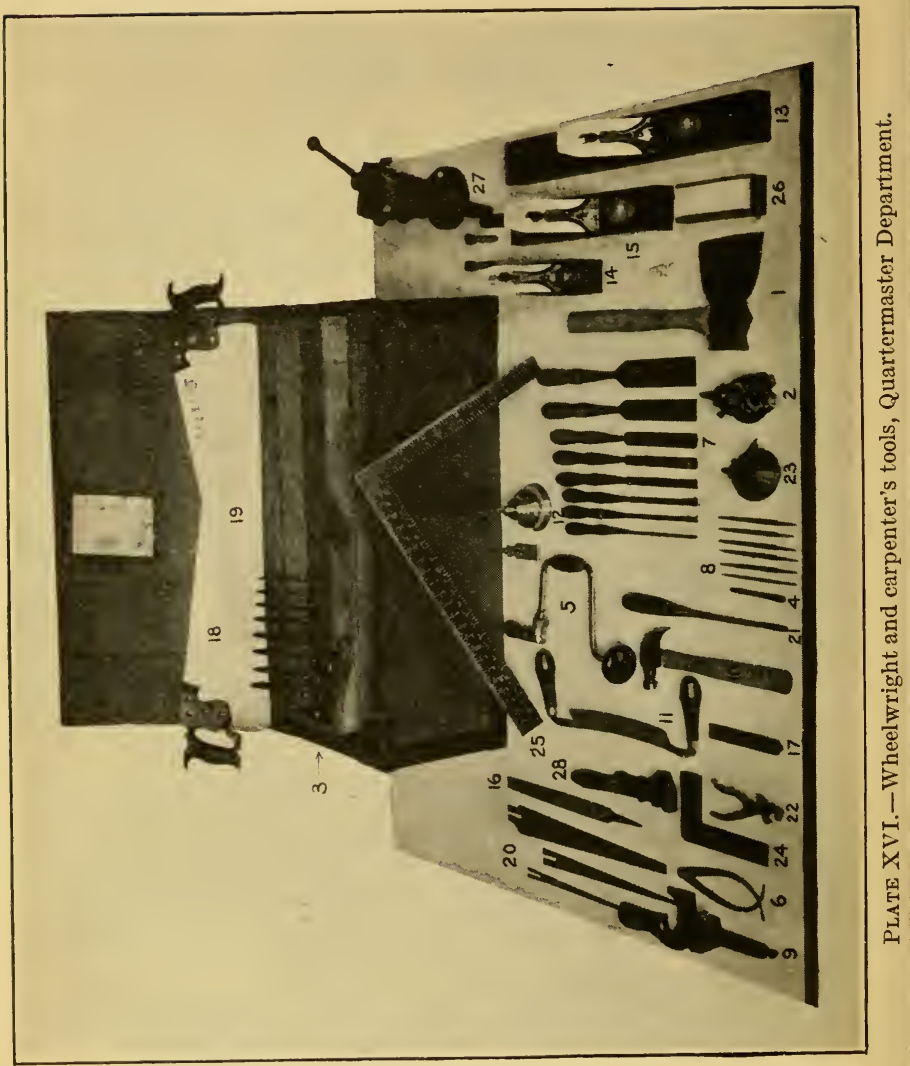




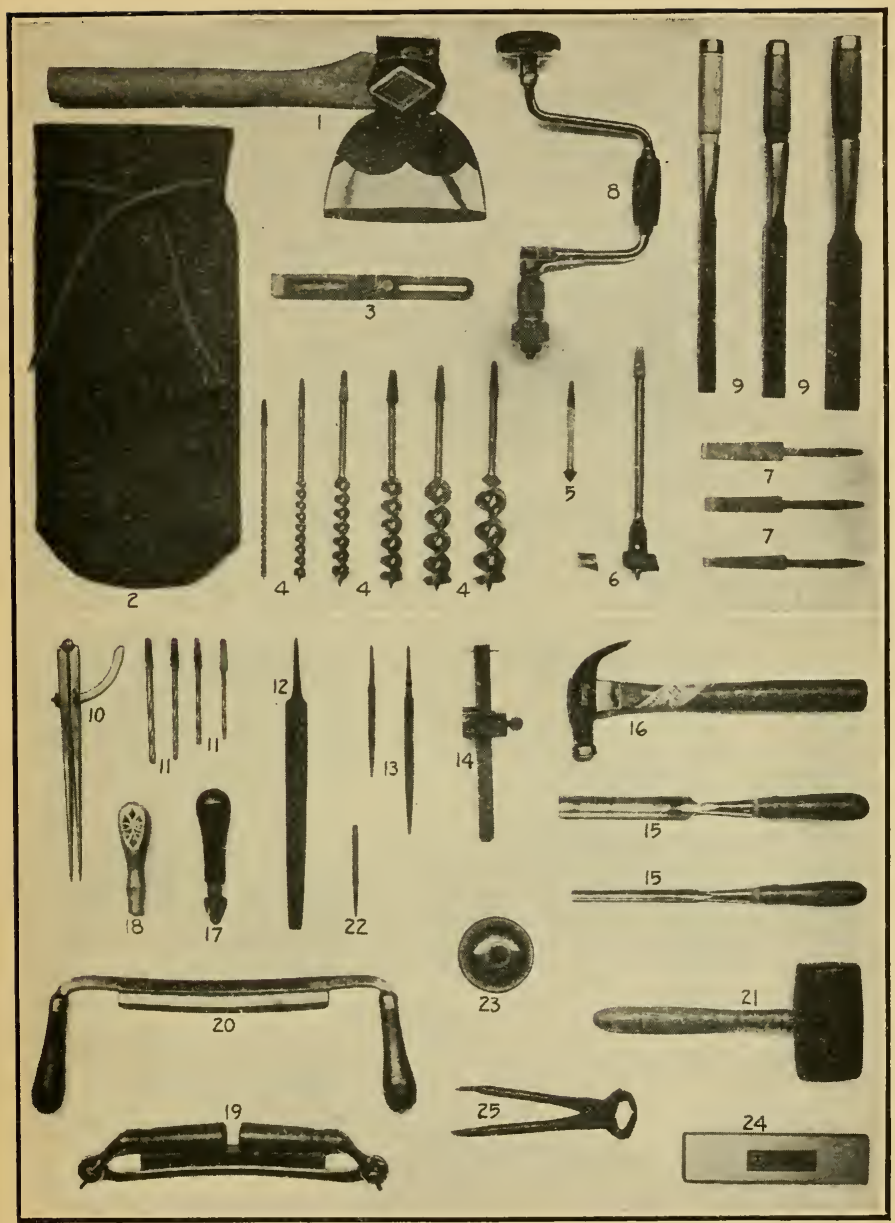

Plate XVII. 
WAGONER OR TEAMSTER.

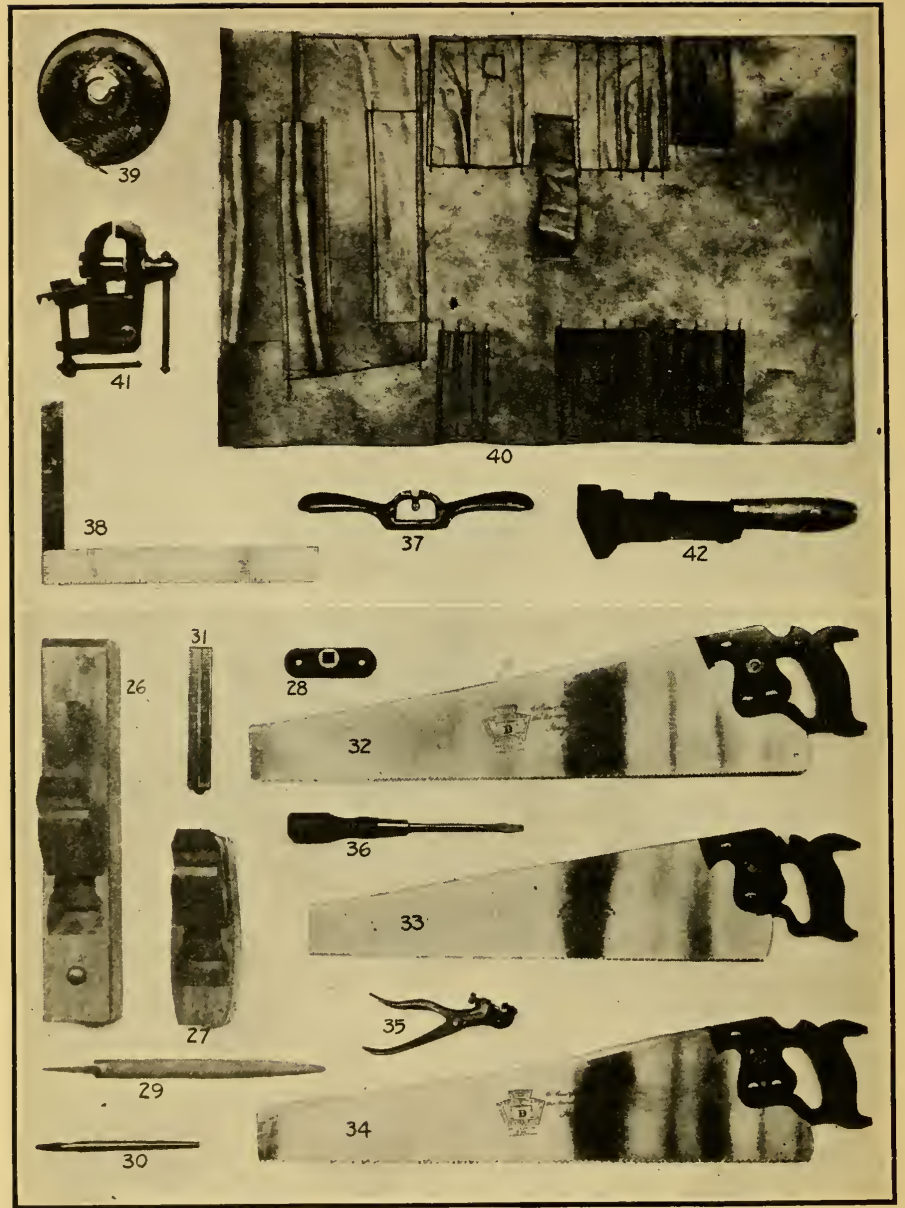

Plate XVIII. 
Carpenter's tools.

\begin{tabular}{|c|c|c|c|}
\hline \multirow[b]{2}{*}{ Figure. } & \multirow[b]{2}{*}{ Article. } & \multicolumn{2}{|c|}{ Number. } \\
\hline & & 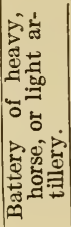 & 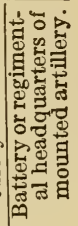 \\
\hline 1 & Bench ax.......... & 1 & \\
\hline 2 & Bags, canvas, for small stores.. & 2 & \\
\hline 3 & 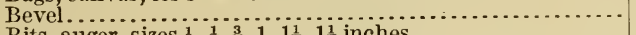 & 1 & \\
\hline 4 & 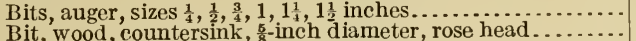 & 6 & \\
\hline 5 & 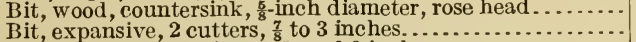 & 1 & 1 \\
\hline $\begin{array}{l}6 \\
7\end{array}$ & & 3 & 11 \\
\hline 8 & 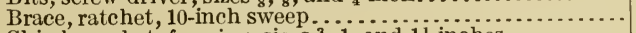 & 1 & 1 \\
\hline 9 & Chisels, socket, framing, sizes $\frac{3}{4}, 1$, and $1 \frac{1}{2}$ inches................. & 3 & 3 \\
\hline 10 & 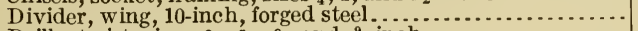 & 1 & \\
\hline 11 & 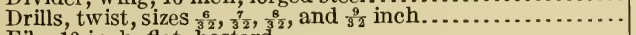 & 4 & 4 \\
\hline 12 & 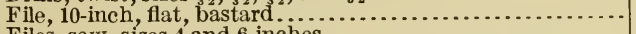 & 1 & 1 \\
\hline 13 & 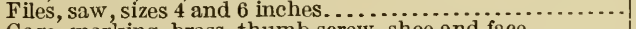 & 6 & 21 \\
\hline $\begin{array}{l}14 \\
15\end{array}$ & 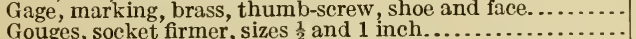 & $\begin{array}{l}1 \\
2\end{array}$ & \\
\hline 16 & Hammer, claw, adze eye, bell face, 1 pound 4 ounces........ & 1 & i \\
\hline 17 & 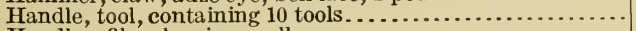 & 1 & 1 \\
\hline 18 & 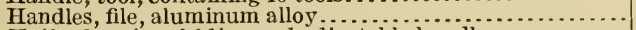 & 2 & \\
\hline 19 & Knife, drawing, folding and adjustable handle............ & & 1 \\
\hline 20 & 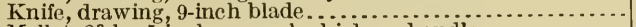 & 1 & .. \\
\hline 21 & 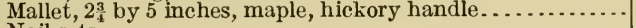 & 1 & \\
\hline 22 & 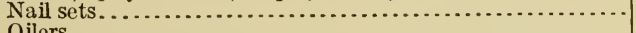 & 1 & - \\
\hline 23 & Oilers................ & 1 & \\
\hline 24 & & 1 & \\
\hline 25 & 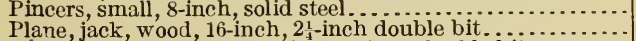 & 1 & \\
\hline $\begin{array}{l}26 \\
27\end{array}$ & 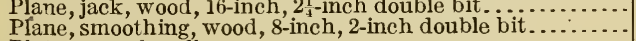 & 1 & 1 \\
\hline 28 & 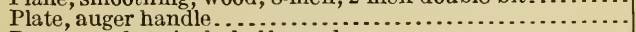 & 1 & \\
\hline 29 & 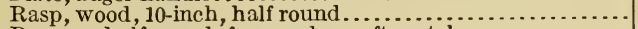 & 1 & $i$ \\
\hline 30 & Reamer, half round, for wood or soft metal............. & 1 & \\
\hline 31 & 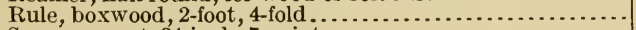 & 1 & \\
\hline 32 & 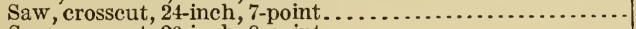 & 1 & \\
\hline 33 & 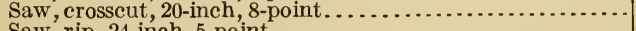 & & 1 \\
\hline 34 & Saw, rip, 24-inch, 5-point...... & 1 & \\
\hline $\begin{array}{l}30 \\
36\end{array}$ & Serew driver, 5 -inch blade, 10 inches over sll. . . . . . . . & 1 & \\
\hline 37 & Spoke shave, adjustable, raised handle, $2 \frac{1}{s}$-inch cutter... & 1 & \\
\hline 38 & Square, steel, 12 -insh body, 8 -inch tongue............ & 1 & 1 \\
\hline 39 & Tape line, linen, metallic warp, 100 -foot, marked 12 ths... & 1 & \\
\hline 40 & 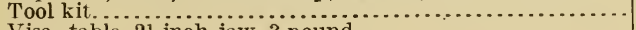 & & 1 \\
\hline $\begin{array}{l}41 \\
42\end{array}$ & 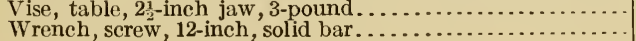 & 1 & \\
\hline & & & \\
\hline
\end{tabular}




\section{ROUTINE OF DUTIES OF TEAMSTER.}

It is a good plan to have a fixed time for every routine duty, for then there will be no chance of overlooking anything. Certain duties should be attended to daily and some weekly. The following is suggested daily: Immediately after rising, water your animals; when taking to water note carefully if they walk lame; then feed grain to animals, wash yourself, and get breakfast; give animals a very hasty cleaning, clean and inspect feet and shoes carefully, clean the ground where animals have stood during night; hitch up and report where ordered; water at every opportunity either from running stream or from bucket-never from public trough unless pronounced healthy by proper authority. When work is finished in evening, park the wagon in place designated, remove harness and hang up, rub off collars, belly bands, and cruppers; water; tie animals to picket line; clean out and examine the feet carefully, make a note of loose or lost shoes; feed grain and hay; report animals requiring shoeing or veterinary attention, especially examine carefully for any abrasion or enlargement; wash and get dinner; glance over harness and the nuts on wagon, making any minor repairs and reporting those which require attention of a specialist; grease the wagon, if required; groom, wash animals' shoulders, and fix the harness so as to remove the pressure the next day from any swollen parts.

Don't ever try to pad a bunch-it only makes things worse. If the felt collar pads are not obtainable, pieces of sheepskin with thongs attached are very handy for use in case of sore shoulder or collar boils; they are tied one on each side of affected part; they should be large enough to cover (except the affected part) the entire half of the collar. Small pieces would only cause undue pressure on the spots covered by these pieces. Especial care should be exercised in fitting of the collar. If too large, it will move about and will make the shoulders sore; if it is too small it will choke the animal. The collar is the right size if the hand (flat) can be put between the bottom (the inside) of the collar and the windpipe. (See "Fitting harness," p. 78.) 


\section{CHAPTER IV.}

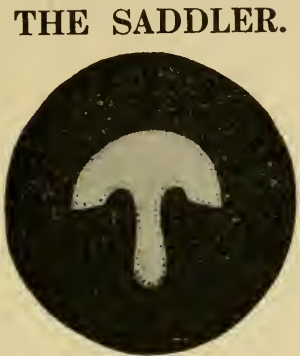

Saddler's chevron.

The saddler is charged with the repair of individual leather horse equipment of the personnel in mounted organizations and with the harness pertaining to the trains.

The individual horse equipment is described in the Cavalry Drill Regulations. The two principal types of harness issued by the Quartermaster Department are known as the "Four-mule Ambulance or Wagon Ilarness" and the "Six-mule U. S. Army Wagon Harness."

The escort wagon is drawn by four mules, which are equipped with one double set of lead harness and one double set of wheel harness, of the "four-mule ambulance or wagon harness" type. This type is distinguished by the traces, which consist of leather from hames to the breeching, the remainder of the length being of chain with hook at the end. This harness is illustrated in Plates XIX to XXI, pages - with list of parts as follows:

The assembled double set of lead harness is shown in Plate XX and of wheel harness in Plate XXI. The entire set (two single, lead, and two single, wheel, sets) for a four-mule team, with team hitched to escort wagon, is shown in Plates IX, X, and XI.

The Six-mule United States Army Wagon Harness (used on reserve ponton, and on heavy "Army six" wagons no longer issued) has no harness saddles, has breeching of a single flat leather strap, and traces are all chain covered with leather. The six-mule team is ordinarily managed by a driver, mounted on a ricing saddle on the near (left) wheel horse or wheel mule, who uses a jerk line and a blacksnake. A riding saddle, check rein, and jockey stick are part of the equipment. 



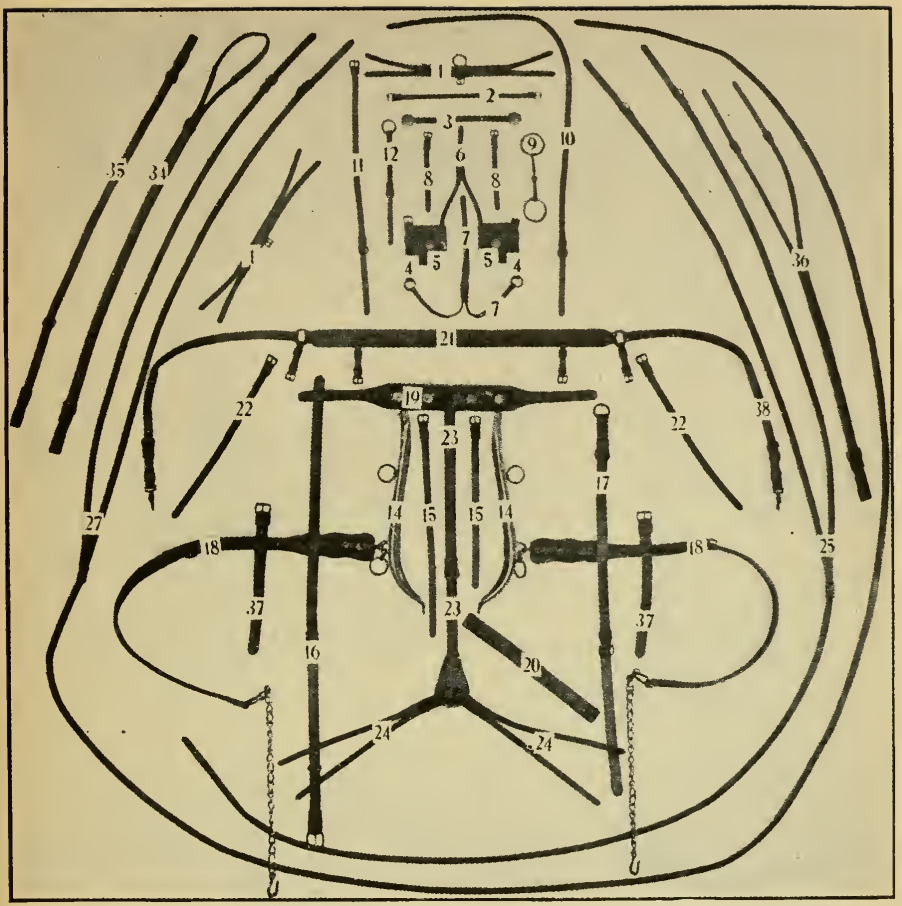

PLATE XIX. $-\Lambda$ mbulance or wagon harness.

No. 1. Crownpiece (lead and wheel).

No. 2. Straps, throat.

No. 3. Bands, brow.

No. 4. Check pieces.

No. 5. Blinds.

No. 6. Winker stays.

No. 7. Face pieces.

No. 8. Straps, bit.

No. 9. Bits, bridle, ambulance, No. 47-A.

No. 10. Reins, bridle, long.

No. 11. Reins, bridle, short.

No. 12. Straps, rein.

No. 14. Hames.

No. 15. Straps, hame, upper and lower.

No. 16. Straps, breast.
No. 17. Straps, choke.

No. 18. Traces, single.

No. 19. Bands, back (straps, back).

No. 20. Bands, belly.

No. 21. Breechings, complete.

No. 22. Straps, breeching.

No. 23. Straps, turnback, complete.

No. 24. Straps, hip.

No. 25. Lines, 2-horse.

No. 27. Lines, 4-horse.

No. 34. Crupper, lead.

No. 35. Straps, carrying.

No. 36. Martingales.

No. 37. Tugs, back-strap (with No.18).

No. 38. Straps, side (21-38). 


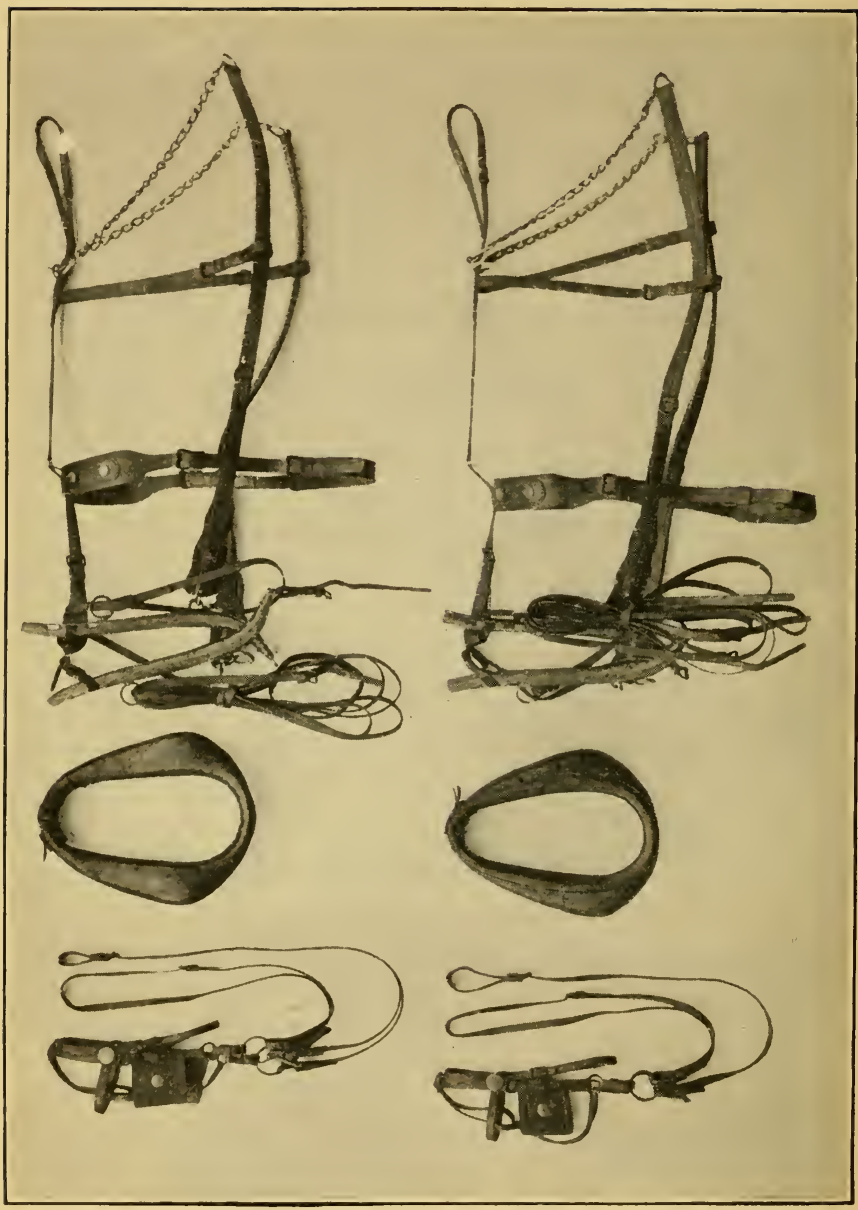




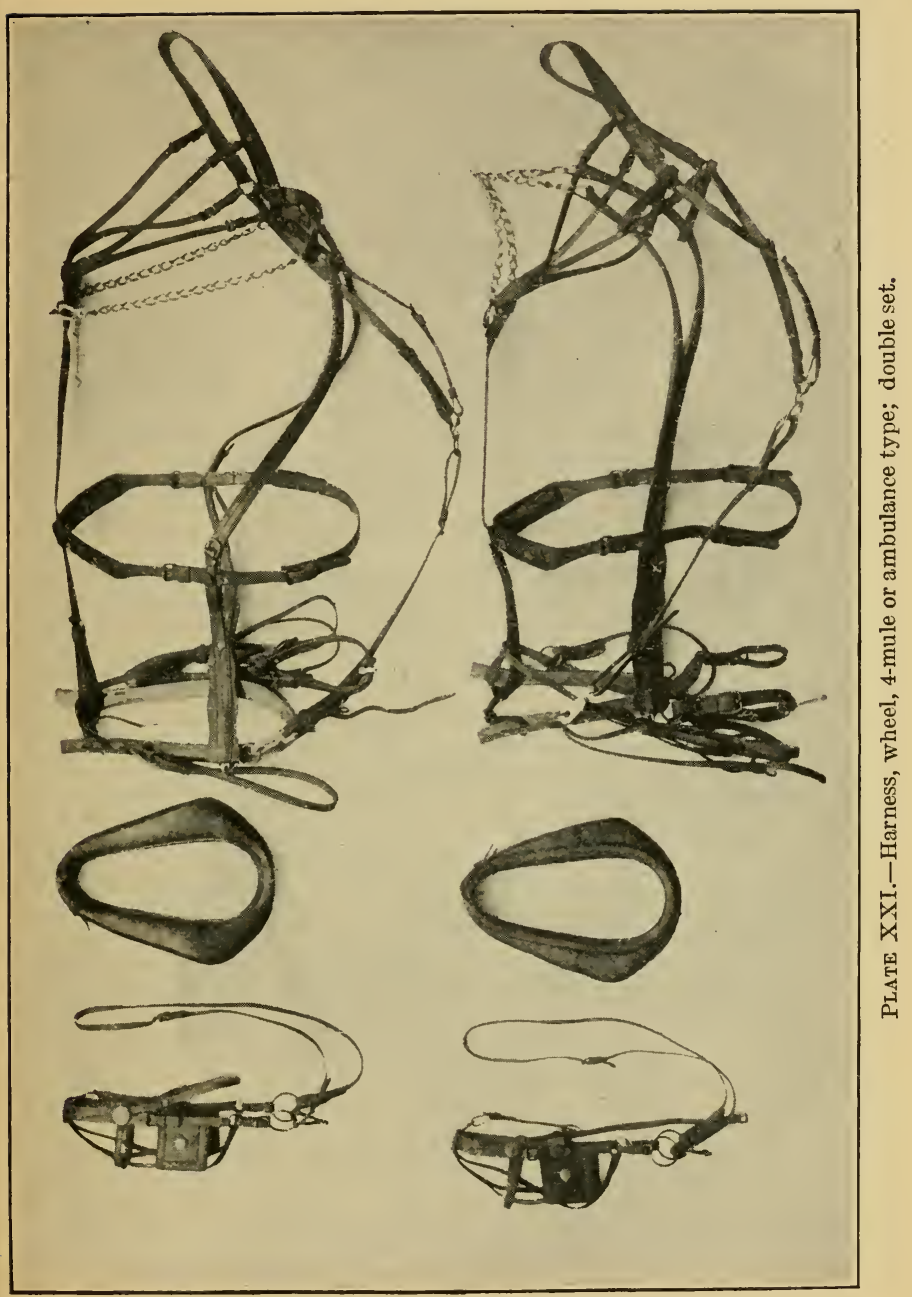




\section{FITTING HARNESS.}

The chief difficulty of the driver is in fitting the collar, and too much pains can not be taken to understand the cause and the prevention of collar sores. Nearly all shoulder sores are due to large collars. If the collar is too long, the pressure is applied too low on the shoulder and sores will occur at the lower part. If the collar is too wide, the pressure is applied on the outer parts of the shoulder, the flesh will be rubbed by the slipping of the collar and sores will form at the upper part of the shoulder. The collar should conform exactly to the shape of the shoulder and should fit so snugly that only the thickness of the fingers can be forced between the collar and the neck. This clearance should be exactly the same from the top of the collar to the throat. Great care should be taken to select the proper size of collar and to work it to the shape of the shoulder by light use before field service is required. The collar should be moist when first used on an animal so that it will be shaped to the neck by the pressure of the draft. This moisture is most effectively given by wrapping the collar in wet sacks and leaving them on for one night before the collar is used. On account of the difficulty of securing proper size collars, pads of cotton or felt should be secured. If not with the harness when issued, every effort should be made to secure them-one for each collar. These pads fill in the irregular space between ill-fitting collars and the neck, and thus partially compensate for the evil.

When sores form, the filling should be removed from the part of the cotton or felt pad over the sore, but the covering of the pad should not be cut. The filling can be removed by ripping the edge and carefully pulling out the required amount without disturbing the surrounding portion.

When suitable sizes of collars can not be obtained, a large collar may be reduced in size by cutting off the top ends and reattaching the buckles and straps. The collar may then be buckled so as to make it shorter and narrower.

Sores on top of the neck result from the pressure of the harsh edges of the upper ends of the collar; from the effort to hold back the wagon by the breast chain; from the rolling effect of a large collar, and from the downward pull of the traces. All these evils may be remedied by proper care. To prevent the upper edges of the collar from rubbing, a steel collar pad should always be used next to the mane; every effort should be made to secure these pads, as they will save much annoyance. These pads are attached to the collar by leather straps and protect the flesh from the harsh ends of the collar and from the roughness of the cotton or felt pad. Breast chains should be lengthened to the last ring and should never 
be tight; they guide the pole and are not intended to hold back the load. A close-fitting collar will not roll over the neck as the animal walks, and thus it chafes the flesh. The trace should be held by the back strap at such a height that its direction at the hames is about perpendicular to the shoulder. This avoids the downward pressure on the neck.

The hames should be adjusted in length by shifting the upper strap to the proper holes. The length should be such that the point of attachment of the trace will be opposite the middle of the surface of the shoulder over which the collar rests. This is for the purpose of distributing the pressure evenly over the shoulder and thus reduce it to the minimum at all points. If the attachment of the trace is too low, or too high, the pressure is localized at one place and produces sores. In adjusting hames, the straps should not be so tight as to squeeze the collar; the upper hame straps should be just long enough to be taut when the lower straps are buckled snug.

In fitting the bridle, the bit should be adjusted so as to be up in the corner of the mouth, but not so far up as to wrinkle it.

\section{CARE OF HARNESS.}

Never throw the harness on the ground; hang it somewhere; place the shoulder side of the collars outside, so they will dry; this will save trouble of cleaning and of caring for animals injured by hard or muddy leather; such animals are useless but must be attended to anyway.

It is better to wipe off the harness immediately after coming inbefore the dirt has gotten hard.

Leather should be kept soft and pliable, and the only way to do this is to keep it cleaned and oiled. Never put leather in, or wash it with, hot water-such treatment ruins it.

In cleaning be sure to get into the cracks, especially about the keepers; take the ends of straps out of the keepers for this purpose.

Do not wear a buckle in the same hole all the time; shift the buckle a hole or so occasionally, and the leather will not rot out at that one place.

Clean harness whenever it gets muddy or dirty; clean and oil it at least twice a month if in use. Think of the uncomfortable feeling on your own foot of a shoe which has gotten wet and has dried rather quickly, and you can realize how a mule feels wearing harness which has not been properly cared for after having gotten wet. Especially should the collars, cruppers, backbands, or saddles, and belly bands or girths be kept soft and pliable. The collar requires particular attention; it should be rubbed clean--not

$76881^{\circ}-15-6$ 
scraped-every day after use, and again just before putting on. The collar should be kept buckled when off-it keeps its shape better.

To clean the harness: First rig up a rack of some sort to hang it on, for it makes the work so much easier. Use the wagon tongue or put the extra coupling pole between the spokes of hind wheel above the hub and strap the other end to the axle. Get a bucketful of water (warm but not hot), sponge, harness soap, neats-foot oil (and some lampblack, if you can). Soften the mud and dirt by using plenty of water, but do not put the leather in the water to soak-it spoils it.

When all the dirt has been removed which is possible with water alone, make a thin lather of the soap on the sponge and complete the cleaning. In cleaning, rub as little as practicable-do it mostly by soaking the dirt off.

Let it dry gradually; never by a fire nor in the hot sun.

If lampblack be available, stir some into the neats-foot oil until it has a glossy appearance. Apply this on a small sponge or piece of cloth and rub this thoroughly into the leather. Then letit dry in.

Cleaning and preserving materials for mounted equipment and artillery harness are furnished by the Ordnance Department; for wagon harness and other quartermaster equipment by the Quartermaster Corps.

\section{REPAIRS.}

The repair work required in caring for leather equipment will vary from the hasty patching of a broken trace on the march to actual making of certain parts in camps of considerable duration. There is a set of saddler's tools issued by the Ordnance Department and one issued by the Quartermaster Department. To organizations having trains of quartermaster transportation, a quartermaster set of saddler's tools is issued, i. e., to each regimental headquarters, wagon company, ambulance company, engineer train, engineer battalion, and Signal Corps battalion. Mounted organizations are furnished suitable sets of such tools by the Ordnance Department. Of the quartermaster sets, portions only are taken into the field, called the "field kits." 


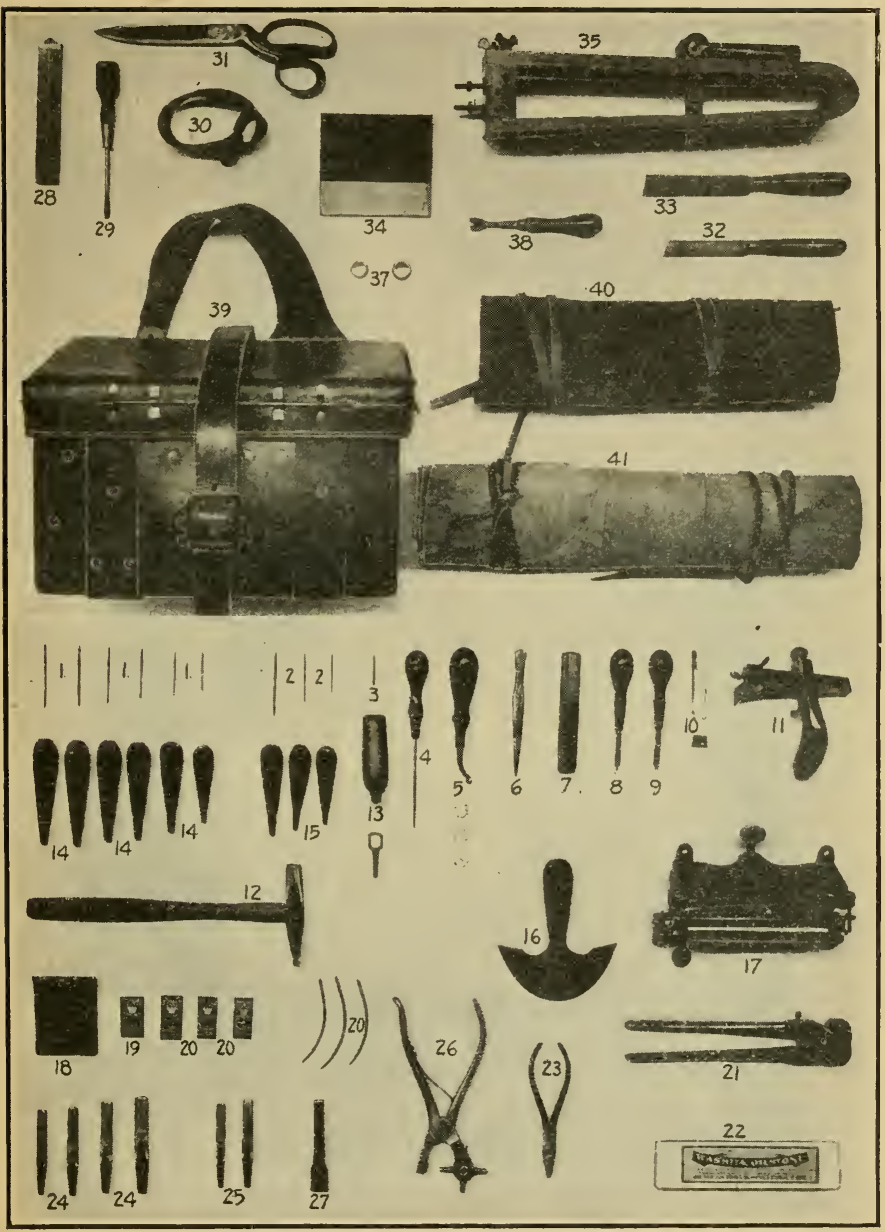

Plate XXII. 


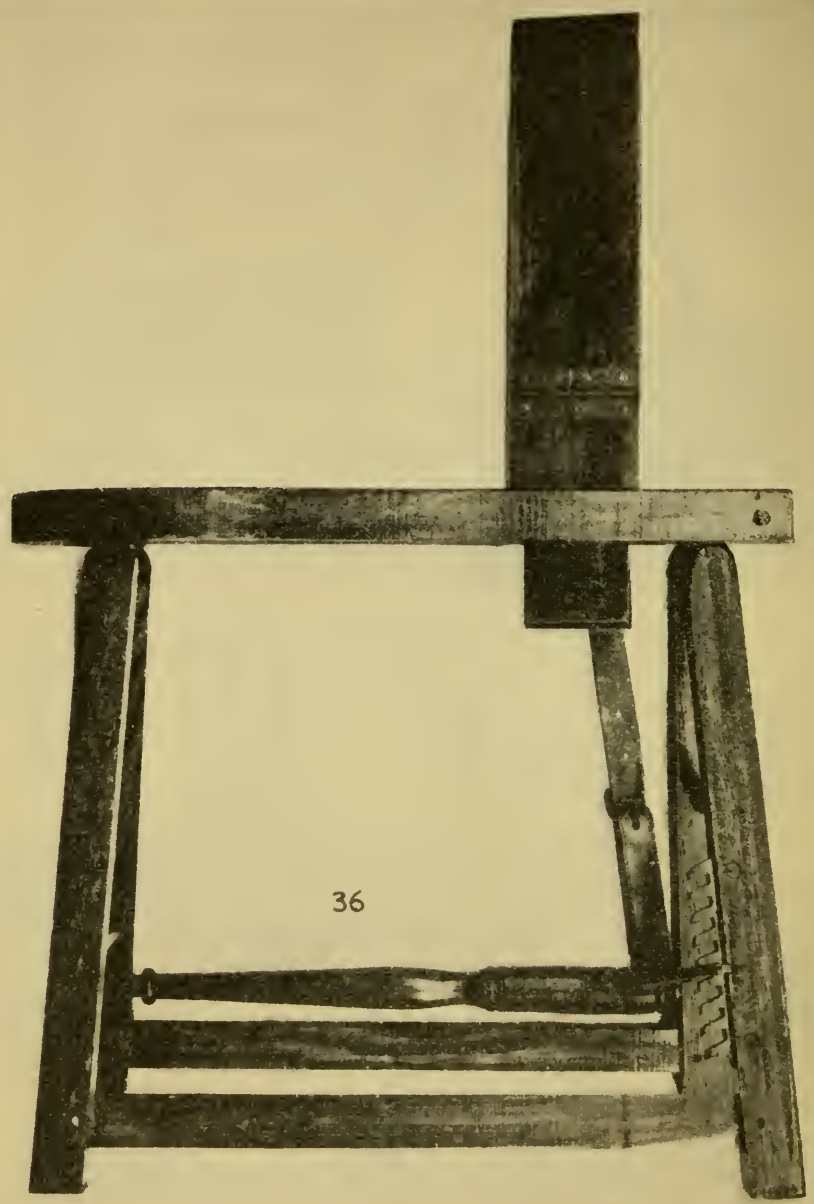

Plate XXIII. 
The ordnance set is as follows (see Pls. XXII and XXIII), viz:

Saddler's tools.

\begin{tabular}{|c|c|c|c|c|c|c|c|c|c|}
\hline \multirow[b]{2}{*}{ 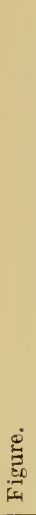 } & \multirow[b]{2}{*}{ Article. } & \multicolumn{8}{|c|}{ Number issued to one- } \\
\hline & & 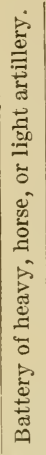 & 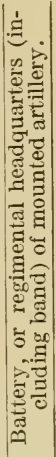 & 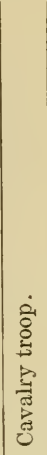 & 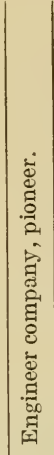 & 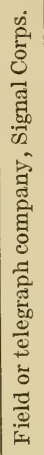 & 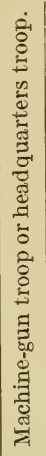 & 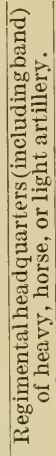 & 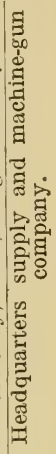 \\
\hline 1 & 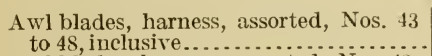 & 12 & 12 & 12 & & 12 & & & \\
\hline 2 & 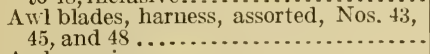 & & & & 3 & & 3 & 3 & \\
\hline 3 & Awl, pegging & 1 & 1 & 1 & & 1 & & $\because$ & \\
\hline $\begin{array}{l}4 \\
5\end{array}$ & $\begin{array}{l}\text { Awl, seat, handled } 3 \text { wheels, Nos. } 7,8 \text {, } \\
\text { Carriage, pricking, } 3 \text { and } 10 . . . .\end{array}$ & 1 & 1 & 1 & & 1 & 1 & 1 & \\
\hline 6 & Compass, 6 -inch $\ldots . . . . . . . . . . . . . .$. & 1 & 1 & 1 & $i$ & 1 & 1 & $\ddot{1}$ & i \\
\hline 7 & Creaser, double, lignum-vitæ.......... & 1 & 1 & 1 & & 1 & $\ldots$ & $\ldots$ & \\
\hline $\begin{array}{l}8 \\
9\end{array}$ & $\begin{array}{l}\text { Edge tool, No. } 1, \ldots \ldots \\
\text { Edge tool, No. } 2 \text {. }\end{array}$ & 1 & 1 & 1 & 1 & 1 & 1 & i & \\
\hline 10 & $\begin{array}{l}\text { Extra blades with followers for draw } \\
\text { gauge } . . . . . . . . . . . . . . . . . . . .\end{array}$ & 2 & 2 & 2 & 2 & 2 & 2 & 2 & \\
\hline 11 & Gauge, draw, brass . . & 1 & 1 & 1 & 1 & 1 & 1 & 1 & \\
\hline 12 & Hammer, No. 3 , riveting.............. & 1 & 1 & 1 & 1 & 1 & 1 & 1 & 1 \\
\hline 13 & Handle, peg (leather top), with wrench. & 1 & 1 & 1 & ... & 1 & $\cdots$ & $\cdots$ & \\
\hline 14 & $\begin{array}{l}\text { Handles, awl, flat, imitation ebony, } \\
\text { assorted, } 6 \text { sizes................................... }\end{array}$ & 6 & 6 & 6 & & 6 & & & \\
\hline 15 & $\begin{array}{l}\text { Handles, awl, flat, imitation ebony, } \\
\text { assorted, } 3 \text { sizes............................... }\end{array}$ & & & & 3 & & 3 & 3 & \\
\hline 16 & 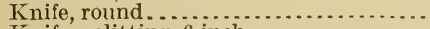 & 1 & 1 & 1 & 1 & 1 & 1 & 1 & \\
\hline 17 & Knife, splitting, 6-inch... & 1 & 1 & 1 & $\because$ & 1 & 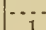 & 1 & \\
\hline $\begin{array}{l}18 \\
19\end{array}$ & $\begin{array}{l}\text { Needle ease, leather ................... } \\
\text { Needles, Glover's, No. } 3 \text {, papers.... }\end{array}$ & 1 & $\begin{array}{l}1 \\
1\end{array}$ & $\begin{array}{l}1 \\
1\end{array}$ & & $\begin{array}{l}1 \\
1\end{array}$ & 1 & 1 & \\
\hline & (Needles, harness, No. 4 , papers...... & 2 & 2 & 2 & $i$ & 2 & 1 & $\ddot{1}$ & \\
\hline 20 & $\begin{array}{l}\text { Needles, harness, No. } 5 \text {, papers..... } \\
\text { Needles, harness, No. } 6 \text {, papers }\end{array}$ & $\begin{array}{l}2 \\
2\end{array}$ & $\begin{array}{l}2 \\
2\end{array}$ & $\begin{array}{l}2 \\
2\end{array}$ & 1 & 2 & 1 & 1 & \\
\hline & 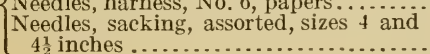 & & & & & 2 & & & \\
\hline
\end{tabular}


Saddler's tools-Continued.

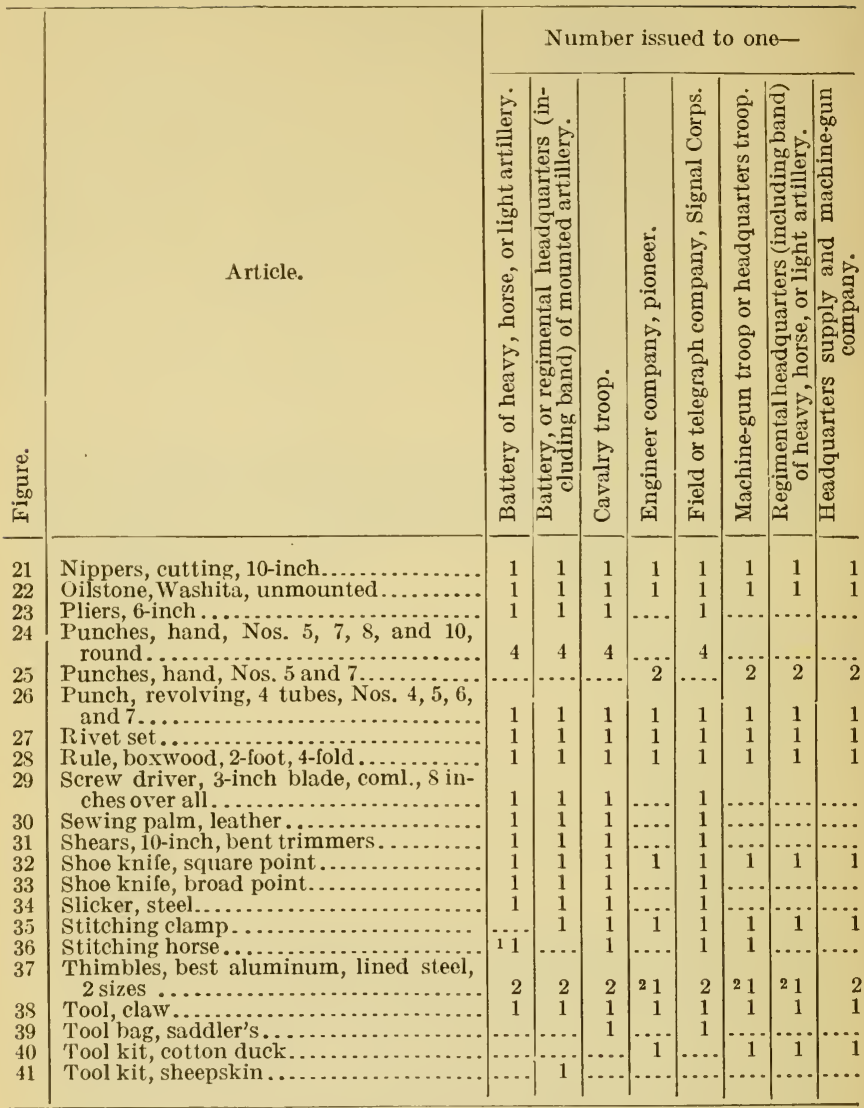

1 Issued to converted 3 -inch battery only.

2 Larger size issued. 


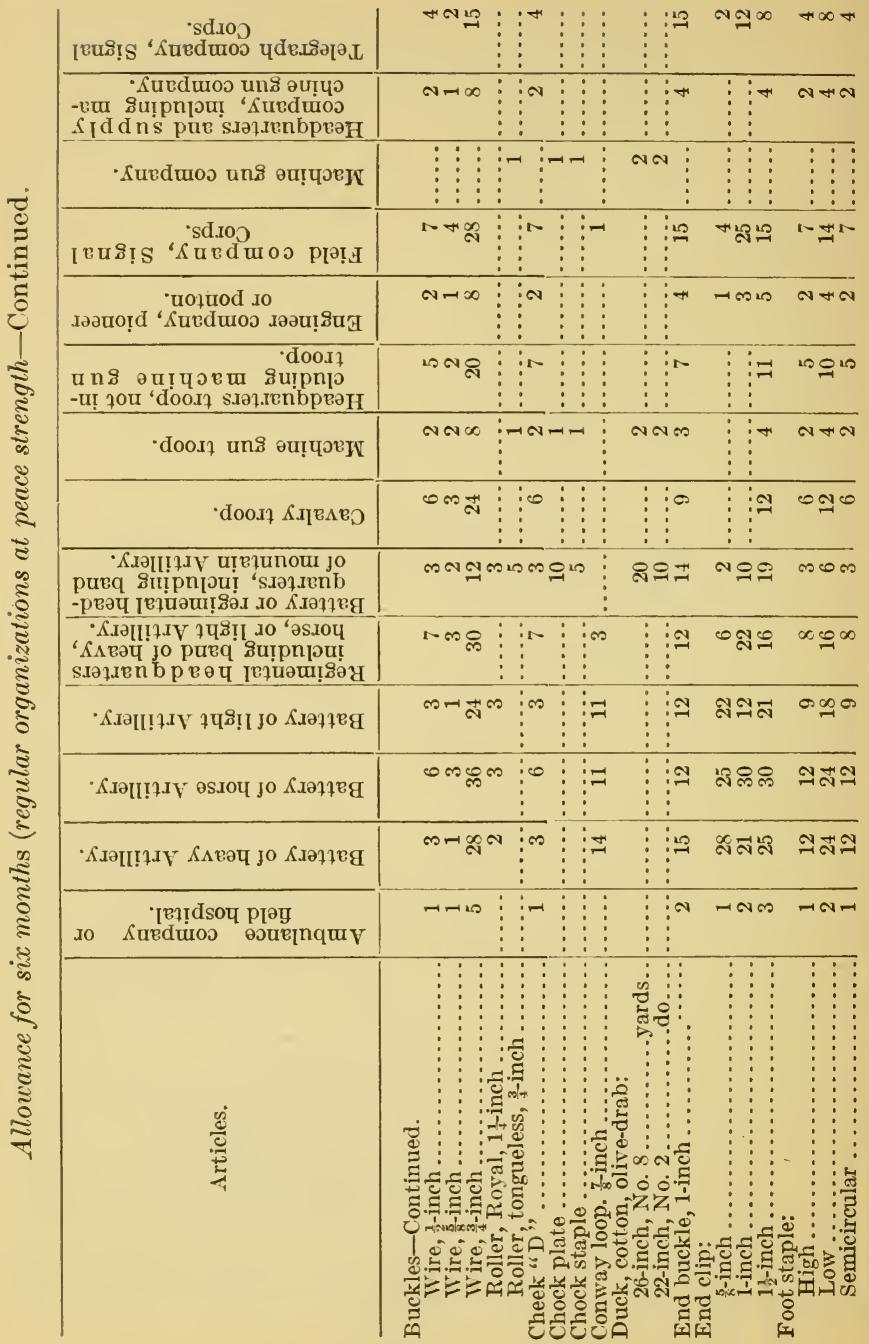




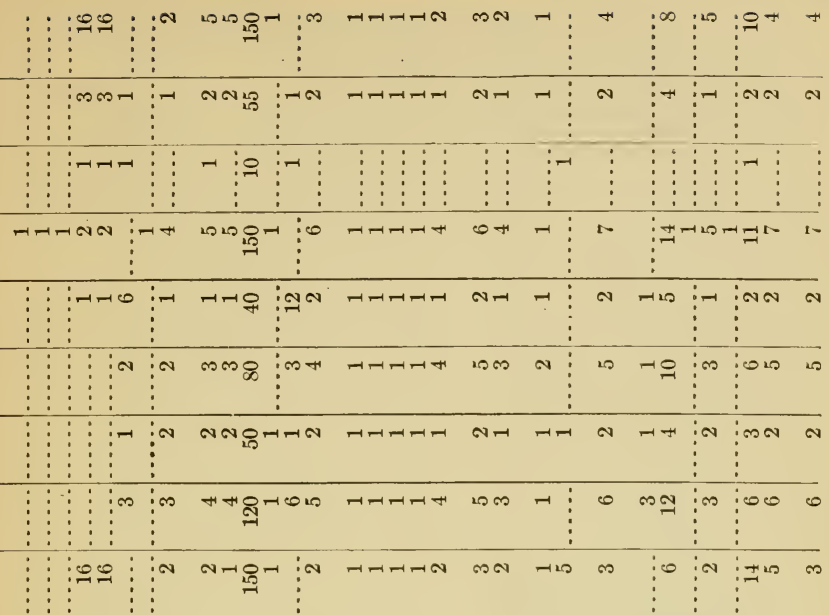

न- $\vdots \vdots \vdots$ -

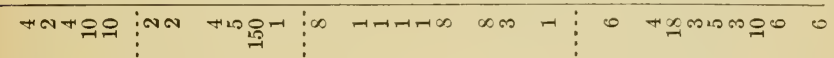

Ha+mo iNm

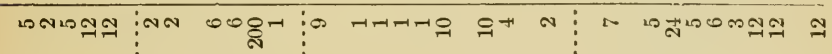

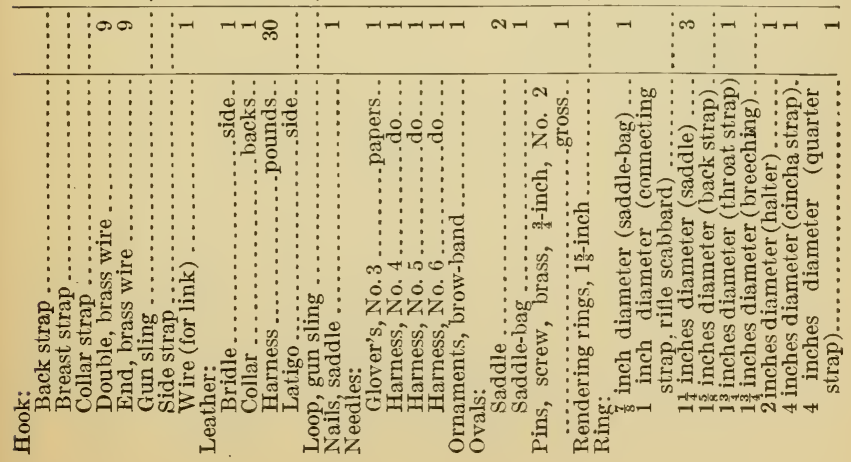




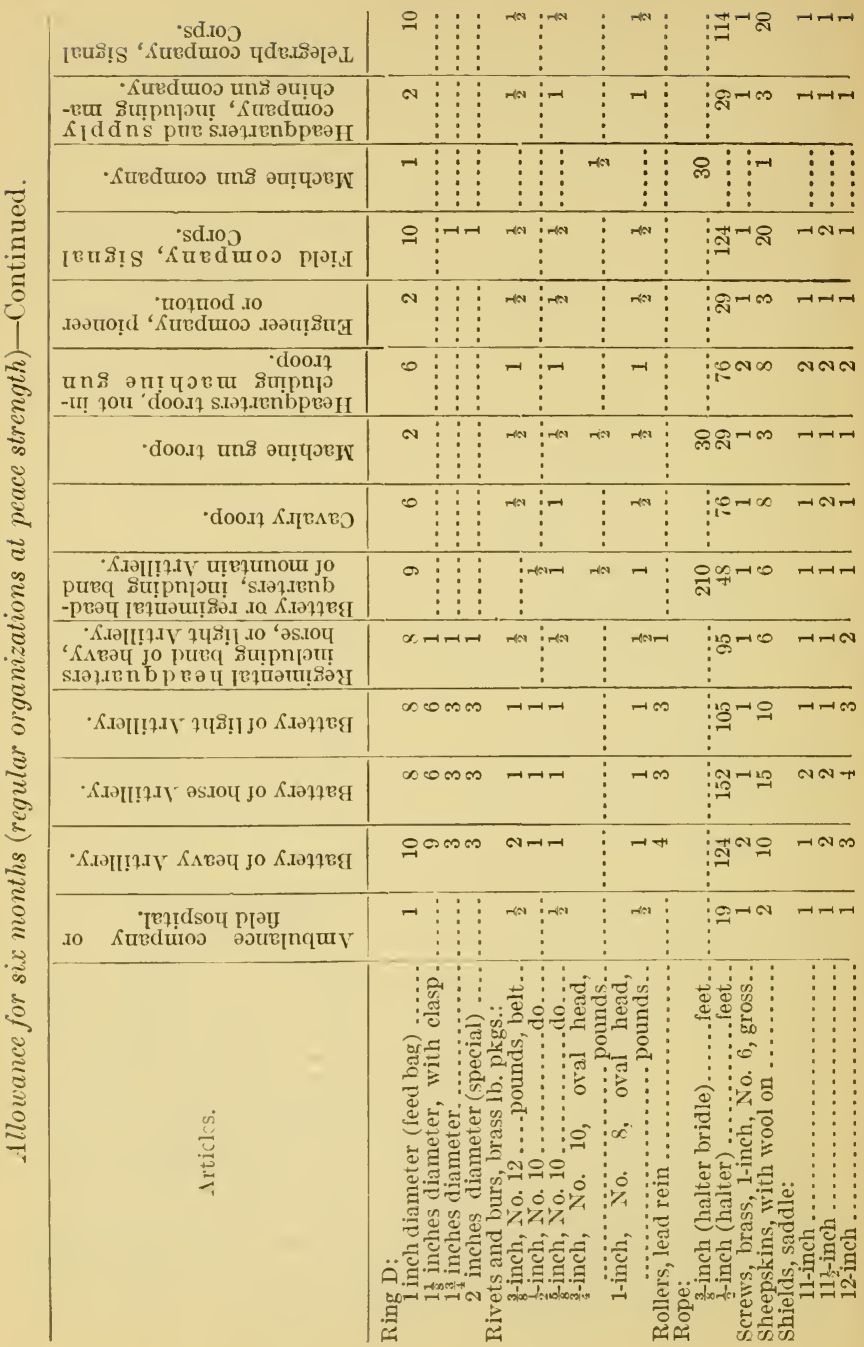




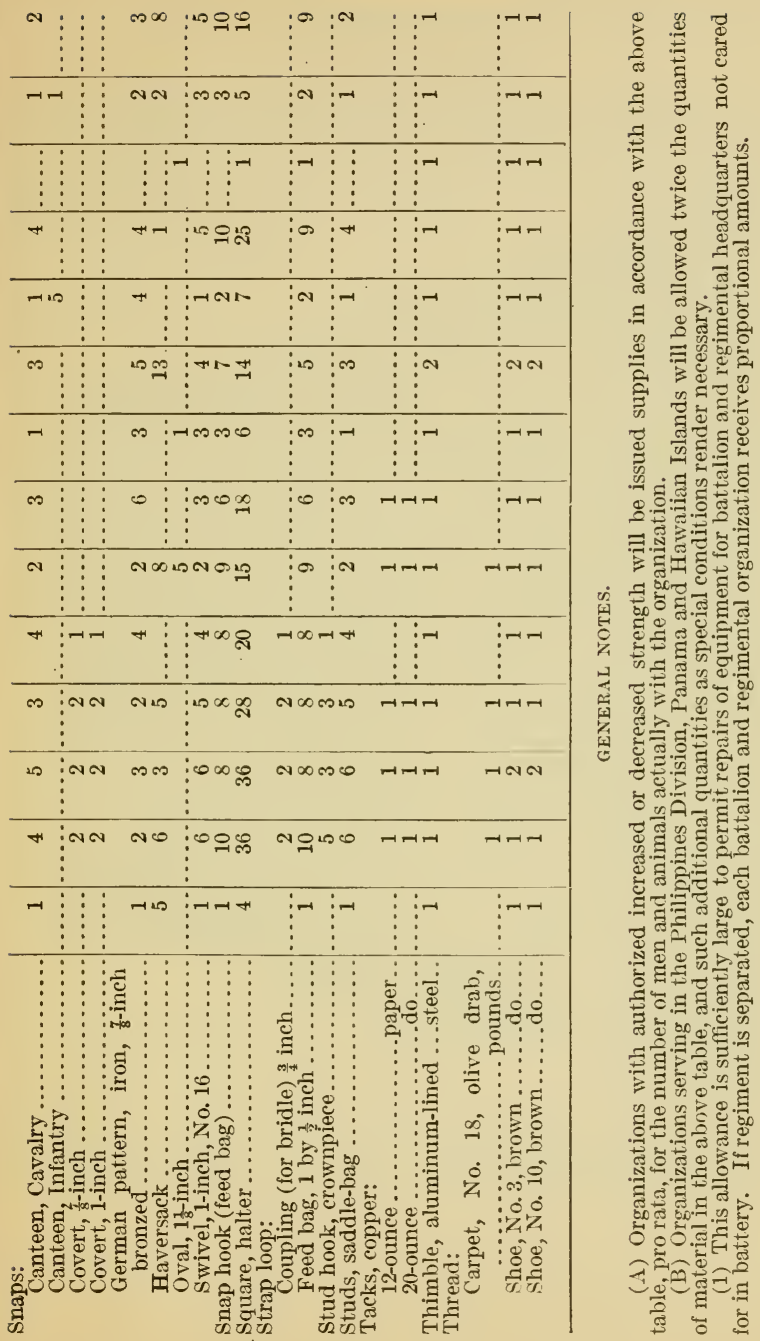


The Quartermaster Corps set is as follows:

Saddler's tools, set.

(See Pl. XXIV.)

\begin{tabular}{|c|c|c|}
\hline Figure. & Articles. & Number. \\
\hline 1 & Awl, collar, with handle $1 .$. & \\
\hline 2 & 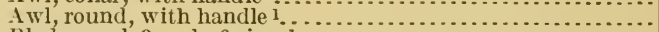 & \\
\hline 3 & 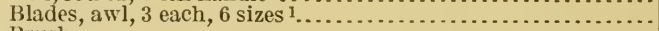 & 18 \\
\hline 4 & ( & 1 \\
\hline 5 & ( & \\
\hline 6 & Chest, tool, saddler's combination. & \\
\hline 7 & 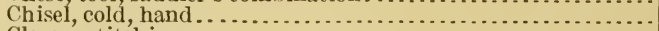 & \\
\hline 8 & 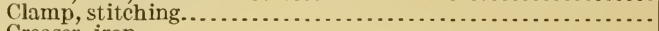 & \\
\hline 9 & 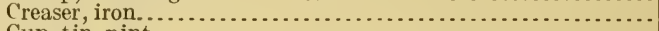 & \\
\hline 10 & (n. & \\
\hline 11 & 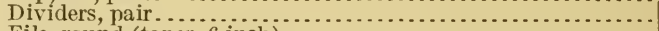 & \\
\hline 12 & File, round (taper, 6 -inch) & 1 \\
\hline 13 & 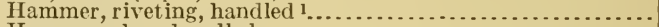 & \\
\hline 14 & 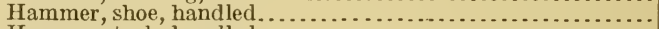 & \\
\hline 15 & 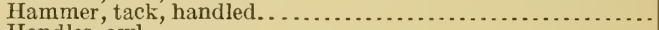 & \\
\hline 16 & (n. & \\
\hline 17 & Knife, gauge, 5 -inch slide $1 \ldots \ldots \ldots \ldots \ldots$ & \\
\hline 18 & 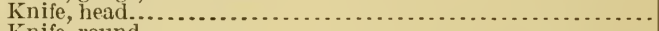 & \\
\hline 19 & (n. & \\
\hline 20 & 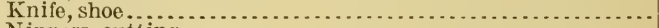 & \\
\hline 21 & . & \\
\hline 22 & 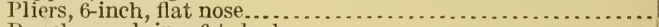 & \\
\hline 23 & $\ldots \ldots \ldots \ldots \ldots \ldots \ldots \ldots \ldots \ldots \ldots \ldots$ & \\
\hline 24 & 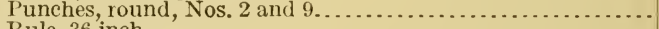 & \\
\hline 25 & 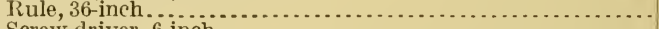 & \\
\hline 26 & .................................. & \\
\hline 27 & 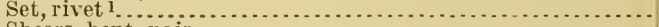 & \\
\hline 28 & 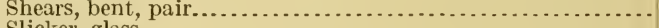 & \\
\hline 29 & 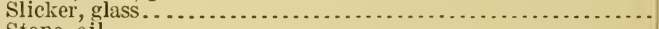 & \\
\hline 30 & Stone, oil & \\
\hline 31 & 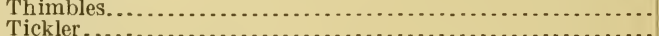 & \\
\hline 32 & 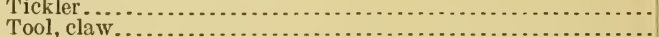 & \\
\hline $\begin{array}{l}33 \\
34\end{array}$ & Tool, claw, .............. & \\
\hline 35 & 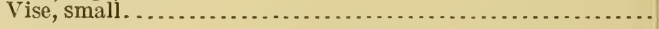 & \\
\hline
\end{tabular}

I These articles, when extracted from the set, form the Saddler's Tool Kit and form a part of Equipment "A" (see preface). The remaining articles are in Equipment "B.",

To each battalion of infantry or squadron of cavalry there is also issued, by the Quartermaster Department, a harness mender, illustrated in Plate XXV, page 92. 


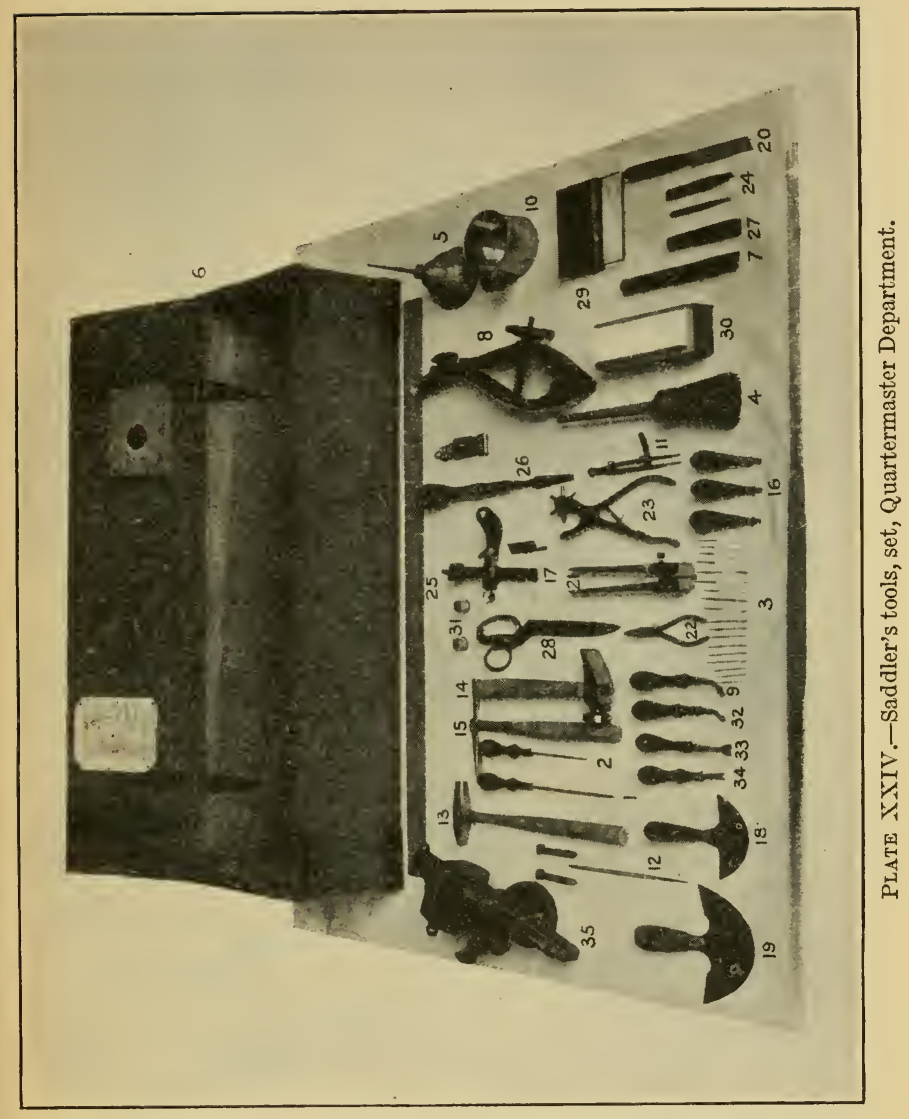


THE SADDLER.

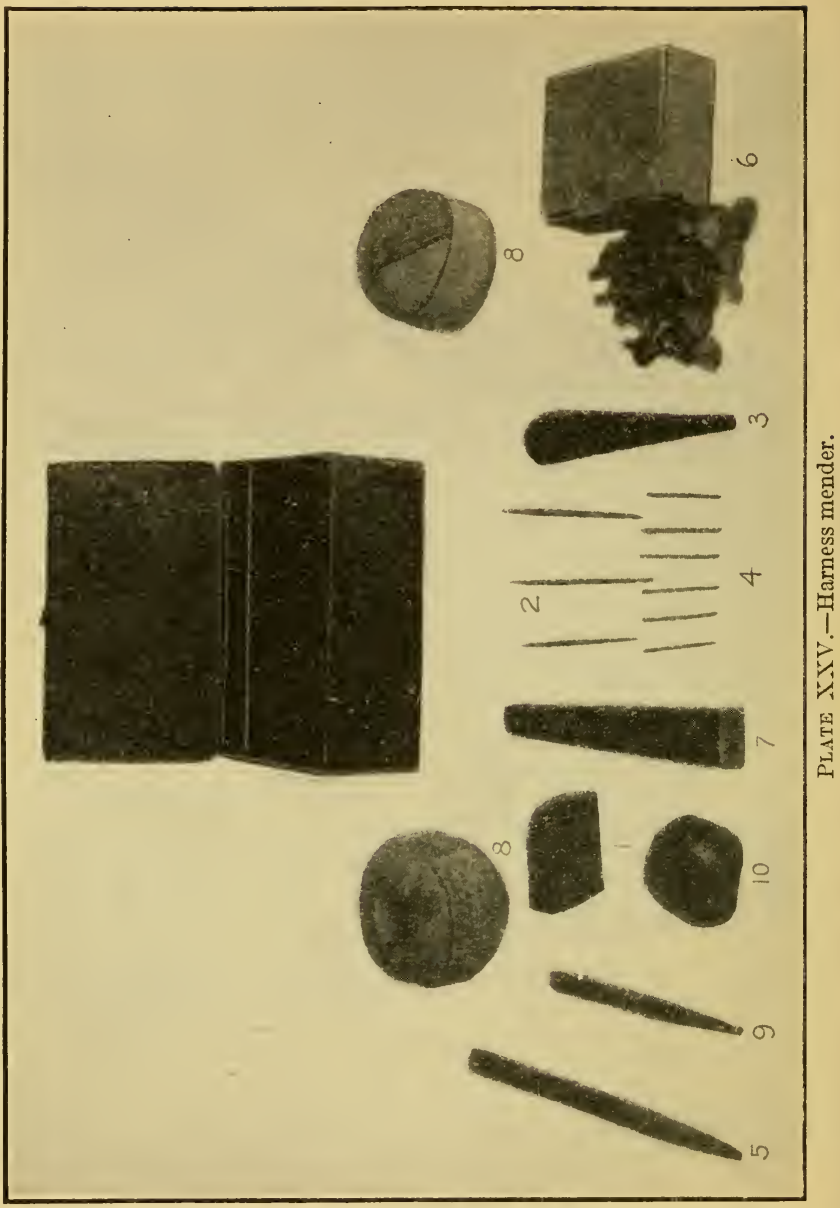


The contents of a harness mender are as follows:

\begin{tabular}{|c|c|c|}
\hline Figure. & Articles. & Number. \\
\hline 1 & Beeswax, piece.... & 1 \\
\hline 2 & Blades, awl, harness.... & \\
\hline 3 & Handle, awl............. & 1 \\
\hline 4 & Needles, harness ( 1 paper). & 6 \\
\hline 5 & 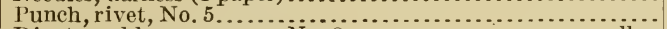 & 1 \\
\hline 6 & 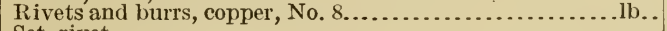 & \\
\hline 7 & 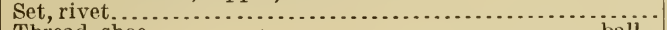 & 1 \\
\hline 8 & 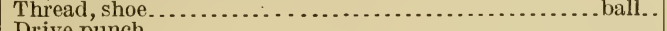 & 2 \\
\hline $\begin{array}{r}9 \\
10\end{array}$ & 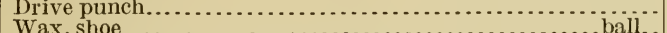 & 1 \\
\hline 10 & Wax, shoe......... & \\
\hline
\end{tabular}

Certain repair parts for harness are carried in the escort wagons and ambulances to which the harness pertains. (See list of wagon parts and accessories, p. 66.) In addition to these, the following allowances of materials for the repair and preservation of harness are prescribed:

For each double set of quartermaster harness-

1 leather, harness, black, pound.

$\frac{1}{10}$ rivets and burrs, copper, pound.

2 thread, saddler's, ounces.

2 wax, saddler's, ounces.

The above amounts are prescribed as Equipment "A" (see Preface). The same amounts are prescribed as Equipment "B." For every 20 double sets of quartermaster harness-

1 needle, glover, paper.

2 needles, harness, No. 2 , papers.

2 needles, harness, No. 3, papers.

2 needles, harness, No. 4, papers.

The above quantities of needles are prescribed as Equipment "A." No additional quantities are prescribed as Equipment "B."

The following sizes of rivets and thread are required:

Rivets and burrs, copper-

No. $8,1 \frac{1}{4}$ inches.

No. $9, \frac{1}{2}$ inch. The rate of consumption by weight of each

No. 9,1 inch. $\quad$ of these sizes is ordinarily the same.

No. $12, \frac{1}{2}$ inch.

Thread, saddler's-Nos. 3 and 10, the same amount of each.

In repairing broken parts the methods for single thickness and double thickness are different. If of single thickness, the two ends to be joined are shaved down so that when lapped the joint will be about the same thickness as the strap itself; then sew parallel to 
the edges-not across, for if you do it will make a weak place in the leather along the line of stitches. However, a couple of stitches should be placed at the ends.

If the broken parts consist of two or more thicknesses, such as traces, shave one end down to a sharp-pointed wedge and the other end from the center so as to receive the wedge-shaped end, then sew parallel to the edges and one or two lines of stitches crosswise.

If the part to be repaired is a trace, care must be taken to see that the distance from buckle holes in the trace, at the hame end, to the singletree holes is the same as in the good trace. Another point, do not place the joint so that the singletree hole must be made through the splice.

In splicing very thick traces it is better to shave down the ends of the break so as to make the joint about the same thickness as the trace and simply tack them together and then cover the joint on each side with a piece of leather of the same width. The ends of these pieces should be shaved down to a thin edge.

Loops or keepers (for holding the ends of straps) oftentimes come unsewed. If ripped considerably, it is better to repair them by removing entirely, then sew one end in along the edge on its own side, after which tuck the other end in and sew it by using sewing needles as far as practicable and then a brass wire doubled, with eye at the middle and suitably curved.

To repair a surcingle or girth, tack the edges together and make a loop just large enough to go around singly. Pin this over the end of the surcingle and over the joint-lap of the loop outside-and sew fairly near the erges (so as to make it smooth) and twice down the middle.

In using a side or part of a side of leather care should be taken to cut from the proper part of the side. Remember that the back is generally the best and the belly and flanks the least desirable, being looser grained.

In working leather into shapes it will be necessary to soak it (if black; not if russet, unless it is hard) for about an hour; it should not be soaked so long that the stuffing (grease) comes out.

If you need a piece of leather of a certain width and length, cut that much out and no more; it may leave an odd shape remaining, but that odd shape may turn out later to be exactly what you need. In other words, save your leather.

Every hamess maker or repairer will find a grained leather finger stall a necessity. Constant sewing with waxed thread soon wears the skin from the fingers and makes them very sore.

If a spot does become thin and tender, it can be relieved by taking a single strand of waxed thread and wrapping close together around the finger over the spot; this method is much better than courtplaster and will last much longer. 
For work around loops and other inaccessible places it will be found very convenient to use an improvised needle consisting of a fine brass or copper wire, doubled and slightly twisted, with an eye left at the middle. This can be bent into almost any shape. The awl holes should be made large in such cases-it will save time and trouble.

In stitching be careful that knots are not left where the harness rubs the animals. A knot is not necessary if a couple of back stitches are used at the beginning and end of the seam.

It is better to sew than to use rivets, for the rivets make an unsightly job and the hole punched for the rivet takes away considerable of the leather. For hasty work, however, rivets must be used, and to rivet well is an art. The proper length rivet should be chosen; with the leather held firmly together and the rivet in place ready to be hammered, the end should not extend more than oneeighth of an inch above the burr. If longer than this, the end should be cut off, for, if not, it will be impossible to properly upset the end, and consequently the rivet shank will bend and make a very poor joint.

$76881^{\circ}-15-7$ 


\section{CHAPTER V.}

\section{THE PACKER.}

The pack mule is used in our service where rail or wagon transportation is impracticable, or where peculiar conditions render his use particularly suitable, such as in mountain field artillery, demolition packs for cavalry, tool packs for engineers, medical equipment for sanitary troops attached to organizations, machine guns for infantry and cavalry, radio outfits of signal corps company, supply trains, and sanitary trains. The numbers for each for the above purposes are shown in the Tables of Organization of the Regular Army and in Tables of Organization of the Organized Militia. The ordnance equipment for each is shown in the several Unit Accountability Manuals (Ordnance Department). The quartermaster equipment will be shown in tables of allowances which are expected to be published shortly (1915).

The following remarks are taken mostly from Engineer Field Manual, 1907, Part VI (Transportation):

Pack saddles.-The adopted pack saddle is of the Spanish type, and is commonly called by its Spanish name, "aparejo," Plate XXVI. Its principal parts are the body, the cover, the cincha, and the crupper. These parts have subdivisions, which are less important. The accessories added to the above to make the aparejo complete are the corona, the blanket, the lash rope (50 feet long, $\frac{1}{2}$ inch diameter) with its cincha, the sling rope (about 30 feet long, $\frac{3}{8}$ inch diameter), the two lair ropes (about 30 feet long, $\frac{3}{8}$ inch diameter with loop or eye at one end), and the two mantas or pack covers.

Aparejo, proper:

I. Body of aparejo.

II. A parejo cover (permanently attached to the body).

III. Cincha.

IV. Crupper.

V. Corona.

Accessories:

VI. Lash rope with cincha.

VII. Sling rope.

VIII. Lair ropes (two).

IX. Mantas (pack covers), two.

X. Blanket.

Carried by packer:

XI. Blind (one every 10 pack mules, or frartion). 


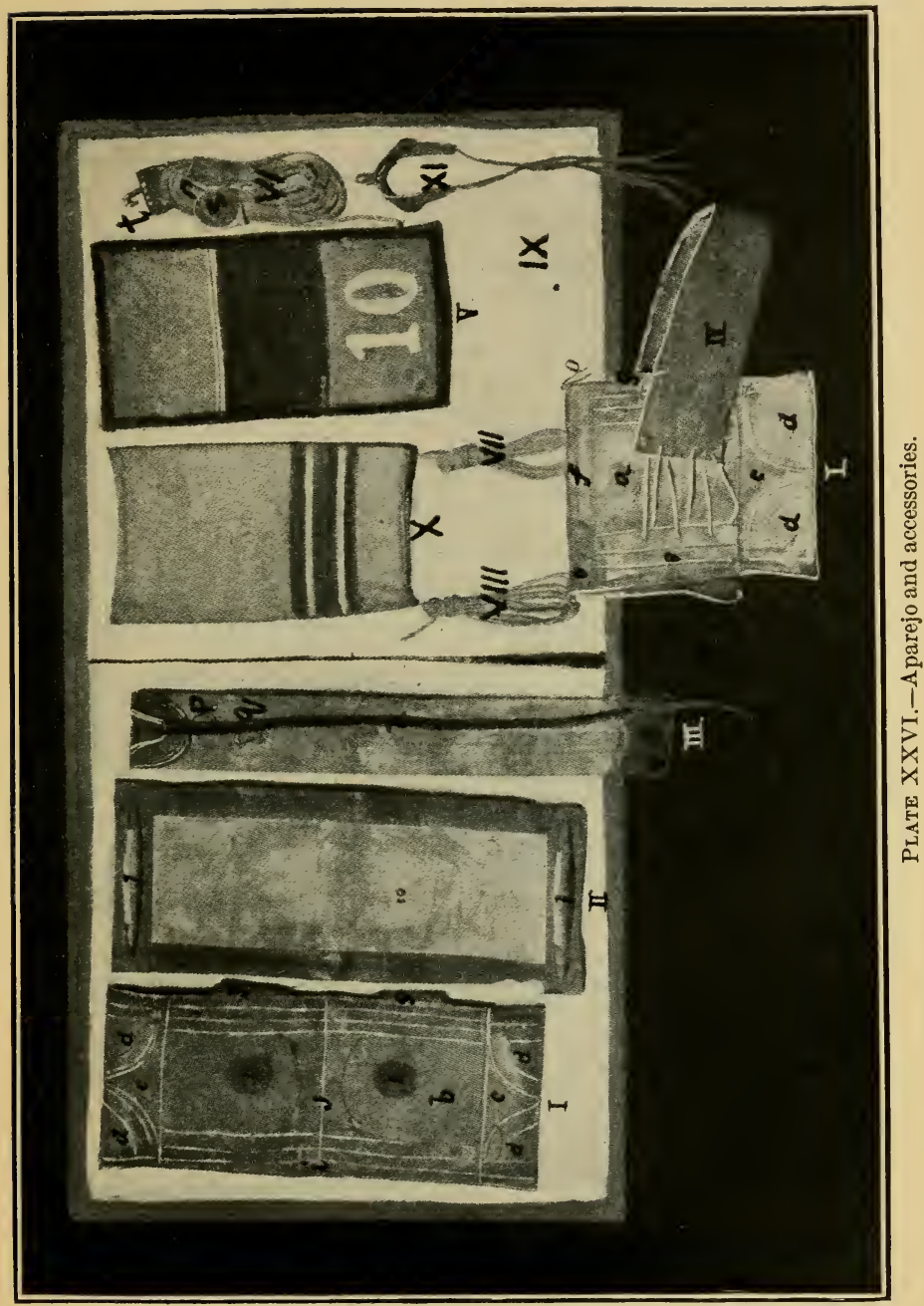


The body of the aparejo consists of 2 pieces of heavy leather 24 inches wide by 58,60 , or 62 inches long, sewed together at the edges and across the middle of the length, forming 2 pouches, into which moss or hay is stuffed to form pads fitting the contour of the animal on either side of the backbone.

In the American form the pads are given a peculiar elastic stiffness by means of ribs of wood or metal extending from a saddle piece at the top of each pouch to a boot piece at the bottom. These ribs are stiffer at the front and more flexible at the back, varying uniformly between. They convert each pad into an elastic lever, by which the pull of the cincha on the bottom acts to raise the aparejo and its load from the backbone, while the stuffing distributes the load uniformly over a large space on the ribs. The stuffing is introduced through a handhole in the middle of the underside of each pad, through which it is always accessible, and the finest art of the packer consists in fitting the pads to the shape of the particular animal which is to carry the aparejo, and keeping them so regardless of changes in the animal's condition by shifting, removing, or renewing the stuffing. If a bunch rises on the animal it can be worked down by taking out stuffing immediately over it so as to take off the pressure at that point. Determine the proper point by wetting the top of the bunch and laying the aparejo on the mule. Aparejos and mules are numbered and the same pack is always on the same mule.

The function of the crupper is not what would naturally be expected. If the aparejo is properly set up and fitted there will be no tendency to move back or forward. The crupper is, in reality, a steadying lever to keep the aparejo from rocking fore and aft as the mule travels. For this purpose the dock piece is large, smooth, and soft, and the crupper is wide, stiff, and firmly laced to the body. The crupper is adjustable in length, and must be accurately fitted, so that when the aparejo is in its proper place the dock piece will ride between tail and dock without pressing on either.

The cincha is of heavy canvas, doubled, and 10 inches wide. It is long enough to reach from the near boot under the mule and around the aparejo to a little beyond the middle. The ends are connected by the latigo, or cincha strap.

The corona is a pad usually of several thicknesses of blanket, with a number or design which identifies the pack. It is important that the corona shall not be separated from its aparejo.

Off the mules the aparejos are placed in a row on the ground or on skids, standing on their boots. The cincha, folded with the "latigo" or cinch strap (n, Pl. XXVI) inside, rests on the aparejo. The crupper is turned so that the dock piece rests on the cincha. The corona is placed on top of all. Canvas covers are stretched 


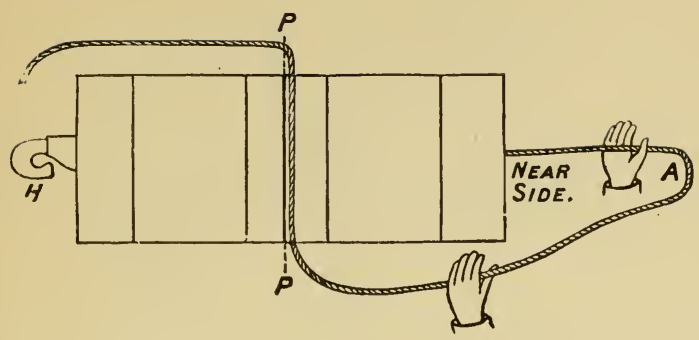

Plate XXVII.

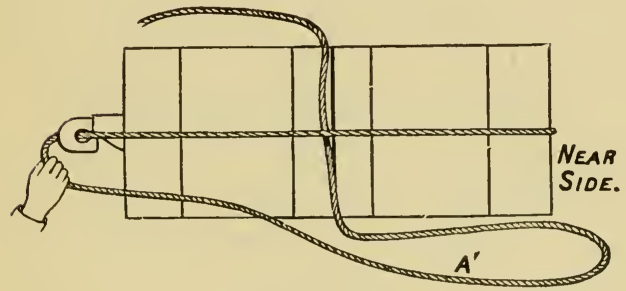

Plate XxVIIa.

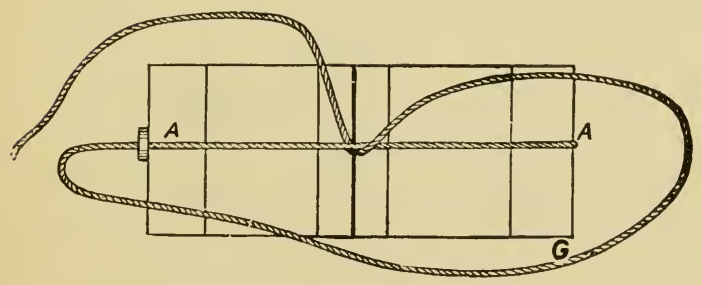

Plate XXViIb. 


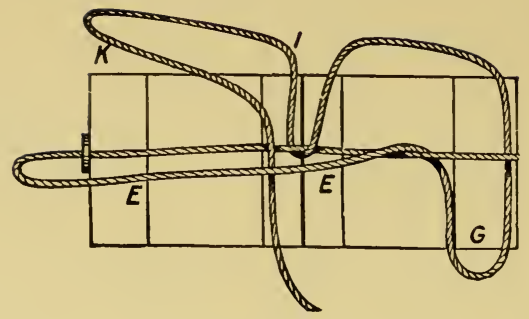

Plate XXViIc.

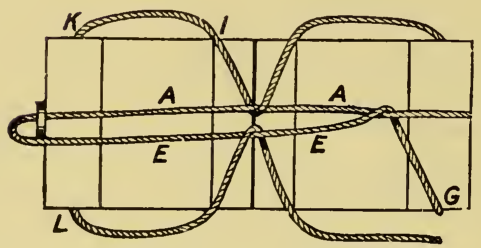

Plate XXVIId.

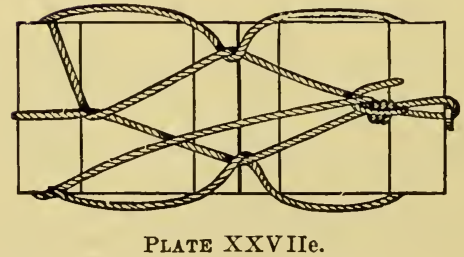


over the line of aparejos and tied down. The line of aparejos so arranged is usually referred to as the rigging.

Each packer is provided with a blind-one for every 10 pack mules or fraction of 10 . The mules are trained to stand perfectly still when blinded, and if it is necessary to move a mule even by a step the blind should be lifted.

To place the aparejo on the mule the corona is first put smoothly on, followed by the blanket folded to six thicknesses. The aparejo is then put on slightly in rear of its place. The crupper is turned, the dock piece adjusted, the aparejo settled to its place, and the cincha unfolded, placed, and tightened. Never put on or adjust a pack with the mule's head uphill.

Loads are divided into side packs and top packs. Side packs should be of approximately equal weight and size. A keg of paint on one side and an equal weight of oakum on the other do not make a proper load. Side packs should not be longer than 30 inches, wider than 20 inches, nor deeper than 12 inches. If the side packs do not fill out a load the rest is placed between them as a top pack. Articles which by their size or shape are not suitable for side packs are carried on top. The center of gravity of the entire load should be below the top of the saddle, and the lower the better. For miscellaneous cargoes the freight is made up into side and top packs, each wrapped in a manta, or canvas cover, and tied, or laired up with lair ropes. If a pack contains articles of different weights, place the heaviest at the bottom. The side packs are slung across the aparejo by the sling ropes and lashed on with the lash rope and cincha in the form of the diamond hitch. Such a load must remain unbroken until the end of the march.

The load is lashed on with the lash rope and cincha by what is known as the "diamond hitch;" the method is explained in Cavalry Drill Regulations.

Care and preservation.-All parts of the rigging should be kept clean and the leather parts soft and pliable. The materials and methods given for harness may be adapted.

In taking off lashed packs, the lash rope is removed; its cincha laid on the ground at the middle of the line to be occupied. The lash rope is coiled down on the cincha and its end stretched out 10 feet to one side. The sling rope is then unfastened, the packs dropped from the aparejo and laid on the lash rope lengthwise with the cincha. The sling rope is coiled on the packs, and the end of the lash rope brought up on top. The cincha of the second pack is laid down on one side of the first and parallel to it at 2 feet distance, but with the end of the lash rope on the opposite side. The packs, etc., are placed on it as described. The third pack is placed on. the other side of the middle one, and so on until all are down in a line. After all cargoes are off the aparejos are removed. Cargoes 
are also covered with pieces of canvas called cargo covers. Mantas may be used if there are spare ones.

For details as to pack transportation, see "Pack Transportation," by Daly, 1910, a Government publication (War Department, Document No. 360). For explanation of the knots and hitches see "Cavalry Drill Regulations," paragraphs 1010 to 1017.

For repairing packs and shoeing pack animals of an organization the ordnance outfits issued to organizations are used; for pack trains (part of the supply quartermaster service) this type of equipment consists of the blacksmith's kit and cargador's kit.

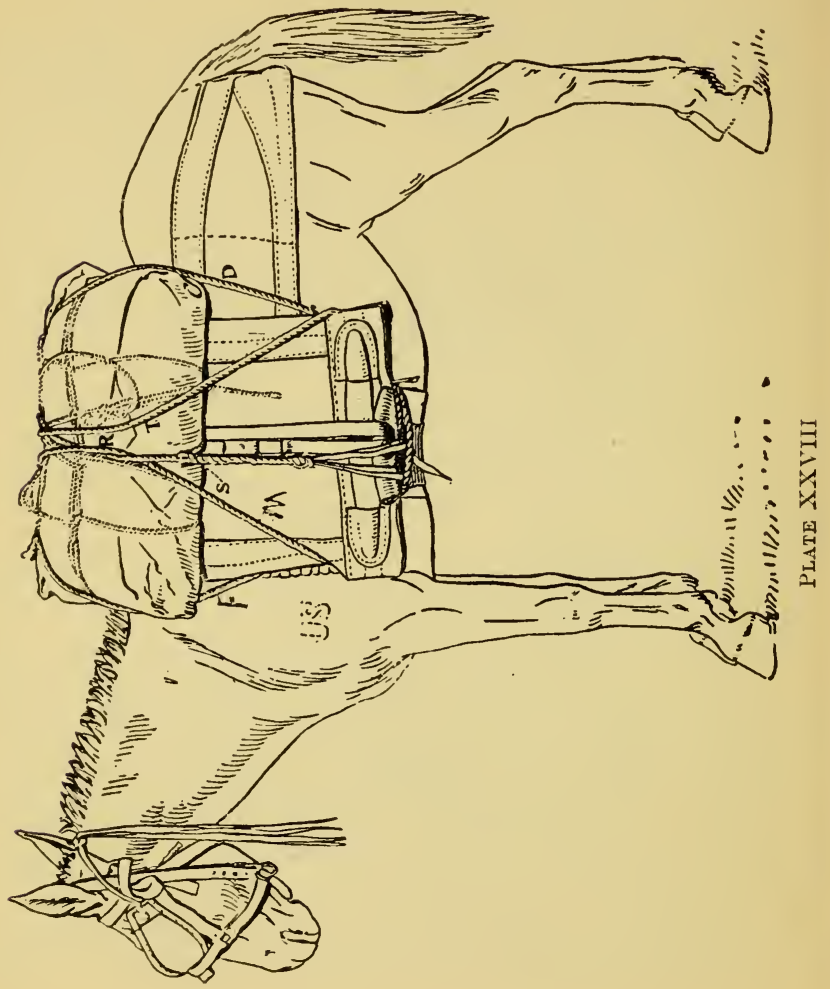


The blacksmith's kit consists of the following articles:

1 anvil, field, packer's.

1 cutter, clinch.

1 hammer, hand.

1 hammer, shoeing.

1 iron, clinch.

2 knives, horseshoe, $3 \frac{1}{4}$-inch blades.

1 pinchers.

1 pritchel.

2 rasps, 16-inch.

To make the field anvil, take a piece of flat iron about 18 inches long, 3 inches wide, and $\frac{1}{2}$ inch thick; shape this into a triangle about 5 inches on the side and weld together.

A pack train cargador's, kit consists of the following articles:

12 blades, awl, assorted sizes.

1 cutter, rivet.

1 hammer, riveting.

3 handles, awl.

1 knife, gauge.

$1 \mathrm{knife}$, half-round.

2 needles, Nos. 2 and 4, papers.

6 needles, sailmaker's assorted sizes.

1 oilstone, small.

1 palm, sailmaker's.

3 punches, hand, size $\frac{3}{8}, \frac{1}{4}$, and $\frac{1}{8}$ inch.

1 punch, spring.

1 set, rivet.

1 shears, tailor's, 6-inch blade.

1 tool, edge.

Ten days' supply of materials, as listed below, required for repairs of the complete equipment of 50 pack animals, forms a part of the cargador's kit, viz:

6 buckles, halter, $1 \frac{1}{8}$ inch.

4 canvas, 28 inch, No. 10 , yards.

6 leather, bridle (or harness), fair, pounds.

6 leather, latigo, fair, pounds.

1 pack cover.

6 rings, halter, $1 \frac{3}{4}$ inch.

$\frac{1}{4}$ rivets and burrs, size $\frac{5}{8}$, No. 8 , pounds.

250 rope, $\frac{3}{8}$-inch, feet.

200 rope, $\frac{1}{2}$-inch, feet.

6 snaps, halter, trigger, size $1 \frac{1}{8}$.

3 thread, harness, No. 10 , ounces.

1 twine, sailmaker's, ball.

3 wax saddler's, ounces. 


\section{CHAPTER VI.}

\section{HORSESHOER.}

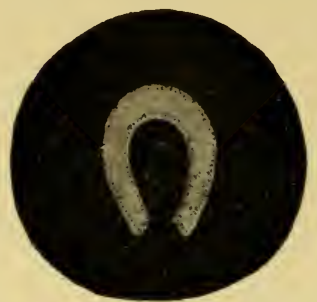

Horseshoer's chevron.

Those whose primary duty is the shoeing of animals should familiarize themselves with the manual "The Army Horseshoer," prepared at the Mounted Service School, Fort Riley, Kans. (War Department Document No. 356), which treats the subject thoroughly. However, the trooper, teamster, or the packer may be called upon to tighten, remove, or to replace shoes or even to adopt temporary expedients for shoes when shoes themselves are not to be gotten.

As long as an animal has energy (which he accumulates by the fuel taken into his stomach in the shape of forage), he can render service if his feet are in condition to carry him; even though he has a sore back (if a mount) or sore shoulders (if a draft animal), he can still-though with pain-do his work. But with lameness in his feet, he can neither carry himself nor his load-on the other hand, he is a burden because he must be cared for.

A driver or mounted man should see that any shoe lost or worn out is replaced, or, if a shoe be loose, that it is tightened at the earliest practicable opportunity.

If the use of the horse and the mule were confined to the soft fields, there would be no necessity for protecting the hoof, but on improved roads, which are a necessity due to the heavy volume of traffic, the hoof will wear away much more than nature can replace. Pough ground also causes the horn to break away. Horseshoes and mule shoes are therefore a necessity in the military service.

The idea of the shoe is to protect the wall of the hoof, but this must be done without interference with the growth of any part of the foot or with the proper functioning of the various parts of the 
foot. When the animal puts his foot on the ground there is a downward movement of all the inside portion of the foot with reference to the ouside covering or wall and the hard sole or bottom of the foot. The frog in the horse corresponds to the heel of the man and it is just as important. Any shoeing which does not permit of the frog's touching the ground is defective; however, this is not to be construed as meaning that horses which have been shod otherwise so long as to dry up the frog or whose feet are otherwise defective should have the horn and sole cut down so much as to bring pressure on the sensitive parts of the foot. The frog can be built up again by putting it to use again; that is, by using a leather pad of sufficient thickness to bring pressure on the frog when the foot is planted. If at any time the sole will give under heavy pressure of the thumbs, the sole is too thin.

Tools for shoeing animals are issued by both the Ordnance Department and the Quartermaster's Department.

For winter use or when necessary and when calked shoes are not issued, toe calks are supplied at the rate of one ( $\frac{1}{8}$ pound) per shoe.

The allowance of smithing coal is, for each 100 animals, 30 pounds in Equipment A, 60 pounds in Equipment B. (See Preface.)

Animals should be shod at least once a month. The animals' feet should be inspected carefully and cleaned out at least twice a day. If an animal goes lame suddenly on the march, look over his feet and see whether he has gotten a stone wedged somewhere about the hoof. It is remarkable how careless the average man is with reference to this-probably the most important-part of the animal.

The Ordnance Department tools and issues (see P1. XXIX, XXIXa, XXIXb, and XXX) are as follows. 


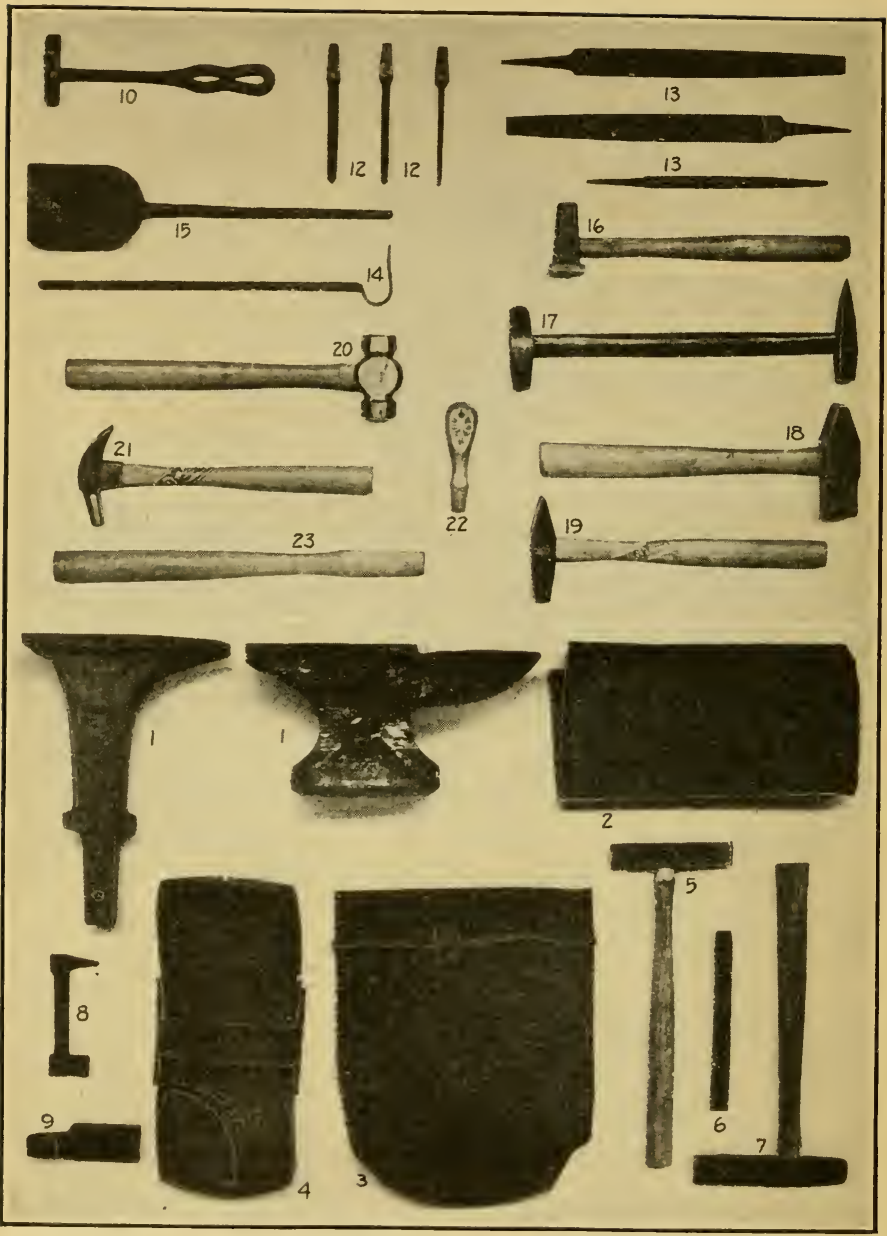

Plate XXIX. 


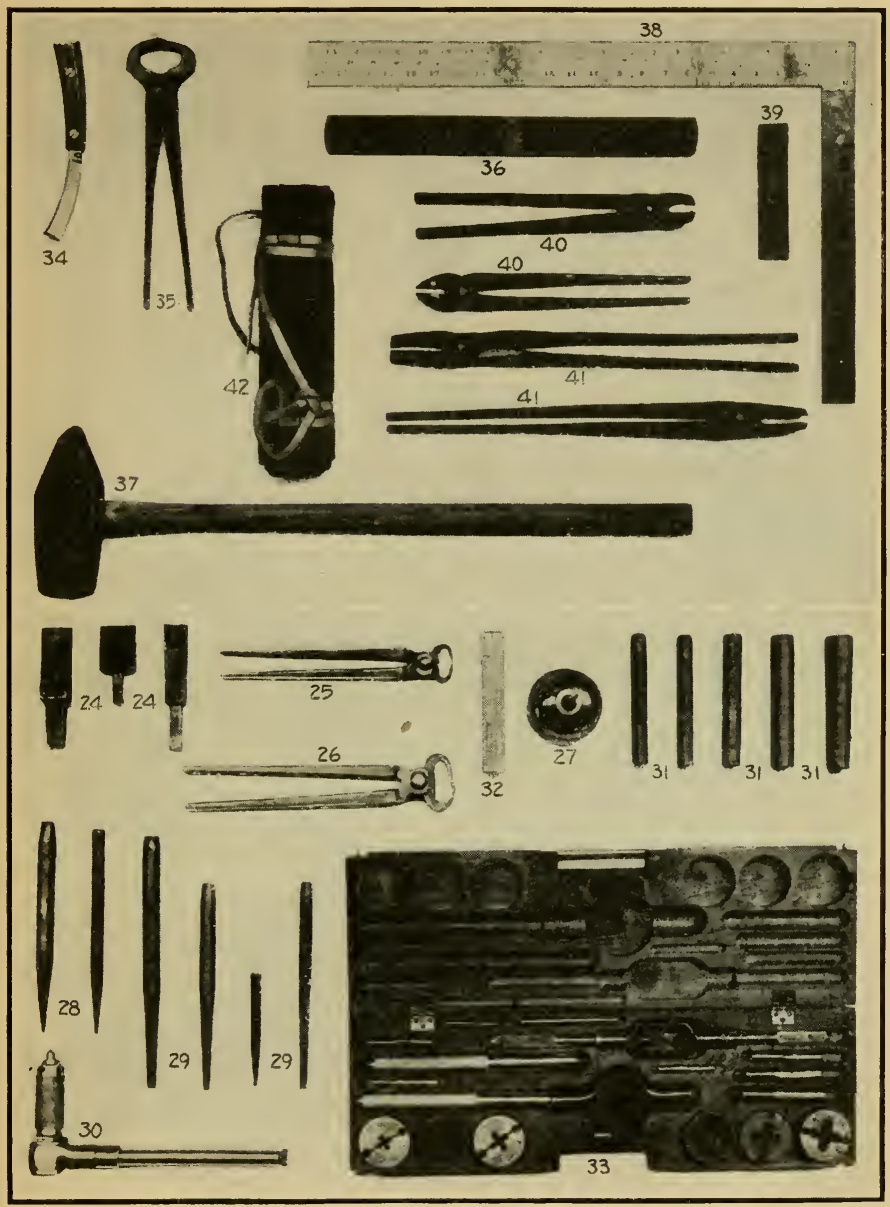

Plate XXIXa. 


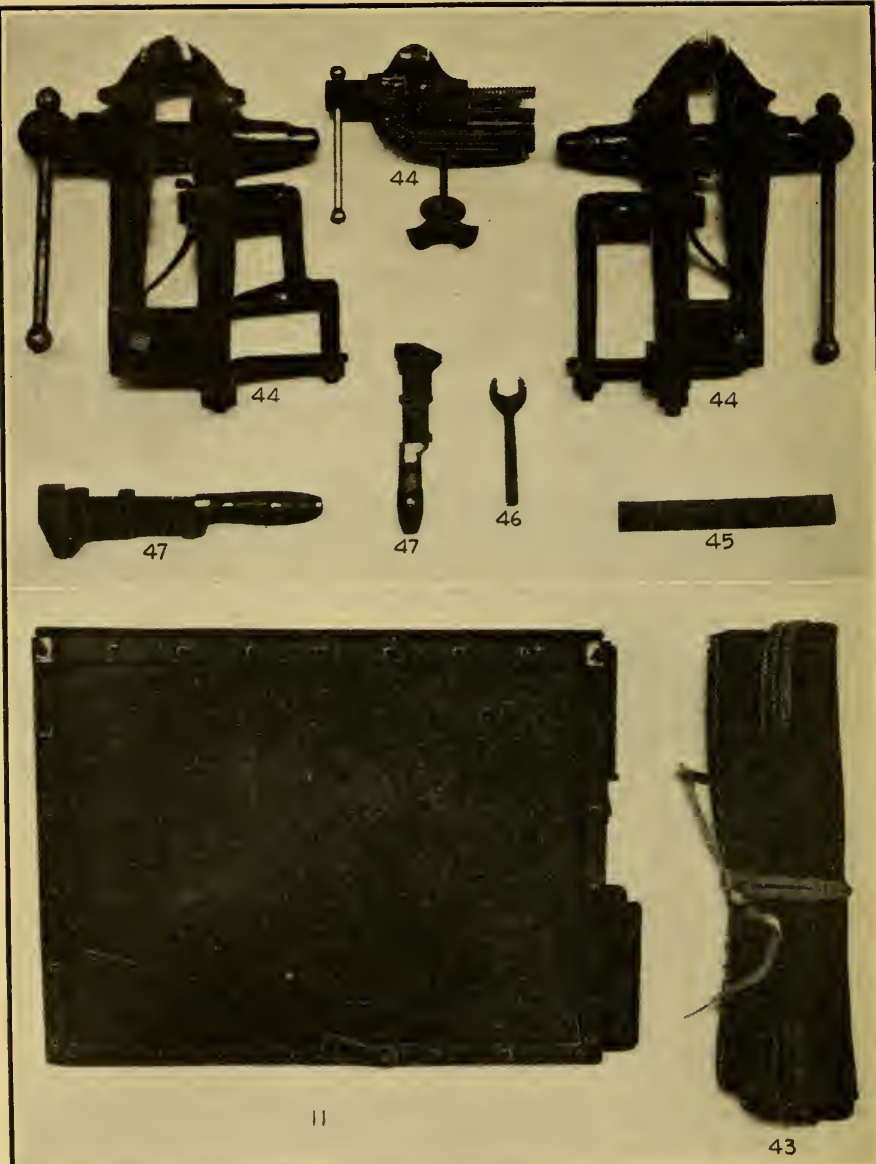

Plate XXIXb. 


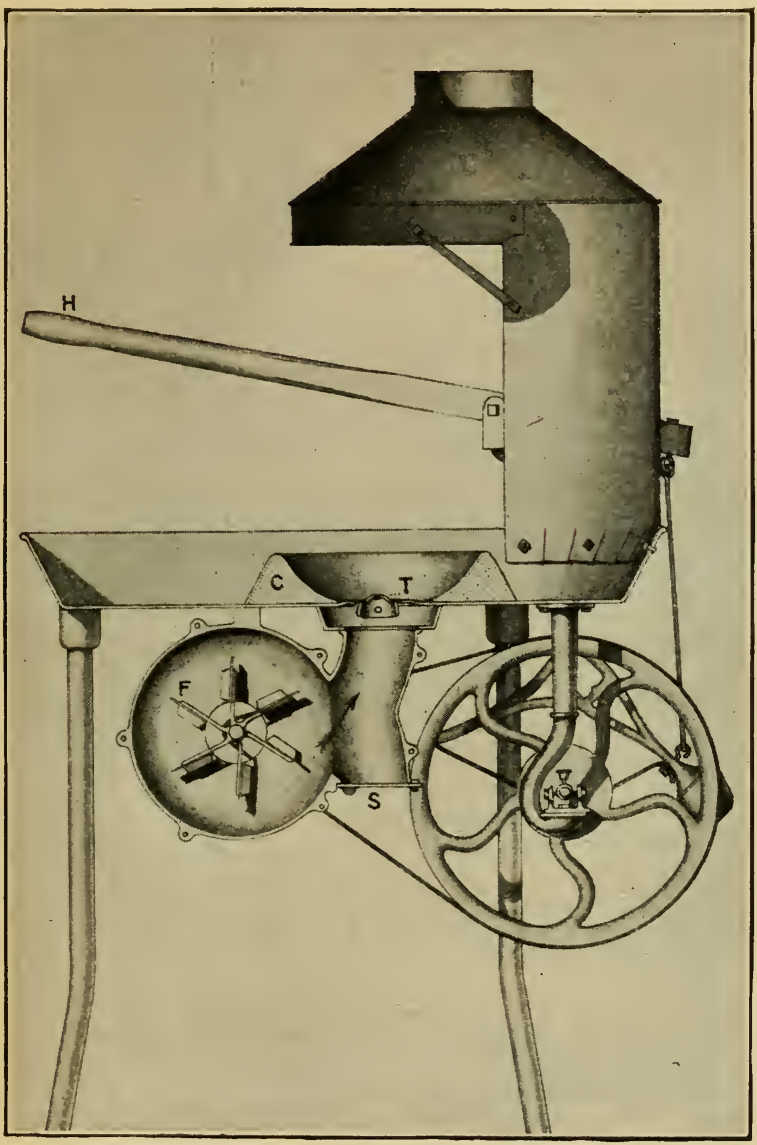

Plate XXX. 


\section{Blacksmith's tools.}

\begin{tabular}{|c|c|c|c|c|c|c|c|c|}
\hline \multirow[b]{2}{*}{ 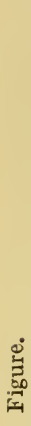 } & \multirow[b]{2}{*}{ Article. } & \multicolumn{7}{|c|}{ Number issued to $1-$} \\
\hline & & 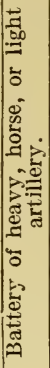 & 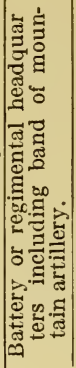 & 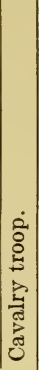 & 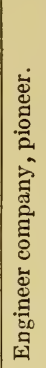 & 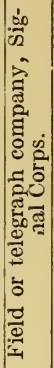 & 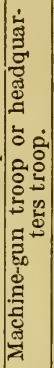 & 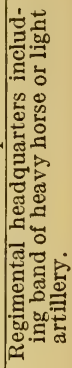 \\
\hline 1 & Anvil, 17.5 pounds & & & & 1 & & 1 & \\
\hline 2 & $\begin{array}{l}\text { Anvil, } 34 \text { pounds.... } \\
\text { Apron, blacksmith's.. }\end{array}$ & & $\begin{array}{l}1 \\
1\end{array}$ & $\begin{array}{l}1 \\
1\end{array}$ & & $\begin{array}{l}1 \\
1\end{array}$ & .. & \\
\hline 3 & Bag, canvas, for nails. & 2 & & & & & & \\
\hline 4 & Anvil, 100 pounds.... & 1 & & & & & & \\
\hline 5 & Box, shooing, leather & 1 & 1 & 1 & & 1 & & \\
\hline 6 & 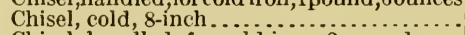 & 1 & & 1 & 1 & 1 & 1 & \\
\hline 7 & $\begin{array}{l}\text { Chisel, handled, for cold iron, } 2 \text { pounds... } \\
\text { Chisel, handled, for hot iron, } 1.5 \text { pounds... }\end{array}$ & 1 & & & & & & \\
\hline 8 & 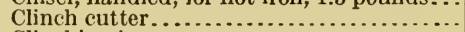 & & & $i$ & 1 & 1 & & \\
\hline 9 & Clinching iron... & 1 & 1 & 1 & 1 & 1 & 1 & \\
\hline 10 & Creaser, steel handled. & & 1 & 1 & & 1 & & \\
\hline 11 & Chest for tools.... & & & & & & 1 & \\
\hline 12 & Drills, flat.. & 6 & 16 & 16 & & 16 & & \\
\hline & 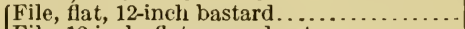 & 1 & & & & & & \\
\hline 13 & File, 12-inch, flat, second cut............ & .. & 1 & 1 & & 1 & & \\
\hline & File, 8-inch, three-square taper........... & & 1 & 1 & & 1 & & \\
\hline $\begin{array}{l}14 \\
15\end{array}$ & 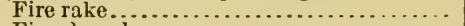 & 1 & 1 & 1 & & 1 & & \\
\hline $\begin{array}{l}15 \\
16\end{array}$ & Fire shovel .......... & 1 & 1 & 1 & & 1 & & \\
\hline $\begin{array}{l}16 \\
17\end{array}$ & Flatter, handled, 1.5-inch square face...... & 1 & & $\cdots$ & & $\cdots$ & 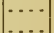 & \\
\hline 17 & 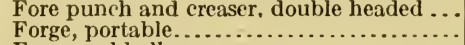 & 1 & & & & & & \\
\hline & 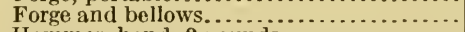 & & & & 1 & & 1 & \\
\hline $\begin{array}{l}18 \\
19\end{array}$ & Hammer, hand, 2 po & 1 & & & 1 & & 1 & \\
\hline 19 & Hammer, riveting, 1 pound 2 ounces...... & 1 & & & & & & \\
\hline 20 & Hammer,rounding, 14-inch handle, 2 pounds & & 1 & 1 & & 1 & & \\
\hline & Hammer, shoeing, 10 ounces............... & 1 & 1 & 1 & 1 & 1 & 1 & \\
\hline 2 & 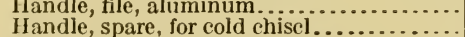 & 1 & 2 & $\ddot{2}$ & & 2 & & \\
\hline & (II ardie, .75 square shank, $1.25 \mathrm{bit} . .$. & i & & & & & & \\
\hline 24 & $\{$ Hardie, .5 square shank, 1.5 bit. & & & & 1 & & 1 & \\
\hline 25 & $\begin{array}{l}\text { Hardie, } .562\left(\frac{9}{16}\right) \text { squ } \\
\text { Hoof and cutting nip }\end{array}$ & & & & & 1 & & \\
\hline $2 f$ & $\begin{array}{l}\text { Hoof and cutting nil } \\
\text { lloof parer, } 12 \text {-inch. }\end{array}$ & & 1 & 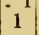 & & 1 & & \\
\hline 27 & Oiler.............. & & & & & & & \\
\hline
\end{tabular}

1 For use in garrisen only. 


\section{Blacksmith's tools-Continued.}

\begin{tabular}{|c|c|c|c|c|c|c|c|c|}
\hline \multirow[b]{2}{*}{$\underset{\mathscr{E}}{\stackrel{0}{0}}$} & \multirow[b]{2}{*}{ Article. } & \multicolumn{7}{|c|}{ Number issued to $1-$} \\
\hline & & 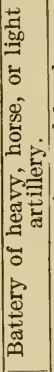 & 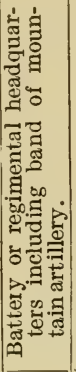 & 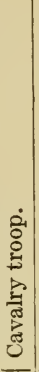 & 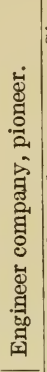 & 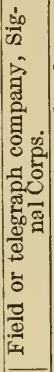 & 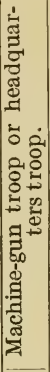 & 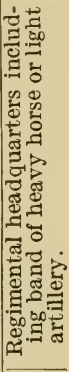 \\
\hline \multirow{2}{*}{28} & SPritchel, .75 flats, 9-inch & 1 & & & 1 & & 1 & \\
\hline & $\begin{array}{l}\text { Pritchel, .562 }\left(\frac{9}{16}\right) \text { flats, 9- } \\
\text { (Punch, round } .375 \text {-inch }\end{array}$ & $\cdots$ & & $\cdots$ & & 1 & & \\
\hline \multirow{2}{*}{29} & 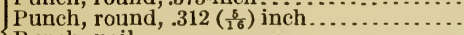 & 1 & & & & & & \\
\hline & 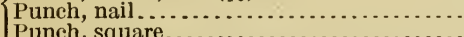 & 1 & & 1 & 1 & & 1 & \\
\hline 30 & Ratchet drill for square-shank drills........ & 1 & $1 i$ & ii &. & 11 & $\cdots \cdot$ & \\
\hline 31 & $\begin{array}{r}\text { Rivet sets, sizes } .187\left(\frac{3}{16}\right), .25, .375, .5 \text {, and } \\
\quad .625 . \ldots \ldots\end{array}$ & 5 & & & & & & \\
\hline 32 & 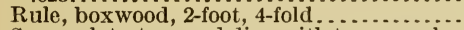 & 1 & & $\cdots$ & & ... & & \\
\hline 33 & 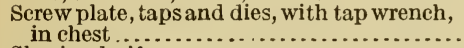 & 1 & & & & & & \\
\hline 34 & Shoeing knife......... & 2 & 1 & 1 & 1 & 1 & 1 & \\
\hline 35 & Shoeing pincers, 12 inches............. & 1 & 1 & 1 & & 1 & & \\
\hline 36 & 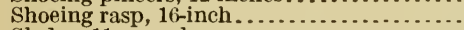 & 1 & 1 & 1 & 1 & 1 & 1 & \\
\hline 37 & Sledge, 11 pounds....... & 1 & 21 & $\cdots$ & 1 & $\cdots$ & 21 & \\
\hline \multirow[t]{2}{*}{38} & Square .................. & 1 & $\because$ & $\cdots$ & $\ldots$. & & $\cdots$ & \\
\hline & $\begin{array}{l}\text { Schaller forge............ } \\
\text { Schaller forge tool chest. }\end{array}$ & & $\begin{array}{l}1 \\
1\end{array}$ & $\begin{array}{l}1 \\
1\end{array}$ & & $\begin{array}{l}1 \\
1\end{array}$ & $\cdots \cdot$ & \\
\hline 39 & Toe knife................... & 1 & & $\ldots$ & 1 & & $i$ & \\
\hline \multirow[t]{2}{*}{40} & Tongs, horseshoer's, 1.5 pounds, 12 -inch ... & 1 & & & 1 & & 1 & \\
\hline & Tongs, horseshoer's, 18.5 ounces......... & & 1 & 1 & & 1 & & \\
\hline 41 & $\left\{\begin{array}{l}\text { Tongs, for } .25 \text { iron } \ldots \ldots \ldots \\
\text { Tongs, for } .5 \text { iron } \ldots \ldots \ldots \ldots\end{array}\right.$ & 1 & & $\cdots$ & & ... & $\cdots$ & \\
\hline 42 & $\begin{array}{l}\text { TTongs, for .5 iron } \\
\text { Tool kit, small... }\end{array}$ & 1 & & 1 & 1 & & 1 & \\
\hline 43 & Tool kit, for Schaller forge & & $i$ & 1 & 1 & 1 & $\begin{array}{l}1 \\
\ldots\end{array}$ & \\
\hline \multirow{2}{*}{44} & odified to fit batterv wagon & 31 & & & & & & \\
\hline & 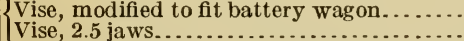 & 41 & & 1 & & & & \\
\hline 45 & Whetstone, farrier's, 10 -inch & 1 & $\begin{array}{l}1 \\
1\end{array}$ & $\begin{array}{l}1 \\
1\end{array}$ & & $\begin{array}{l}1 \\
1\end{array}$ & & \\
\hline 46 & Wrench, forge.......... & 1 & & ... & $\cdots$ & - - & & \\
\hline 47 & h, ser & 1 & & & & & & \\
\hline & rench, screw, & & & & & 1 & & \\
\hline
\end{tabular}

1 For use in garrison only.

2 Ordered with pack outfit.

3 Ordered with battery wagon for light or liorse battery only.

4 Ordered with battery wagon for heavy battery only.

$76881^{\circ}-15-8$ 
The field outfit issued to the Cavalry by the Ordnance Department is designed especially for portability, and is packed in two chests.

Chest No. 1 ( 22 by 18 by 13 inches) contains a small knockdown forge with fan and drivewheel and a complete set of forge and shoeing tools. Weight of chest, packed, 122 pounds.

Chest No. 2 (21 by 17 by 10 inches) contains a small anvil and block, water bucket, leather shoeing box, and apron. Weight of chest, packed, 68 pounds.

The field anvil weighs 17 pounds.

Description and uses of the tools (from "Army Horseshoer") are as follows (see Pl. XXIX to XXX, pp. 106-109):

The clinch cutter (fig. 8) consists of two parts-the blade and the point. The blade is used to cut or to raise the clinches, being placed under the edge of the clinch and struck with the driving hammer. The point is used to punch nails and stubs out of the hoof. It is often placed in the crease of the shoe, under the head of the nail to be withdrawn, and struck smartly with the hammer. The blow raises the nail sufficiently to enable the pincers to grasp the nail head.

The pincers (fig. 35) are used to remove shoes and to draw nail stubs and improperly driven nails.

The driving hammer (shoeing hammer) (fig. 21) should be used only to drive horseshoe nails, to wring off nails after they have been properly driven, and to make clinches.

The nippers (fig. 25) are used to remove the surplus growth of wall.

The shoeing knife (fig. 34) is used to pare away the dead horn near the white line; to remove loose particles from the hoof; to relieve pressure on corns and cracks; and to open the sole and wall for the escape of pus or for the removal of foreign bodies.

The horseshoers' rasp (fig. 36) is used to prepare a level bearing surface of the foot, to remove extra length of toe, to smooth the edges of the wall, to even clinches, to make a slight groove under each clinch, and to run lightly over the clincers in order to smooth them.

The hammers, hand and rounding (figs. 18 and 20) are used in fitting and in turning shoes.

The clinching iron (fig. 9) is used to turn the clinches.

The tongs (fig. 41) are used in handling hot metals.

The pritchel (fig. 28) is made by hand from round or octagonal steel, and is used for opening the nail holes in horseshoes. The point is shaped the same as the shank of a nail near the head, so that the hole punched in the shoe will fit the nail snugly and not allow much motion. Examine the nail carefully and learn the exact size for the pritchel. To draw out the point of the pritchel, heat it to a cherry red and, placing the pointed end flat on the face of 
the anvil near the far edge, strike with the hammer held at an angle to properly change the upper face, turning it as necessary so that the finished point will be of the shape desired. Never heat the pritchel beyond a cherry red; cool it gradually by placing it in the coal at the edge of the forge and never in the water. The face of the horseshoers' anvil should have a round edge near the base of the horn on the far side. This edge is used for sharpening tools.

Hardies (fig. 24) are used to cut hot metals. Their principal use for horseshoers is in cutting off the heels of shoes, and for this purpose a sharp cutting edge is required. When the hardy becomes dull, the edge is drawn out on the face of the anvil in the same manner as the pritchel. A sharp edge is then put on by hot rasping, using the smooth side of the rasp. After sharpening, the cutting edge should be tempered as follows: Heat the whole hardy slowly to a cherry red; hold the cutting edge under water so that about one-half inch of the blade is immersed, and, when there is no longer any sizzling, plunge the whole hardy under water and remove it at once; now carefully observe the change in color as the remaining heat in the body extends back to the edge; the color will be first straw, then copper, and finally blue; as soon as the blue color has reached the cutting edge, place the whole hardy under water and leave it there until thoroughly cooled.

The creaser (fig. 10) is used to crease the shoes and to repair damaged creases.

Horseshoe nails retain the shoe on the foot. These nails (furnished in several sizes) are machine made and pointed; they are slightly concave on one side and flat on the other. In driving the nail into the hoof the flat side is held faced outward.

The anvil.-The working parts of the anvil are the horn, the face, and the heel.

The face, or the upper plane surface, is of steel, and is welded to the iron body. The anvil is firmly fastened to a wooden block, which is sunk into the ground to a depth that will bring the surface of the face at a convenient working height above the ground-from 30 to 36 inches.

The horn is used to open and to shape shoes, the face to level the web and for welding, and the heel to straighten heels of shoes and to turn calks. Clips are ordinarily drawn on the edge of the face, but in the anvil shown there is an attachment near the base of the horn which is used for this purpose. The square hole in the face (hardy hole) is a socket for hardies; the round hole (pritchel hole) permits the passage of the pritchel through the nail hole of the shoe.

Plate XXX shows a section of a portable forge. In every forge air is forced through the fire by a bellows or a fan $(F)$; the latter is 
made to revolve by a drive wheel or by a handle $(H)$. The twyer ball ( $\mathrm{T}$ ) corresponds to the grate of a stove. Firmly attached to it and extending toward the worker is an iron rod by which the ball may be rocked. The end of this rod is shown by the small circle in the center of the twyer ball. A crater (C) should be made around the twyer ball in orler to confine the fire. Clay may be used for this purpose, but cement is better.

The quartermaster set of farrier's and blacksmith's tools issued to each regiment, wagon company, ambulance company, engineer train, engineer battalion, and signal corps battalion (organizations having a large number of wagons) consists of the following articles (contained in a substantial wooden chest) (see Pl. XXXI):

Figure.

Article.

Numbar.

1 Anvil, small 1

2 Apron, leather 1

3 Chisels, cold handled

4 Chisel, hot, handled 1

5 Chisel, cold, hand 1.

6 Clinch cutter (buffer) ${ }^{1}$

7 Clinch iron 1 .

8 Dividers, wing.

9 File, flat, bastard, 12-inch

10 Hammer, ball pein, with handle 1

11 Hammer, riveting, handled.

12 Hammer, shoeing 1

13 Hammer, sledge, handled.

14 Hardie 1

15 Knife, farrier 1 .

16 Nippers, cutting 1

17 Nippers, hoof-paring

18 Pinchers, farrier 1

19 Pritchel 1

20 Punches, hand, round 1 ( 2 in kit)

21 Rasps, 16-inch 1 ...

22 Set stocks and dies, $\frac{1}{4}$ to $1 \frac{1}{4}$ inches.

23 Tong, shoeing 1

24 Tongs, large 1

25 Vise, small .

26

27

Wrenches, monkey, 18 -inch and 12 -inch

Wrench, "S"

1 These articles, when extracted from the set, form the Kit of Farrier's and Blacksmith's Tools and form a part of Equipment " $\Lambda$." The remaining articles are in Equipment "B."

To each infantry regiment there are issued two Horseshoer's Emergency Equipments (see PI. VIII, p. 41), one for shoeing animals with the column on the march and one for shoeing animals with the field trains. The outfits are carried by the horseshoer or acting horseshoer. (See p. 38.) 


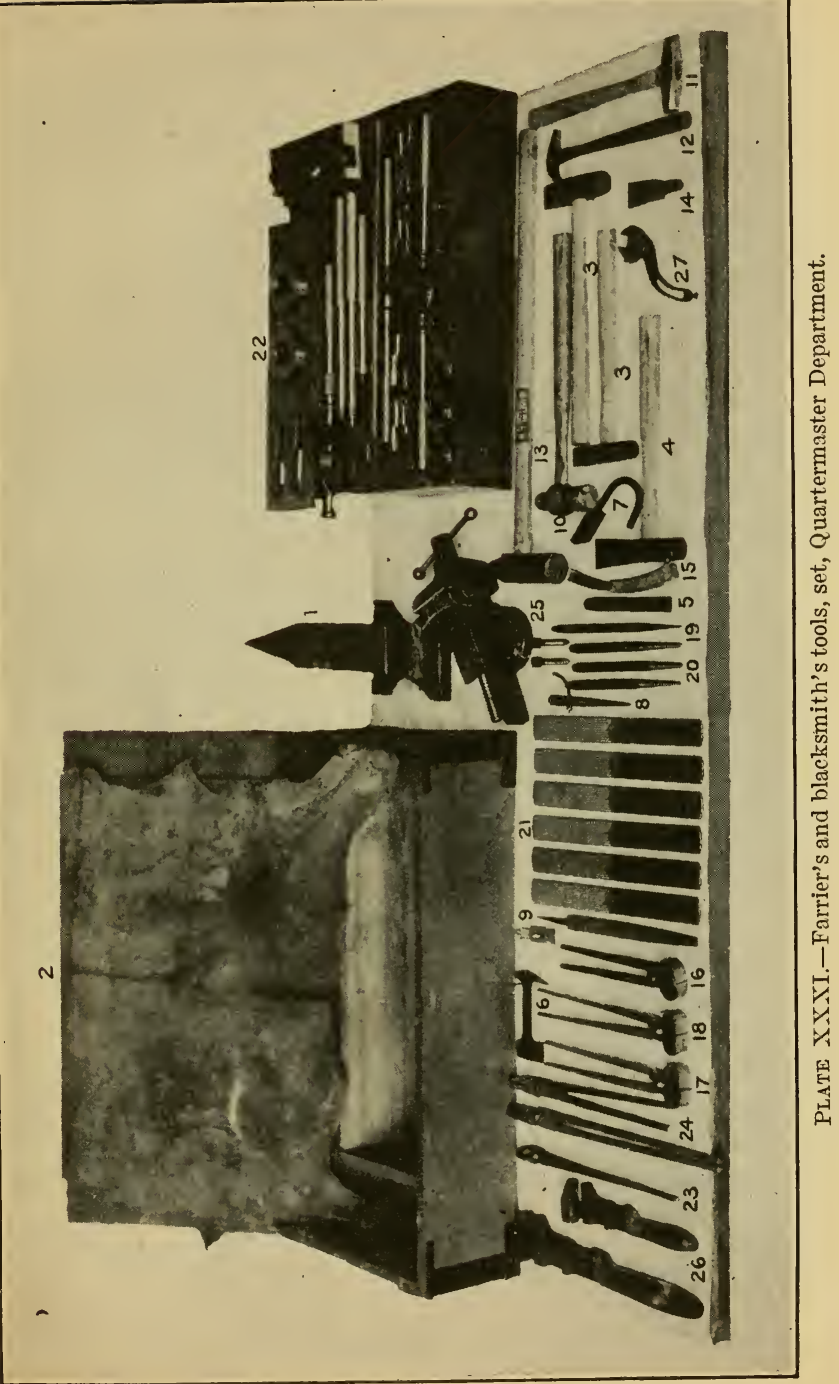


Two sets of shoes, one set on the feet and the other already fitted (and 8 horseshoe nails per shoe), for each animal are a part of the equipment of an escort wagon. Each mounted man carries one fitted fore shoe and one fitted hind shoe and 16 horseshoe nails as part of his equipment. All shoeing materials (coal, fitted shoes, extra nails, etc.) for animals provided with store wagons or store pack mules are carried in the combat train.

It is difficult to keep the horseshoer or blacksmith from using the fitted shoes carried on the mount or in the vehicle. These should be used only on the march. The teamster or the mounted man should resist any attempt to use these shoes at any other time, and if it is necessary to use them he should replace them at the very earliest opportunity.

Horseshoes for the ordinary mount run about No. 3 or No. 4; they require No. 6 horseshoe nails, or, for horses hard on shoes, No. 7 . Draft horses use as high as No. 7 shoes and require No. 8 nails. Mules ordinarily use No. 2 or No. 3 (mostly the latter) mule shoes. They require No. 6 horseshoe nails. There are 100 pounds of shoes in a keg and a keg contains 85 No. 3 mule shoes or 100 No. 2 mule shoes. Horseshoe nails run about 120 to the pound.

There are four nail holes on each side of the shoe, but ordinarily only the three front ones are driven on the outside and the two front ones on the inside for riding horses, and four and three, respectively, on draft horses. The number depends, however, on how severe the animal is on shoes. Horseshoe nails are curved on one side and are straight on the other; the nail is driven with the straight side toward the outer edge of the hoof.

In preparing the hoof for shoeing and in mailing the shoe on, the structure of the foot should be borne in mind. Attention is drawn to the accompanying cuts of the foot (PI. XXXII) and of the hoof (Pl. XXXIII). The membranes and tissues of the foot are probably more tender, or, being so closely confined, require more delicate treatment than those of any other part of the body. On the other hand, they are subjected to the most pounding and often they receive the least care. Men who would be very careful of the foundation of a house are most neglectful when it comes to the foundation of the horse. The hoofs of the horse and mule correspond closely to the nails on the fingers or the toes; think of how very painful any injury to the nail is and it can be appreciated how tenderly the hoofs should be treated.

First shape the hoof so that when viewed from the front and from the side, the axis of the pastern (that is, between the ankle and the hoof) and the center line of the hoof are parallel. In removing the wall, begin at the toe. When the proper position has been obtained, the edge of the hoof should be rasped off very slightly-just enough to take off the sharp elge. Then the shoe should be fitted to this 


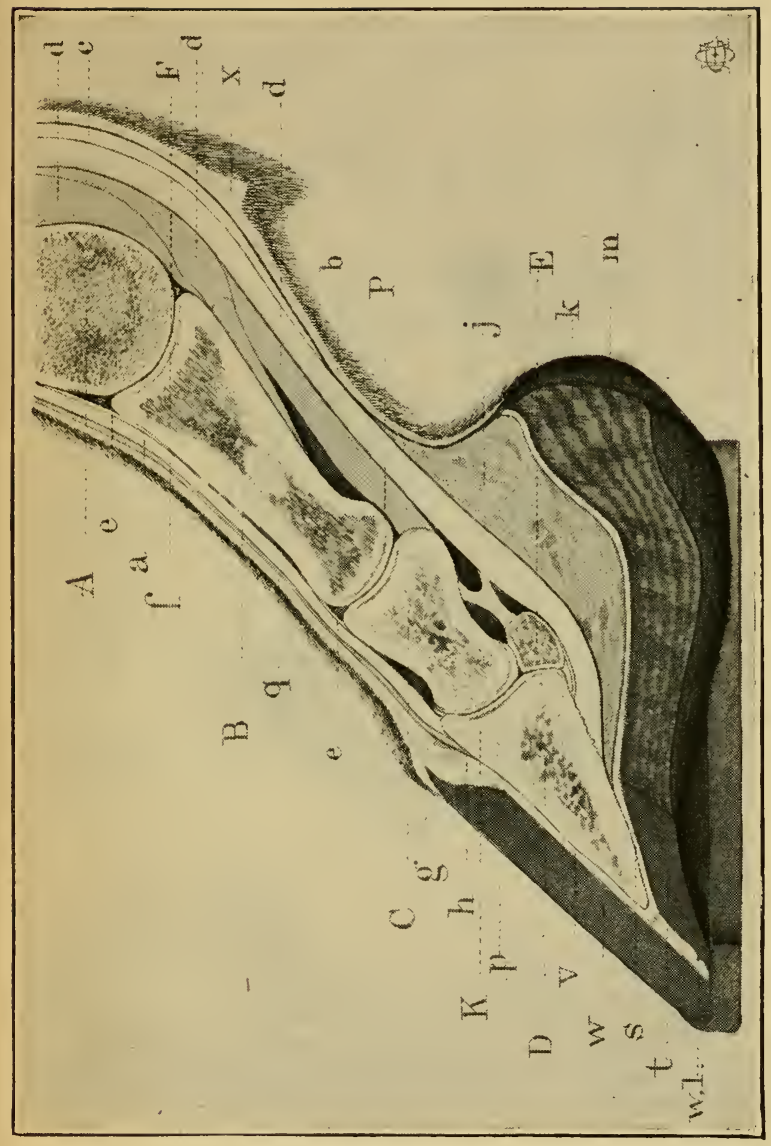

焉

范

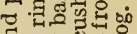

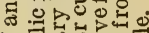
궁 त.

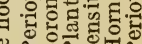

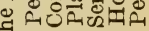
نंग्रं 荥 严

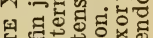

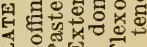
जिएक का संत्वां

ปี่

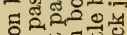
인

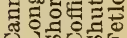

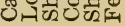

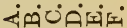


shape-clo not ever shape the hoof to the shoe; if in circumstances where reshaping of the shoe is impossible, it is better to tack the shoe on as nearly symmetrical as practicable and have the work properly done at the first opportunity.

In preparing the feet for the shoe, no cutting whatever, with a knife, is permitted except slightly at the toe to make a seat for the toe clip, when such is used.

It is safer never to apply a hot shoe to the hoof, but, if at all, then only for an instant to see whether the hoof is level.

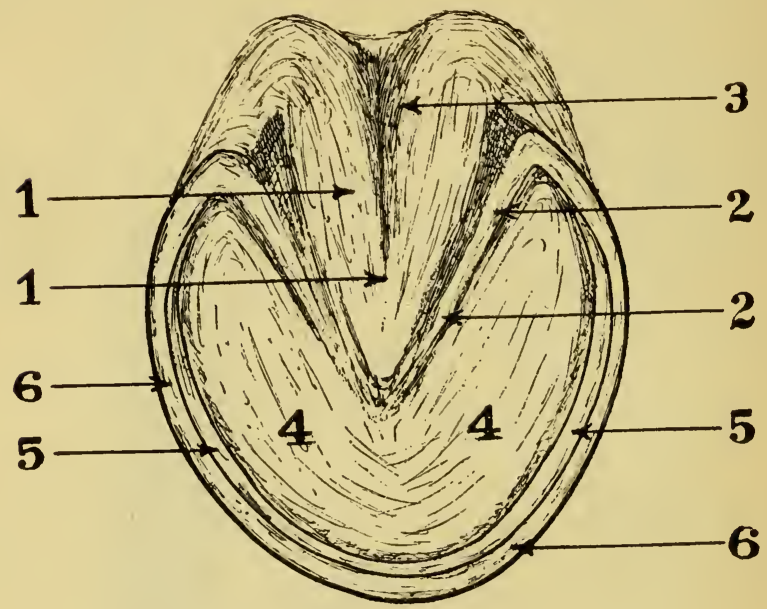

P'LATE XXXIII.-Horse's hoof.
1. Frog.
3. Cleft of frog.
2. Bar.
4. Sole.
5. White line.
6. Wall.

In removing surplus growth of the wall (the only part which should be touched at all with a cutting tool), use the cutting pincers or the rasp. It is dangerous to use a knife, because the pressure required to cut is so great that the shoer may cut into the sensitive parts before he knows it.

A large percentage of animals have dry hoofs and, as a result, contracted heels. Contracted heels are caused also by faulty shoeing, by putting nails in the hoof back of the micllle half, by rutting away the bars, by "opening the heels," or by giving an inclination inward to the upper surface of the heels of the shoes. 
The hoofs should be soitened (see Dry Hoofs, p. 50), shoes be nailed on properly, and shoes so shaped as to spread the hoof at the heels by giving the upper surface of the heels of the shoe a slight inclination downward toward the outer erlges.

Interfering may be either the striking of the inside of the fetlocks by the hoof of the foot alongside or by striking the fore shoe, hoof, or quarter (just above the hoof), by the hoofs of the hind feet (called "forging"). The fault is caused principally by faulty shoeing or by weakness or fatigue of the animal. If due to weakness, of course the animal should be built up. If the fault is detected shortly after shoeing, an inspection should be made to ascertain whether the shoe protrudes beyond the hoof, and the clinches smoothed off. The striking portion may be detected by chalking the part which is struck, trotting the horse off; when the hoof strikes, the chalk will rub off on to the hoof.

Sometimes the outer bar of the shoe is weighted (by making it broader) and this causes the foot to be carried wide in planting. Forging can sometimes be remedied by rolling the toe, that is shaping it much the same as it becomes after considerable wear; this causes the back of the hoof to turn up quicker than it would ordinarily, and thus clears the hind hoof as it moves forward.

Ankle boots, of leather, for interfering at the fetlocks and quarter boots for forging are the last resorts if strengthening physically and shoeing properly do not remedy the faults.

The heels of the shoe should not extend beyond the heels of the hoof. At the heels the shoe is allowed to extend outside the outer edge of the wall about $\frac{1}{8}$ of an inch. The shoes as issued have nail holes too small; these should be opened to receive the nail heads.

With the foot shaped and the shoe fitted to the proper shape, the nails are next driven. Be very careful in driving the first nail. It is a fine piece of work to place the shoe exactly in its proper position. When in position, drive the first nail (second from the front-exactly in the middle of the hole) just far enough so it will hold; then look again to see if the shoe sits right, and if so, drive the nail home. Aftera nail has been driven, the shoe should not be hammered sidewise because that will only loosen the nails by enlarging the nail holes and the shoe will always be loose, and before long the job must be done again. After the tacking on in to proper position has been arcomplished, the nail on the opposite side is then driven. The others are then driven in order-usually alternating sides. Each nail as it is driven is bent back atrightangles to the hoof and the point is twisted off with the claw of the hammer.

When all the nails have been driven, the foot is raised and a piece of iron (usually the pinchers) with a right-angled shoulder is held against the wall and against the end of each nail, and the nail hammered on the head. Then the foot is carried forward and rested on 
the knee; a slight groove is rasped nnder the ends of the nails and they are clinched in succession, the pinchers or iron being held on the head of the nail as it is being clinched. When clinched, the ends are rasped slightly to make them smooth.

No nails should be driven back of the line where the hoof starts to curve in; that is, where the "quarter" begins, or, in other words, in the back half of the hoof. To clo so prevents the natural expansion and growth of the foot.

Nails should not be driven inside the "white line," because this marks the boundary of sensitive portion of the foot. The shoe should not press against the sole at any point; this will not occur if the top surface of the shoe is made level. In driving horseshoe nails be sure, by the time they have gone into the hoof $\frac{3}{4}$ of an inch, that they are going with considerable resistance, which shows that they are penetrating horn and not the "quick" or an old nail hole.

Horses or mules upon which it is difficult to keep shoes, are commonly shod with a clip on the toe of the shoe. In order to prevent the shoe's sticking out in front, due to the clip, a seat is cut in the wall at the toe just large enough to contain the clip. To do this, the foot is raised and the shoe held in its proper position, clip resting against the toe of the hoof, and the position of the clip is marked on the wall with the knife. The wall is then very carefully whittled away, little by little, to make a proper seat. If too much be cut away, the value of the clip is lost.

If a shoe becomes loose slightly, it can be tightened by reclinching the ends of the nails, as explained above. If the shoe becomes very loose, such clinching will probably do little good, for the holes are worn large. In this case the shoe should be reset, but if this be not practicable for the time, two (one on each sicle) or more nails may be removed and new nails driven at slightly different angle. In removing a nail, the clinched end should be cut off before the nail is pulled through the hoof. The clinch cutter in the blacksmith outfit is ordinarily used for this purpose, but a cold chisel or any blunt sharpened elge will do. After the clinch is cut off the nail may be driven part or all the way out by using another nail, but very carefully.

If necessary to remove a shoe which is almost off-hanging by one or two nails at one side only-care must be taken not to bend it off over the edge of the hoof, for that will almost certainly break away all the wall between the clinched end and the bottom. Instead, raise the shoe as far as practicable without forcing the nails and place a piece of iron or wood between bottom of the hoof and the shoe and pry the tight part of the shoe up. It should not be necessary to do this, however, if the clinched end be straightened or removed before attempting to remove the shoe. 


\section{INDEX.}

Abscess ........... 52

" $A$ " equipment.......................................... 7

Allowances:

Accessories, escort wagon.................... 66, 67

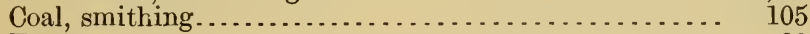

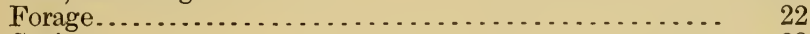

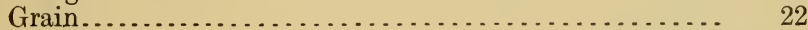

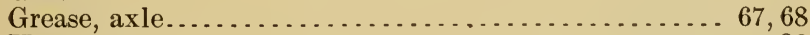

Hay........................................ 22

Medicines........................... . . 33, 36, 43,45

Nails, horseshoe....................... . 67, 116

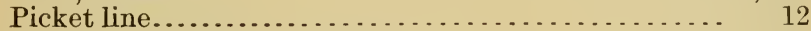

Saddlers, materials, ordnance.................. 85

Saddlers, materials, quartermaster............ . 93, 103

Shoes, horse and mule...................... 67

Soap, harness.......................... . . . . . . 67

Water......................................... 23

Weight on escort wagon............................ 21, 58

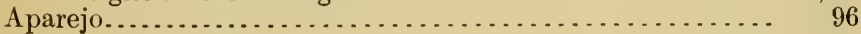

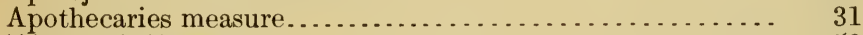

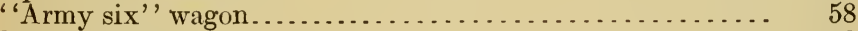

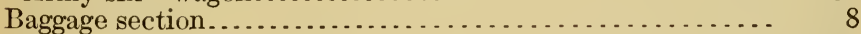

Bags, saddle, veterinarians....................... 34

Balking.................................... 17, 18

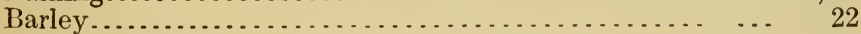

"B' equipment.............................. 7

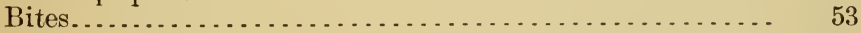

Biting. . . . . . . . . . 16

Bitting........................................... 19

Blacksmith tools.............................. . . . . . . . . 106,14

Blacksmith and farrier's kit. . . . . . . . . . . . . . . . . 103, 114

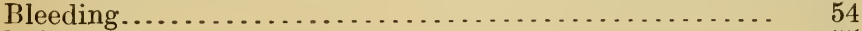

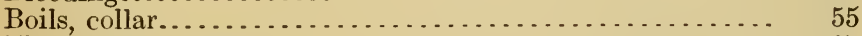

"Breaking"' horses............................... 17

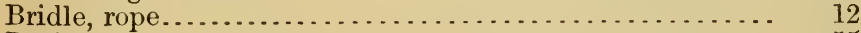

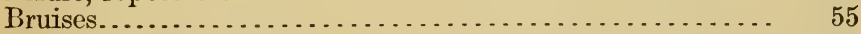

Bushel, weights, grain, per........................ 30

Calk, toe, shoe.............................. 105, 120

Canker............................................. 51

Carbolic acid....................................... 33 
Care of-

Page.

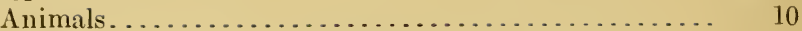

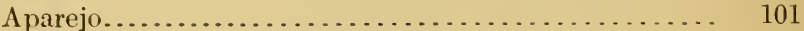

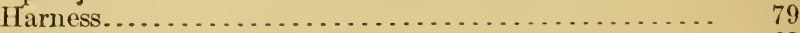

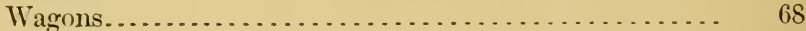

Cargador's kit..................................... 103

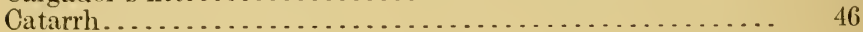

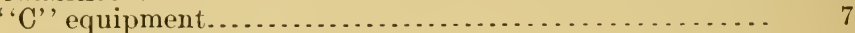

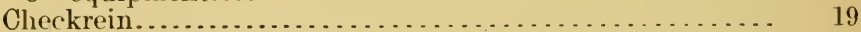

Chests, veterinary's field....................... 34

Chevrons:

Farrier's. . . . . . . . . . . . . . . . . . . . . . . . 25

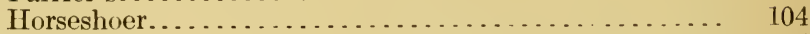

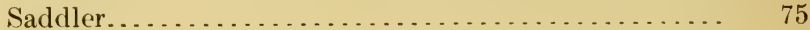

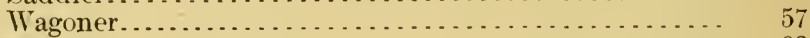

Cincha........................................ 98

Cleanliness.......................... 10, 12, 74, 79, 101

Cleaning -

Aparejo................................. 101

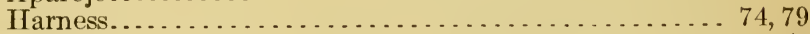

Wounds...................................... 54

Clips, shoe...................................... 120

Goal, smithing. . . . . . . . . . . . . . . . . . . . . . . 105

Colds....................................... 46

Colic mixture...................................... 45

Collar boils.................................... 74

Collar pads necessary .......................... . . . . . . . . 78

Combat train.................................... 8

Containers, amounts in........................... 31

Contracted heels................................ 51

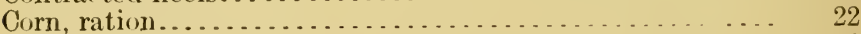

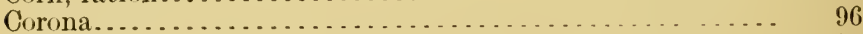

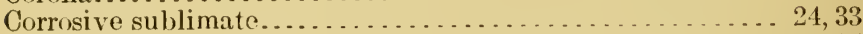

Cribbing............................................ 15

Decimal system......................... . . 30

Destroying animals. . . . . . . . . . . . . . . . . . . 33

Detection of disease........................... $\quad 26$

Diarrhea...................................... 47

Diseases, external. . . . . . . . . . . . . . . . . . . . . 49

Diseases, internal. . . . . . . . . . . . . . . . . . . . . . 45,46

Disinfectants............................. . . 33

Distance, table of ............................. 32

Drowning, rescuing from............................ 57

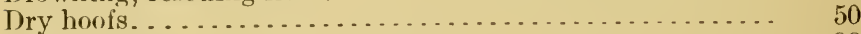

Dry measure.................................. 32

Duties of teamster....................... 57,74 
Page.

Eczema.

Equipment "A" $\mathrm{A}$ "............................... 7

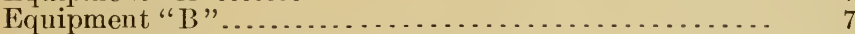

Equipment "C"

Equipment, escort wagon........................... 58

Equipment, farrier's.......................... $33,38,114$

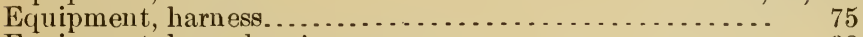

Equipment, horseshoer's emergency................ 38

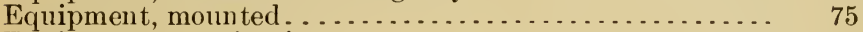

Equipment, veterinarian's............................ 34

Excessive urinating. .......................... 48

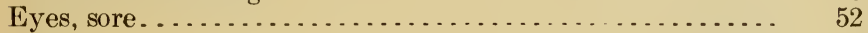

Farrier........................................... II

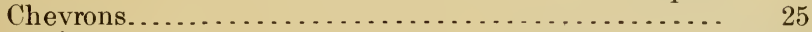

Duties................................. 25-56

Field equipment................................... 38

General instructions............................. 25

Medicines, list of, for . . . . . . . . . . . . . . . . . 33, 43

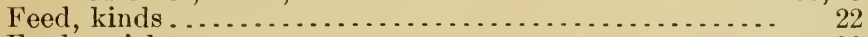

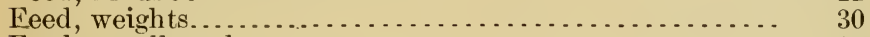

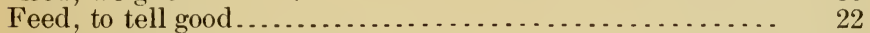

Fever mixture....................................... 45

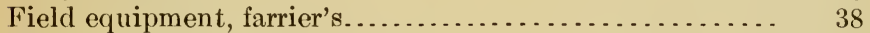

Field equipment, veterinarian's. . . . . . . . . . . . . . . 34

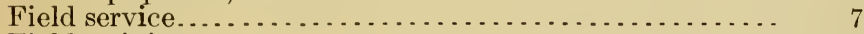

Field training. . . . . . . . . . . . . . . . . . . . . .

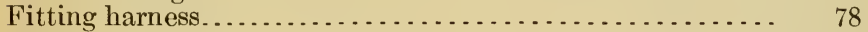

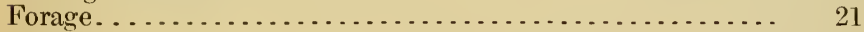

Fording............................................. 57

Founder............................... 24, 50

Four-mule harness . . . . . . . . . . . . . . . . . . . . . 76, 77

Four-mule team .................................... 59

Frequency of shoeing . . . . . . . . . . . . . . . . . . . 105

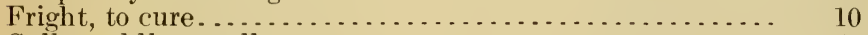

Galls, saddle or collar........................... 55

General instruction:

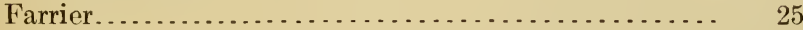

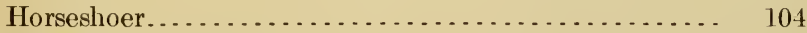

Regarding animals............................ 10

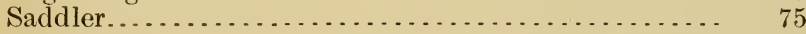

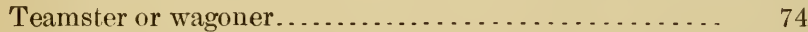

Giving medicines................................... 43

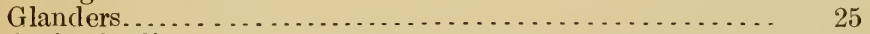

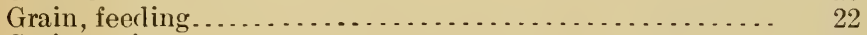

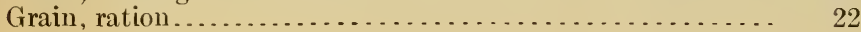




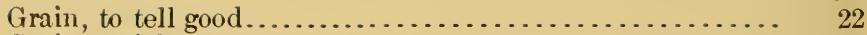

Grain, weights................................ $\quad 30$

Grease, axle............................ 66, 68

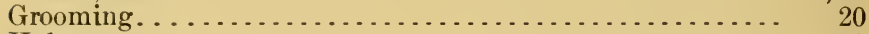

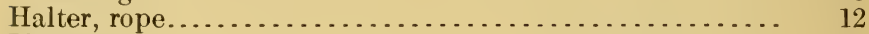

Harness:

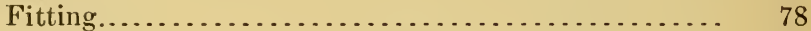

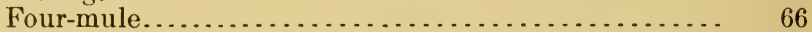

Lead................................... $\quad 75$

Mender.................................... 93

Repairing............................. $\quad 80$

Six-mule........................... 62,75

Wheel................................ 75

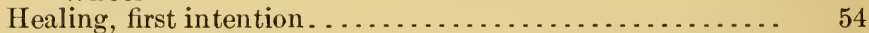

Healing, granulation............................ 54

Heat, as disinfectant........................... $\quad 33$

Heat, exhaustion............................ 48

Hobbling.................................... 16

Hoof, dry ................................... $\quad 50$

Hoof, puncture.............................. 49

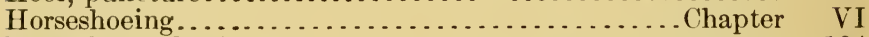

Horseshoer, the Army .............................. 104

Horseshoer, chevron.......................... 104

Horseshoer, emergency equipment .................... 38

Horseshoer's allowances ............................ 105

Horseshoes, kinds ............................ 116

Horseshoe nails ........ . . . . . . . . . . . . . . . . . . . 116

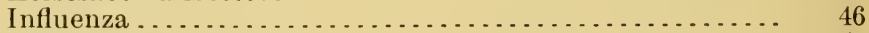

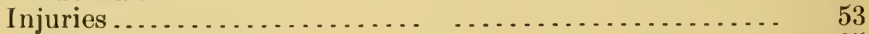

Inspection, animals ............................... 25

Inspection, feed .............................. 21

Inspection, harness ................................ $\quad 74$

Inspection, wagons .................................. 74

Instructions, general ............................. $\quad{ }^{10}$

Instructions, farrier ............................. 25

Instructions, teamster ....................... 57, 74

Instruments, farrier's ........ . ................ 42

Instruments, veterinary ........................... 34

Instruments, uses ............. ................ ${ }_{4} 42$

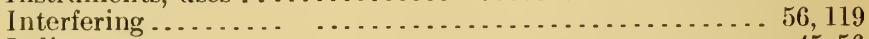

Iodine ............................... 45,56

Jack, wagon .................................. 68

Kicking animals ........................... 15, 16, 17, 19

Kicks, treatment ............................. 55

Killing animals ................................. $\quad 33$ 
Page.

Kindness.

$10,14,25,28$

Kit, blacksmith's

103,114

Kit, cargador's................................... 103

Kit, carpenter's and wheelwright's. . . . . . . . . . . . . 69

Kit, saddler's................................. 9

Lameness............................................ 49

Lashing, rope................................ $\quad 96$

Lashing packs.................................... 101

Lead bars..................................... 58

Lead harness.

Length, tables of....................................... 32

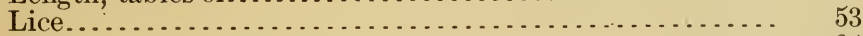

Lime...... .............................. 24

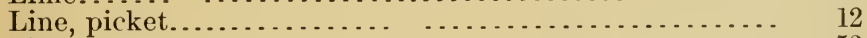

Mange....................................... 53

Manure, disposal of .............................. $\quad 24$

Materials, repair, ordnance....................... $\quad 85$

Materials, repair, quartermaster................... . $\quad 93$

Measures, tables of ............................. 32

Medicines, allowances............................ 36, 45

Medicines for farrier's use ........................ . 33, 43

Medicines for veterinarian's use................... 33

Medicines, table of............................ 32, 45

Mercury bichloride................................ 33,36

Nails, horseshoe, allowance..................... 67, 116

Nails, horseshoe, kinds......................... 116

"Near" and "Off," definition..................... 17,20

Neat's-foot oil............................... $\quad 66$

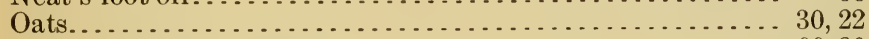

Oil, neat's-foot.................................... 66,80

Ordnance, blacksmith's tools..................... 105

Ordnance, carpenter's tools......................... 69

Ordnance, farrier's tools......................... $\quad 105$

Ordnance, repair materials....................... $\quad 85$

Ordnance, saddler's tools ......................... 83

Outfit, packing.................................. 96

Packing .............................................

Paint.

Pannier.

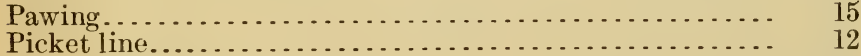

Pneumonia................................... ${ }_{46}$

Pocket case, farrier's instrument..................... $38,40,42$

Pocket case, veterinarian's instrument.............. 34,35

Pulling back................................ 16 
Page.

Punctures, hoof.......................... 49

Quartermaster Department:

Carpenter and wheelwright tools................ 69

Carpenter and wheelwright kits.................. 69

Farrier's tools.............................. 114

Harness mender................. . . . . . . . . . 93

Horseshoer tools............................ . . . . . . 105, 114

Saddler's kit.................................. 90

Saddler's tools. . . . . . . . . . . . . . . . . . . . . . . . 83,90

Table of allowances........................... 33

Transportation, kinds...................... $8,21,58$

Ration, forage................................. 22

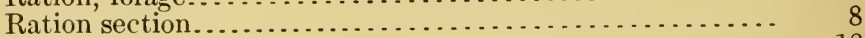

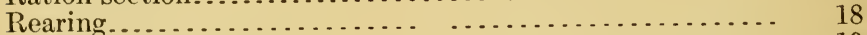

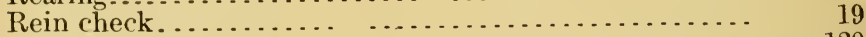

Removing shoes................................. 120

Repairs, harness........................... . $80,93,103$

Repairs, materials.......................... $80,93,103$

Restraining animals........................... 28

Retention of urine................................... 48

Rivets, allowance............................. 93

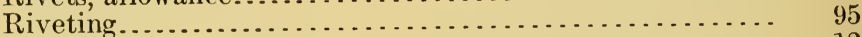

Rope bridle........................................ 12

Rope burns.............................. 12,56

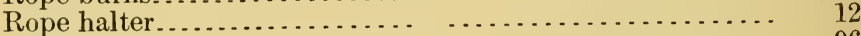

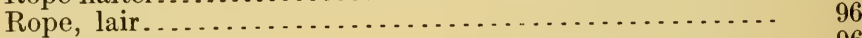

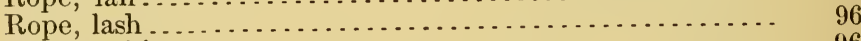

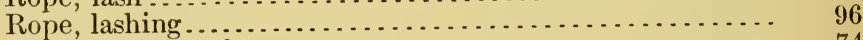

Routine duties of teamster.......................... 74

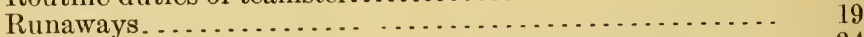

Saddle bags, veterinarian's......................... 34

Saddle galls. . . . . . . . . . . . . . . . . . . . . . . 55, 78

Saddler ........................................... IV

Saddler, materials for.......... ................ 85

Saddler tools, ordnance.......................... 83

Saddler tools, quartermaster......................... 80

Scratches................................ 10.

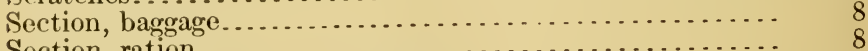

Section, ration ................................... ${ }^{8} 85$

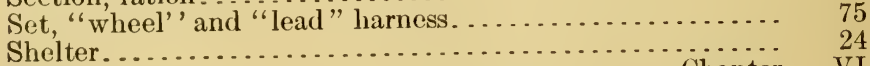

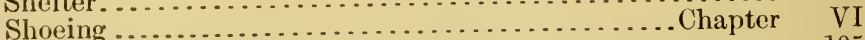

Shoeing outfit, ordnance....................... 105

Shoeing outfit, quartermaster................................ 114

Shoer, The Army Horse.............. . . . . . . . . . . . 104 
Page.

Shoer, horse, emergency equipment. 38,41

Shoes, horse, allowances....................... 116

Shoes, horse, nails.............................. 116

Shoes, horse, removing......................... 120

Shoes, horse, sizes.......................... 116

Shoes, horse, tightening.......................... 120

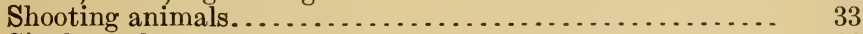

Single set harness. . . . . . . . . . . . . . . . . . . . . . . . 66

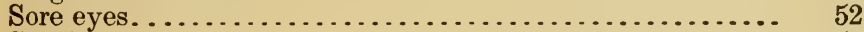

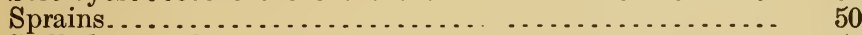

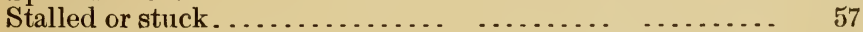

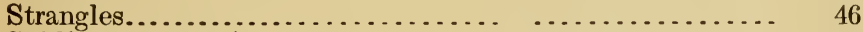

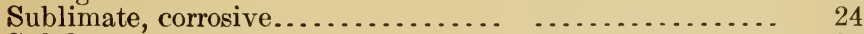

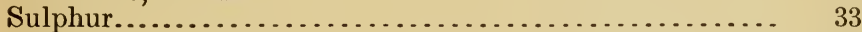

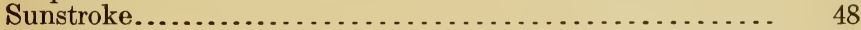

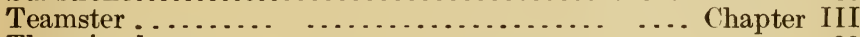

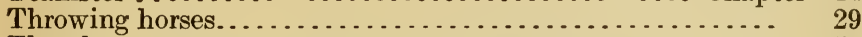

Thrush........................................... 51

Ticks............................................... 53

Training, horse... ............................. 17

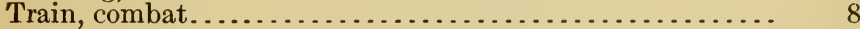

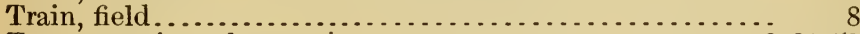

Transportation, classes....................... $8,21,58$

Urine, excessive.... ... ................... 48

Urine, retention of ............................ 48

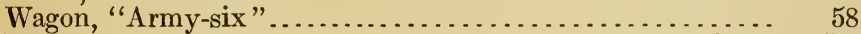

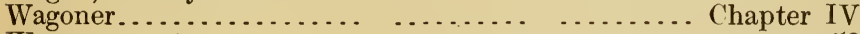

Wagon, escort. $\ldots \ldots \ldots \ldots \ldots \ldots \ldots \ldots \ldots \ldots \ldots \ldots \ldots . \ldots \ldots$

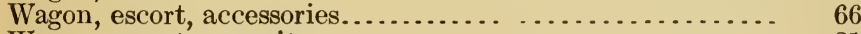

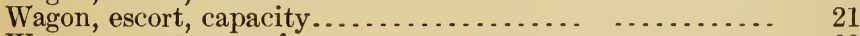

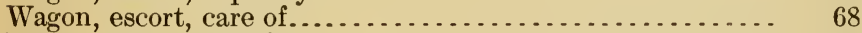

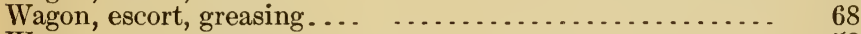

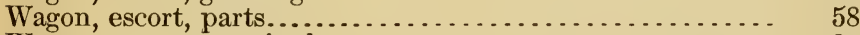

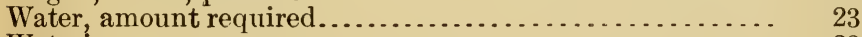

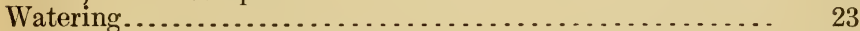

Watering, prohibited when warm................. 10

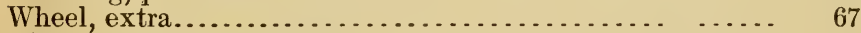

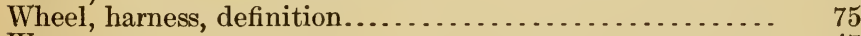

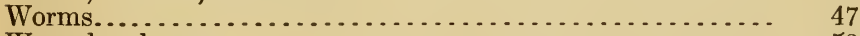

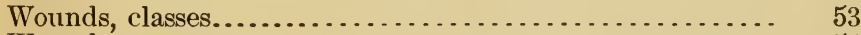

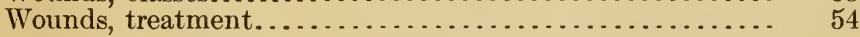




\section{ADDITIONAL COPIES}

OF THIS PUBLICATION MAY BE PROCURED FROM THE SUPERINTENDENT OF DOCUMENTS GOVERNMENT PRINTING OFFICE WASHINGTON, D. C. AT

40 CENTS PER COPY 



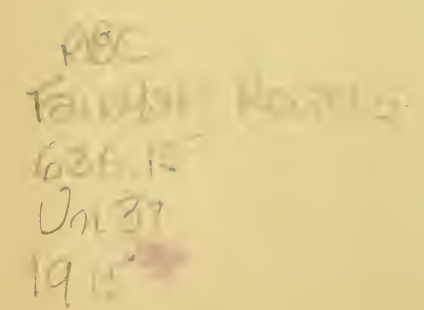






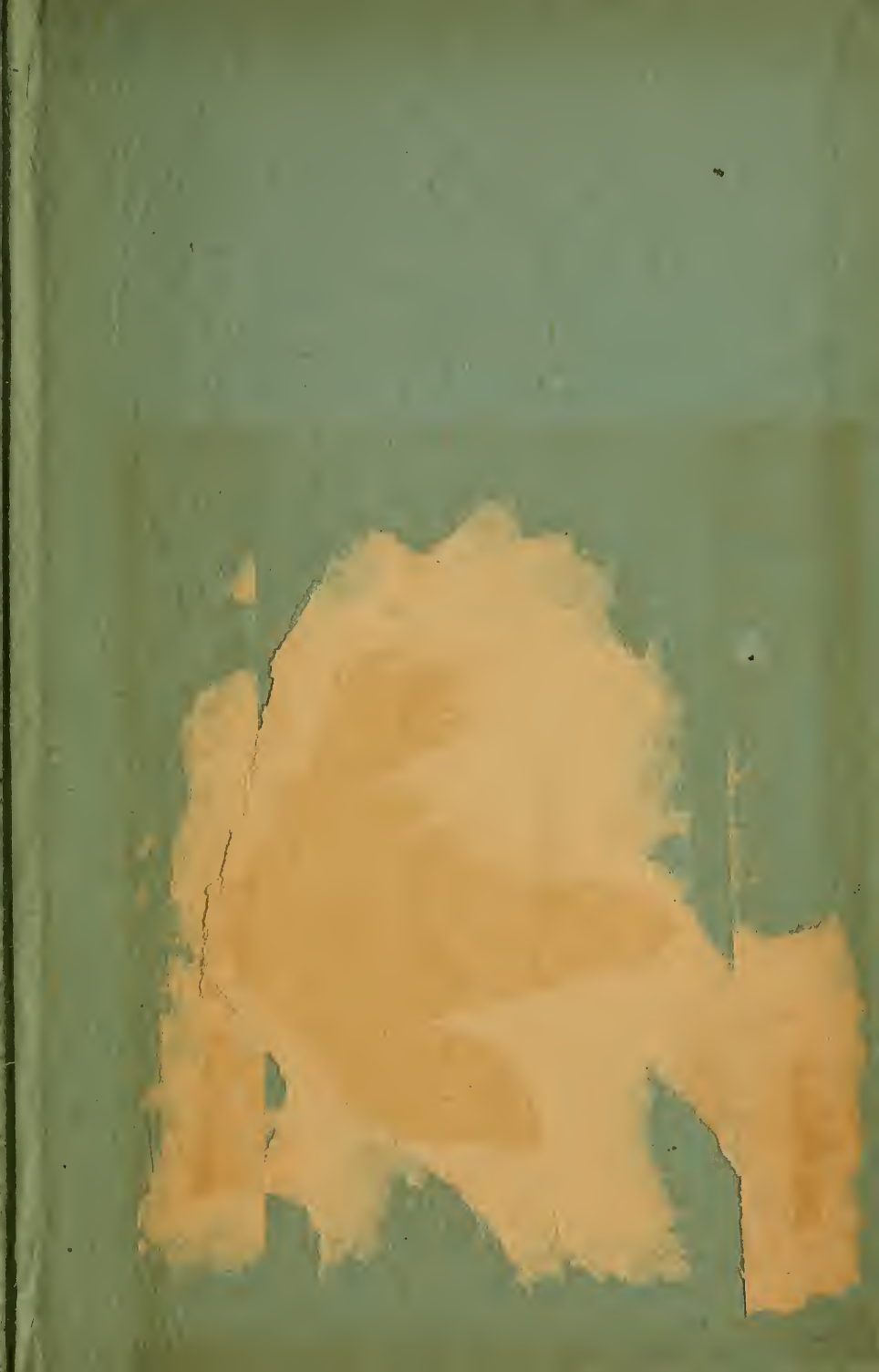


